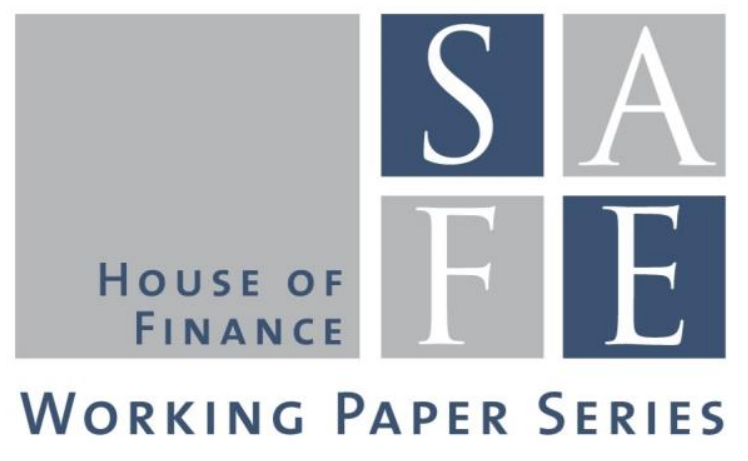

Elia Berdin - Cosimo Pancaro - Christoffer Kok

\title{
A Stochastic Forward-Looking Model to Assess the Profitability and Solvency of European Insurers
}

SAFE Working Paper No. 137

SAFE I Sustainable Architecture for Finance in Europe A cooperation of the Center for Financial Studies and Goethe University Frankfurt 


\section{Non-Technical Summary}

In recent years, the level of interest rates has been declining to historical lows worldwide. This development has given rise to concerns for the stability of the financial system and in particular of insurers due to their exposure to downside risks in a low interest rate environment. Life insurance business - representing the lion's share of the balance sheet for European insurance companies appears particularly vulnerable to low interest rates due to the extended use of financial guarantees which, in some markets, were massively sold to policyholders in the past and which are now becoming very expensive to fund. European life insurance business has been traditionally characterized by the presence of financial guarantees embedded in the savings products, i.e. a minimum rate of return that is granted to policyholders. In times of low interest rates, this business model might represent not only a threat for the profitability of the insurance companies but it might also endanger their solvency position. Insurance companies tend to allocate large portions of their investment portfolio to bonds in order to replicate their liability portfolio. Thus, as interest rates remain low and the reinvestment risk materializes, the expected return on investments declines, making it more difficult for companies to honor returns guaranteed to policyholders and consequently to generate profits. This effect is also reflected in the valuation of assets and liabilities: under a marked-to-market solvency regime, such as the Solvency II regime in Europe, the decline in interest rates increases the value of both assets and liabilities. However, due to the typical duration mismatch observed in the insurance business, i.e. the duration of liabilities being higher than the duration of assets, the value of liabilities tend to rise more than the value of assets, thereby reducing the market value of own funds of the company and in turn its solvency level.

A comprehensive model that allows for studying the impact of different financial developments on the profitability and solvency of insurance companies or for regular financial stability assessments of the insurance sector is still missing. Within the financial stability mandate of central banks, such analysis appears to be fundamental to better understand the upcoming challenges that insurance companies and the financial system as a whole will have to face in the future. Moreover, in the insurance sector there is the need for models, which allow for timely analysis and the creation of early warning signals. This is a relevant aspect, since the insurance business as a long-term horizon business, tends to display very slow dynamics in which risks materialize slowly in the balance sheet. Therefore, it is very important to dispose of analytical frameworks which allow for a timely detection of potential downside risks and threats and thereby allow for timely interventions. The present paper aims at filling this gap.

This paper has a twofold aim: on the one hand, to develop an analytical framework for financial stability analyses in which the effects on the profitability and solvency of the main euro area insurance markets of different financial market scenarios as well as different features of the balance sheet of insurance companies can be investigated in a forward-looking manner; on the 
other hand, to conduct a quantitative forward-looking assessment of the effects that a persistent low interest rate environment has on both the profitability and the solvency of the main euro area insurance sectors. More specifically, in this paper, we model the balance sheet of an insurance company encompassing both life and non-life business and we calibrate it using country level data to make it representative of the major euro area insurance markets. Then, we project this representative balance sheet forward under stochastic capital markets, stochastic mortality developments and stochastic claims. Against this background, this paper proposes an analysis that takes into consideration key elements of the insurance business which vary across markets. We calibrate the insurer's balance sheet at country level as to introduce heterogeneity both in the business mix, e.g. life and non-life, and in business practices, e.g. duration mismatches. In fact, a more diversified business portfolio as well as better matching strategies have beneficial effects in terms of risk mitigation, which in turn positively influence both the profitability and the solvency of the insurance company.

The results of this work suggest that under a protracted period of low interest rates, insurers more exposed to products with financial guarantees display a marked reduction in both profitability and solvency over time. As expected, we find that the specific local regulation and the applied business practices with respect to certain products (e.g. the minimum return guarantees and duration mismatches) are key drivers of both the profitability and solvency and of insurers. Our model also highlights the importance of business portfolio diversification. Indeed, as the business portfolio becomes more diversified and less concentrated on interest rate sensitive business, e.g. financial guarantees, both profitability and solvency improve. The model also displays interesting results when it is extended to the group case, i.e. the insurer's balance sheet includes both life and nonlife business lines. In fact, under the assumption that within a group, capital can be managed and transferred to different lines of business to improve the solvency situation, negative spillovers may emerge. As the non-life business has in general a limited exposure to financial risk, its profitability and solvency position are less affected by the low interest rate environment, but largely depend on the performance of the underwriting portfolio. However, once we allow for capital redistribution within the group, we can observe how a low interest rate environment might also negatively affect the solvency position of the non-life business due to both lower return on assets and most importantly to capital that is redistributed from the non-life towards life business. Overall, the presented framework provides a new perspective on the financial stability assessment of insurance sectors, which may help supervisors and regulators to design more effective macro- and microprudential policy actions. 


\title{
A Stochastic Forward-Looking Model to Assess the Profitability and Solvency of European Insurers
}

\author{
Elia Berdin* Cosimo Pancaro, Christoffer Kok ${ }^{\ddagger}$
}

May 2016

\begin{abstract}
In this paper, we develop an analytical framework for conducting forward-looking assessments of profitability and solvency of the main euro area insurance sectors. We model the balance sheet of an insurance company encompassing both life and non-life business and we calibrate it using country level data to make it representative of the major euro area insurance markets. Then, we project this representative balance sheet forward under stochastic capital markets, stochastic mortality developments and stochastic claims. The model highlights the potential threats to insurers solvency and profitability stemming from a sustained period of low interest rates particularly in those markets which are largely exposed to reinvestment risks due to the relatively high guarantees and generous profit participation schemes. The model also proves how the resilience of insurers to adverse financial developments heavily depends on the diversification of their business mix. Finally, the model identifies potential negative spillovers between life and non-life business thorugh the redistribution of capital within groups.
\end{abstract}

Keywords: Financial Stability, Insurance, Interest Rate Risk, Stress Test

JEL Classification: G20, G22, G23

*Affiliation: International Center for Insurance Regulation and Center of Excellence SAFE Sustainable Architecture for Finance in Europe, Theodor W. Adorno Platz 3, Goethe University Frankfurt, D-60629 Frankfurt am Main., Germany; e-mail berdin@finance.uni-frankfurt.de.

${ }^{\dagger}$ European Central Bank; e-mail: cosimo.pancaro@ecb.europa.eu

${ }^{\ddagger}$ European Central Bank; e-mail: christoffer.kok@ecb.europa.eu

$\S$ The authors are grateful to the Actuarial Association of Europe, Fabrice Borel-Mathurin (ACPR), Daniel Perez (EIOPA), Wybe Hamersma and Yildiz Ekinci (DNB) and Pablo Muelas Garcia (Spanish Ministry of Economy and Competitiveness) for inputs on local insurance regulation; Helmut Gründl, Katri Mikkonen, the participants to the DG Macro-Prudential Policy and Financial Stability internal seminar and the participants to the EIOPA Advanced Seminar on Quantitative Techniques in Financial Stability for comments and suggestions. We, however, are solely responsible for any errors that remain. The findings, views and interpretations expressed herein are those of the authors and should not be attributed to the Eurosystem, the European Central Bank, its Executive Board, or its management. Elia Berdin gratefully acknowledges research support from the Research Center SAFE, funded by the State of Hessen initiative for research LOEWE. 


\section{Introduction}

In recent years, the level of interest rates has been declining to historical lows worldwide. This development has given rise to concerns for the stability of the financial system and in particular of insurers due to their exposure to downside risks in a low interest rate environment. ${ }^{1}$

Among insurers, life business appears the most vulnerable due to the extended use of financial guarantees which, in some markets, were massively sold to policyholders in the past and which are now becoming very expensive to fund. In Europe, life business and in particular traditional life savings products, represent the largest portion of investments for insurance companies: according to Insurance Europe (2015), in 2014 the amount of investments allocated to life business was $€ 8.16$ bn, whereas non-life amounted to $€ 1.68$ bn, corresponding to $83 \%$ and $17 \%$ of total investments respectively. Within the life business, more than $80 \%$ of premiums still come from traditional life business, i.e. products which risk is borne from shareholders, whereas the remainder stems from unit-linked products, i.e. products which risk is borne by policyholders. ${ }^{2}$ Thus, life business represents the lion's share of the balance sheet for European companies, with traditional life business still playing a prominent role.

European life insurance business has been traditionally characterized by the presence of financial guarantees embedded in savings products, i.e. a minimum rate of return that is granted to policyholders. In times of low interest rates, this business model might represent not only a threat for the profitability of the insurance companies but it might also endanger their solvency position. ${ }^{3}$ Insurance companies tend to allocate large portions of their investment portfolio to bonds in order to replicate their liability portfolio. ${ }^{4}$ Thus, as interest rates remain low and the reinvestment risk materializes, the expected return on investments declines, making it more difficult for companies to honour returns guaranteed to policyholders and consequently to generate profits. This effect is also reflected in the valuation of assets and liabilities: under a marked-to-market solvency regime, such as the Solvency II (S II) regime in Europe, the decline in interest rates increases the value of both assets and liabilities. However, due to the typical duration mismatch observed in the insurance business, i.e. the duration of liabilities being higher than the duration of assets, the value of liabilities tend to rise more than the value of assets, thereby reducing the market value of own funds of the company and in turn its solvency level. ${ }^{5}$

As interest rates have fallen to historical lows in recent years, the interest of both academics and policy makers on the resilience of the insurance sector to the low interest rate environment has

\footnotetext{
${ }^{1}$ See for instance Berdin et al. (2015) and EIOPA (2015). The present paper outlines the model used in Berdin et al. (2015).

${ }^{2}$ In this context, risk essentially refers to financial risk.

${ }^{3}$ A study conducted by Swiss Re (2012) highlights how the sensitivity of these products to changes in interest rates appears to be particularly higher in some jurisdictions, such as Germany and Italy, and lower in others such as the U.K. and France.

${ }^{4}$ In 2013 , directly held bonds represented $52.3 \%$ of total investments (Insurance Europe, 2015).

${ }^{5}$ In this context, duration refers to the Macaulay duration, i.e. the time weighted present value stream of future cashflows of a financial instrument (Macaulay, 1938).
} 
materially increased, however the existing literature is still scant. Indeed, the works which focus on financial stability issues related to the insurance sector are limited and mostly qualitative. ${ }^{6} \mathrm{~A}$ first attempt to quantitatively estimate threats to German life insurers due to low interest rates is presented in Berdin and Gründl (2015). The authors propose a model in which insolvency probabilities can be derived. In their framework, a representative balance sheet of a German life insurer under the S II regulatory regime is developed; the analysis allows to observe the evolution of both the profitability and the solvency of the business in the low interest rate environment and the results suggest that there exists a relatively high vulnerability for a sub-set of German life insurers, in particular for those less capitalized. ${ }^{7}$ Wedow and Kablau (2011) using a different approach, study the evolution of the solvency of German life insurance companies. Although the study is based on the Solvency I regime, it confirms that should interest rates remain low, a portion of German life insurer would not been in the position to meet their capital requirement in a 10 year horizon. Similar conclusions were reached by EIOPA Stress Test (2014). The European authority carried out a stress test on the European insurance sector in 2014, in which a large portion of European insurance companies have been tested with respect to their resilience to both instantaneous asset market shocks and a protracted period of low interest rates. Findings confirm that, in a prolonged period of low interest rates, a relatively large portion of insurers would not meet their solvency capital requirements, thereby highlighting the strong reduction in their solvency levels. More recently, Domanski et al. (2015) propose an empirical analysis of the hunt for duration of German life insurers and conclude that, due to the low interest rate environment, German insurers buy more long date bonds to improve their matching strategy thereby further pushing down yield on bonds and, thus, creating a downward spiral which might become a further source of concern.

However, a comprehensive model that allows for studying the impact of different financial developments on the profitability and solvency of insurance companies or for more regular financial stability assessments of the insurance sector is still missing. Within the financial stability mandate of central banks, such analysis appears to be fundamental to better understand the upcoming challenges that insurance companies and the financial system as a whole will have to face in the future. Moreover, in the insurance sector there is the need for models, which allow for timely analysis and the creation of early warning signals. This is a relevant aspect, since the insurance business as a long-term horizon business, tends to display very slow dynamics in which risks materialize slowly in the balance sheet. Therefore, it is very important to dispose of analytical frameworks which allow for a timely detection (forward-looking) of potential downside risks and threats and thereby allow for timely interventions. The present paper aims at filling this gap.

Thus, the present paper has a twofold aim: on the one hand, to quantitatively estimate the impact that a persistent low interest rate environment has on both the solvency and the profitability

\footnotetext{
${ }^{6}$ See among others Tower and Impavido (2009) and Antolin et al. (2011).

${ }^{7}$ The focus on the German life insurance industry is justified by the combination of very low rates on sovereign yields, which represent a large portion of bond holdings of German insurers, and relatively high existing guarantees in the back book.
} 
of the 5 biggest euro-area insurance markets in terms of total gross written premiums, i.e. Germany, France, Italy, the Netherlands and Spain ${ }^{8}$; on the other hand, to create an analytical tool for financial stability analyses in which the effects of different financial market scenarios as well as different features of the balance sheet of insurance companies, such as business mix, dividend payout policies and pricing policies can be investigated. The focus on both the profitability and solvency is essential to assess the stability of the insurance industry and of the financial system at large. ${ }^{9}$ In addition, this paper proposes an analysis that takes into consideration key elements of the insurance business which vary across markets. Indeed, in this paper, we calibrate the insurer's balance sheet at country level as to introduce heterogeneity both in the business mix, e.g. life and non-life, and in business practices, e.g. duration mismatches. In fact, a more diversified business portfolio as well as better matching strategies, have beneficial effects in terms of risk mitigation, which in turn positively influence both the profitability and the solvency of the insurance company. ${ }^{10}$ To the best of our knowledge, this is the first model which attempts to replicate all main features of the balance sheet of an insurance group, active in both the life and non-life businesses, and that can be calibrated to analyse the interplay of different aspects of the insurance business. ${ }^{11}$

The results of this work suggest that under a protracted period of low interest rates, insurers more exposed to products with financial guarantees display a marked reduction in both profitability and solvency over time. As expected, this work finds that the specific local regulation together with the applied business practices with respect to certain products (e.g. the minimum return guarantees and duration mismatches) are key drivers of both the profitability and solvency of insurers. Among the countries considered in the analysis, Germany appears to be the most exposed to a protracted period of low interest rates, due to both its relatively high level of outstanding guarantees and a more generous profit participation mechanism. However, under a severely adverse scenario coupling low interest rates with higher financial markets volatility, the model shows that Italy and Spain display a very high volatility in their solvency ratios mainly due to home bias in their asset allocations. Finally, our model highlights the importance of business portfolio diversification. Indeed, as the business portfolio becomes more diversified and less concentrated on interest rate sensitive business, e.g. financial guarantees, both profitability and solvency improve. The model also displays interesting results when it is extended to the group case, i.e. the insurers balance sheet includes both life and non-life business lines. In fact, under the assumption that within a group, capital can be managed and transferred to different lines of business to improve the

\footnotetext{
${ }^{8}$ See Insurance Europe (2015).

${ }^{9}$ In fact, low interest rates in presence of minimum guaranteed rate of returns might create incentives for excessive risk taking behaviour of managers and thereby create instability in the financial system. In the literature, this is commonly referred as the risk of gambling for redemption or search for yield, see for instance Rajan (2005) and Antolin et al. (2011). Moreover, recent empirical evidence suggests that long-term investors, such as life insurers and pension funds, reacted to the current low interest rate environment by increasing their risk taking behaviour, i.e. increasing the riskiness of the asset allocation, see for instance Joyce et al. (2014).

${ }^{10}$ For a discussion on insurance groups, see for instance Schlütter and Gründl (2012).

${ }^{11}$ Indeed, the present framework can be used to analyse a wide range of important aspects of the insurance business, such as pricing/competition, demand for new products, lapse ratios, etc.
} 
solvency situation, negative spillovers may emerge. As the non-life business has in general a limited exposure to financial risk, its profitability and solvency position are less affected by the low interest rate environment, but largely depend on the performance of the underwriting portfolio. Thus, once we allow for capital redistribution within the group, we can observe how a low interest rate environment might also negatively affect the solvency position of the non-life business due to capital that is redistributed from the non-life towards life business. ${ }^{12}$ This is an innovative contribution to the existing literature on the effects of low interest rates on insurance companies. Indeed, this work provides a new perspective on the financial stability assessment of insurance companies, which may help supervisors and regulators to design more effective micro and macro-prudential policy actions.

The paper is organized as follows: In Section 2 the model and its features are presented: the insurer's asset side and the liability side are described, together with the regulatory constraints and the set of decisions the management faces in every period; In Section 3 the calibration of the different parameters of the model is introduced; In Section 4 the results of the different calibrations and different specifications are illustrated and finally, in Section 5 the main findings are discussed and the analysis is concluded.

\section{The Model}

\subsection{Methodology}

The methodology builds on Berdin and Gründl (2015) and Berdin (2016): the model features a representative balance sheet of an insurance group active in both life and non-life business, stochastic developments of financial markets, i.e. stochastic term structure of interest rates, stochastic yield spreads and stochastic stocks and real estate returns, and in addition stochastic developments of mortality and claims for non-life business. The model is then specifically calibrated for each one of the 5 countries of interest (i.e. Germany, France, Italy, the Netherlands and Spain): in particular, we specify different asset allocations, different liability structures and different regulatory requirements with respect to the pertaining legislation. ${ }^{13}$ Moreover, the stochastic developments of interest rates, stocks and real estate returns, which take into account the correlations among the different processes, are also calibrated at country level. This is a key feature since it allows us to study how diverse developments of these variables across countries differently impact the balance sheet of the insurance company at country level. Ultimately, this reflects part of the heterogeneity across countries, which is an important part of the analysis.

Figure 1 depicts the timeline of the model: we create a balance sheet with an existing back

\footnotetext{
${ }^{12}$ Clearly, the opposite might also happen, i.e. capital redistribution from life towards non-life business, in particular when the performance of the underwriting portfolio is poor.

${ }^{13}$ In fact, even though European insurance markets in recent years have been largely harmonized in the light of the recent introduction of S II, some regulatory features still remain different al local level. This is particularly true in life business, in which the level of maximum allowed minimum guaranteed return and the level of minimum profit participation are set by the national regulator.
} 
book of contracts and an asset portfolio at time $t$ by accumulating backward in time underwritten contracts (for the liability side) and available coupons (for the asset side). Against this background, we assume that the insurer sold a cohort of contracts each year and depending on the expected time to maturity of the contracts, we accumulate funds using past data on the total return granted to policyholders and the relative guarantee rate, up to the starting point $t$. In this way, we obtain at time $t$ a fixed number of cohorts of insurance contracts, replicated by cohorts of bonds, each of them sold and bought yearly with a residual time to maturity from 1 year up to their expected time to maturity. See Figure 3. By doing so, we are able to model the legacy business, which is particularly important in life business, since the back book might be a major source of financial distress under certain financial market scenarios.

We then model an insurance group by consolidating the balance sheets of both the life and nonlife business under a holding company: we take a simple approach and assume that the holding company fully owns the subsidiaries, i.e. life and non-life subsidiary, and that it has a claim on the free cash flow yearly generated by the subsidiary. The holding company ultimately is responsible for managing capital within the group and to pay out dividends to shareholders. Under certain conditions, the holding company can transfer shares of the generated cash flows to the subsidiary which is experiencing shortages of capital. The underlying assumption, as also highlighted in Schlütter and Gründl (2012), is the possibility of establishing intra-group reinsurance contracts, guarantees, or profit and loss transfer agreements, as well as lines of credit. ${ }^{14}$ Figure 4 depicts the group structure and its consolidation within the holding.

Figure 1: The Timeline of the Model

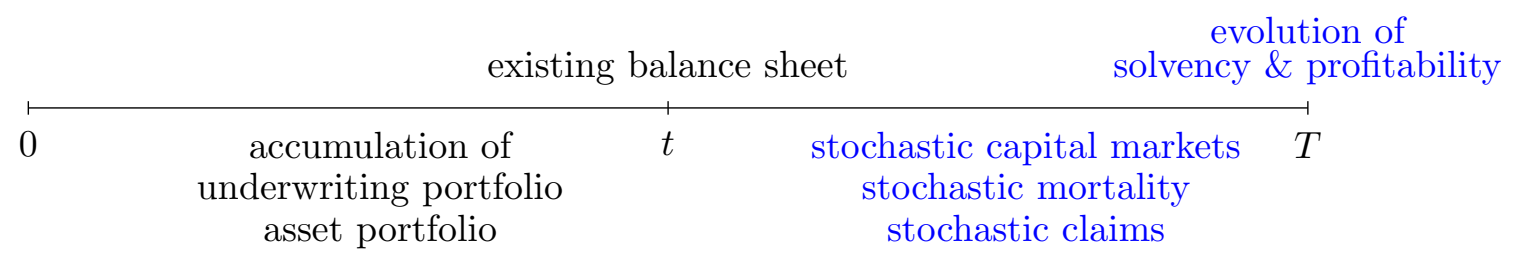

In this work, we specifically focus our attention on the marked-to-market balance sheet according to the S II regulatory regime. Although relevant metrics are at market values, the book value balance sheet (or historical cost) still plays a role, particularly for life business. In particular, the amount of profits to be distributed to policyholders is computed on the book value balance sheet. Therefore, the book values of relevant items in the balance sheet are also computed. The balance sheet structure of each subsidiary is represented in Figure 2. $A(t)$ and $L(t)$ respectively represent the portfolio of assets and liabilities at market value at time $t$.The market value of liabilities is given by $L(t)=L_{t}^{B E}+R M_{t}$ where $L^{B E}$ is the sum of the best estimate of contracts and $R M$ is a

\footnotetext{
${ }^{14} \mathrm{~A}$ recent article in the German press (Handelsblatt) reports how many German holding companies are transferring funds to their life business subsidiary through credit lines.
} 
risk margin for non hedgeable risks. ${ }^{15}$

Figure 2: The Balance Sheet of the life (l) / non-life (nl) Subsidiary

\begin{tabular}{|c|c|}
\hline \multicolumn{1}{|c|}{ Assets } & Liabilities \\
\hline \multicolumn{1}{|c|}{$A(t)$} & $O F(t)$ \\
& \\
& \\
& \\
& \\
&
\end{tabular}

Finally $O F(t)$ is the market value of the own funds that the subsidiary can pledge for solvency purposes: under S II, $O F(t)$ must be larger or equal to the $S C R(t)$, where $S C R(t)$ is the solvency capital requirement, i.e. the minimum amount of capital that must be held at single entity level in order to continue operations. ${ }^{16}$

\subsection{Stochastic Processes}

The stochastic processes under consideration are defined on a filtered probability space containing processes for interest rates, stocks and real estate returns, a process for mortality development and the random variable that describes the development of claims. The filtered probability space is defined as $(\Omega, \mathscr{F}, \mathbb{F}, \mathbb{P})$ with filtration $\mathbb{F}=\left(\mathscr{F}_{t}\right)_{t \in[0, T]}\left(\mathscr{F}_{0}=\{\emptyset, \Omega\}\right)$ which represents the information available up to time $t \in[0, T]{ }^{17}$ Against this background, the filtration $\mathscr{F}$ contains the knowledge of the evolution of all state variables up to time $t$, namely interest rates, stocks and real estate developments, mortality developments and claims developments which are assumed to be independent from each other. Throughout the paper, we specify all processes under the real world probability measure $\mathbb{P}^{18}$ Moreover, we consider a discrete time setting, whereby variables still depend on time but are defined within a partition of the time set $[0, T]$. Thus, $T$ represents the number of years considered in the model with $t$ representing $1 / T$ of the time set.

\footnotetext{
${ }^{15}$ We follow the same definitions applied under S II.

${ }^{16}$ More precisely, there is a lower level of capital, i.e. the minimum capital requirement $(M C R)$, under which the company ceases its operations.

${ }^{17}$ The usual conditions for the filtration are satisfied, i.e. right continuity and $(\mathbb{P}, \mathscr{F})$ - completeness. For further mathematical details see for instance Shreve (2004).

18 For pricing purposes, we would need to derive risk neutral martingale processes. As this is notoriously a challenging task, for the aim of the present work, we abstain from deriving an appropriate market price of risk.
} 


\subsubsection{Financial Markets Dynamics}

In order to simulate the term structure of interest rates, we rely on the model presented by Vasicek (1977). ${ }^{19}$ The model introduces the following interest rate dynamics, i.e. a standard Ornstein-Uhlenbeck process, under the risk neutral measure $\mathbb{Q}$

$$
d r(t)=k(\theta-r(t)) d t+\sigma_{r} d W_{r}^{\mathbb{Q}}(t)
$$

where $W_{r}^{\mathbb{Q}}(t)$ is a standard Brownian motion under $\mathbb{Q}, r(t)$ is the instantaneous interest rate, $k>0$ is the speed of adjustment, $\theta>0$ is the mean reversion level and $\sigma_{r}>0$ is the volatility of the short rate dynamics. In addition, assuming the absence of arbitrage and a market price of risk $\lambda(t, r)$ of the special form $\lambda(t)=\lambda r(t)$, the short interest rate dynamics under the real world probability measure $\mathbb{P}$ can be written as follows

$$
d r(t)=\left[k \theta-\left(k+\lambda \sigma_{r}\right) r(t)\right] d t+\sigma_{r} d W_{r}^{\mathbb{P}}(t)
$$

where $W_{r}^{\mathbb{P}}(t)$ is a standard Brownian motion under $\mathbb{P}$. Moreover, the model allows the pricing of a zero coupon bond according to

$$
P(t, T)=A(t, T) e^{-H(t, T) r(t)}
$$

where $t$ is the time spot and $T$ is the maturity time of the bond. $A(t, T)$ is defined as

$$
\left.A(t, T)=e^{\left\{\left(\theta-\frac{\sigma^{2}}{2 k^{2}}\right)[H(t, T)-T+t]-\frac{\sigma^{2}}{4 k} B(t, T)^{2}\right.}\right\}
$$

and the discount rate $H(t, T)$ is defined as

$$
H(t, T)=\frac{1}{k}\left[1-e^{-k(T-t)]}\right.
$$

Thus, the model enables us to generate a (quasi) risk free term structure of interest rates ${ }^{20}$ which we employ both to estimate future bonds' coupons and to determine the market value of assets and

\footnotetext{
${ }^{19}$ The Vasicek model is a wide-spread interest rate model. Although its ability to reproduce observed term structure of interest rates has been challenged over the years, it allows, by using an appropriate calibration, to generate term structures of interest rates in which there exists a positive probability of observing negative rates on shorter maturities. This feature is in line with the current environment, in which negative rates have been persistently observed (European Central Bank, 2015).

${ }^{20} \mathrm{By}$ quasi (or alternatively locally) risk free term structure of interest rates, we imply the German term structure of interest rates, which is the safe haven (AAA rated) for capital markets in Europe and often the benchmark curve for bond markets. Of course, the presence of a term premium and a non-zero credit risk justifies the quasi risk free status.
} 
liabilities. ${ }^{21}$ The term structure of interest rates is given by the following equation

$$
r_{f(t, T)}=-\frac{\ln (A(t, T))}{T-t}+\frac{H(t, T)}{T-t} r(t)
$$

in which $T-t$ is the maturity of the rate. ${ }^{22}$ In addition, we assume that risky bonds pay a stochastic premium on the risk free rate of return: for simplicity, we assume that such premium varies across issuers $j$ (each issuer is either a sovereign $(g)$ or a corporate $(c)$ ) but remains constant across maturities. Thus, the spread also follows an Ornstein - Uhlenbeck (mean reverting) process, although its distribution is truncated at 0 , and it is defined as follows

$$
\left.d \delta_{g / c}^{j}(t)=\left\{k \overline{\left(\delta_{g / c}^{j}\right.}-\delta_{g / c}^{j}(t)\right) d t+\sigma_{g / c}^{j} d W_{g / c}^{j, \mathbb{P}}(t)\right\}^{+}
$$

in which $\overline{\delta_{g / c}^{j}}$ is the mean reversion level and $\sigma_{g / c}^{j}$ its standard deviation. Thus, the term structure of risky bonds is given by

$$
r_{c / g(t, T)}^{j}=r_{f(t, T)}+\delta_{g / c}^{j}(t)
$$

which we employ to both value and determine coupons over time.

Stock $(s)$ and Real Estate $(r e)$ returns also vary across issuer $(j)$ and evolve over time following a Geometric Brownian Motion (GBM) which is specified as follows

$$
d S_{s / r e}^{j}(t)=\mu_{s / r e}^{j} S_{s / r e}^{j}(t) d t+\sigma_{s / r e}^{j} S_{s / r e}^{j}(t) d W_{s / r e}^{j, \mathbb{P}}(t)
$$

where $\mu_{s / r e}^{j}$ is the drift rate and and $\sigma_{s / r e}^{j}$ is the volatility of the return. The solution to equation (9) is given by

$$
S_{s / r e}^{j}(t)=S_{s / r e}^{j}(0) e^{\left(\mu_{s / r e}^{j} e^{-\frac{\sigma_{s / r e}^{j}}{2}}\right) t+\sigma_{s / r e}^{j} W_{s / r e}^{j, \mathbb{P}}(t)} .
$$

Finally, all processes, namely the instantaneous interest rate process of the Vasicek model, stochastic spreads and stock and real estate returns, are correlated through a Cholesky decomposition. ${ }^{23}$

\subsubsection{Mortality Dynamics}

We model the mortality developments using the standard Lee-Carter framework (LC model) with modifications as proposed by Brouhns et al. (2002a). The model specifies the central death

\footnotetext{
${ }^{21}$ However, the value of liabilities is subject to EIOPA guidelines which prescribe that only the first 20 years have to be considered at market values. Indeed, from the $20^{t h}$-year maturity onward, rates have to converge to the Ultimate Forward Rate which foresees a rate of $4.2 \%$ at 60 - year maturity.

${ }^{22}$ For further details on the dynamics of the bond pricing equation refer to Brigo and Mercurio (2006) pp.58-62.

${ }^{23}$ For more details on the Cholesky decomposition, see Appendix A.1.
} 
rate or force of mortality $\mu_{x, t}$ as follows

$$
\ln \left[\mu_{x, t}\right]=a_{x}+b_{x} \cdot k_{t}+\varepsilon_{x, t} \Leftrightarrow \mu_{x, t}=e^{a_{x}+b_{x} \cdot k_{t}+\varepsilon_{x, t}}
$$

in which $a_{x}$ and $b_{x}$ are time constant parameters for age $x$ that determine the shape and the sensitivity of the mortality rate to changes in $k_{t}$ which is a time varying parameter capturing the changes in the mortality rates over time. Finally, $\varepsilon_{x, t}$ is a stochastic error term. As originally proposed by Lee and Carter (1992), the estimation of the time varying parameter $k_{t}$ can be performed by fitting a standard $A R I M A$ model using standard time series analysis techniques. The $A R I M A(p, d, q)$ process is given by the following equation

$$
k_{t}=\left(\alpha_{0}+\alpha_{1} k_{t-1}+\alpha_{2} k_{t-2}+\ldots+\alpha_{p} k_{t-p}+\beta_{1} \varepsilon_{t-1}+\beta_{2} \varepsilon_{t-2}+\ldots+\beta_{q} \varepsilon_{t-q}\right)+\varepsilon_{t}=\widehat{k}_{t}+\varepsilon_{t}
$$

in which the error term is defined as follows $\varepsilon \sim N\left(0, \sigma_{k}\right) \cdot{ }^{24}$ Brouhns et al. (2002a) propose a convenient modification of the original LC model: the realized number of deaths at age $x$ and time $t$ is given by the following specification

$$
D_{x, t} \sim \operatorname{Poisson}\left(E_{x, t} \cdot \mu_{x, t}\right) \Leftrightarrow D_{x, t} \sim \operatorname{Poisson}\left(E_{x, t} \cdot e^{a_{x}+b_{x} \widehat{k}_{t}}\right)
$$

in which $\widehat{k}_{t}$ is the forecasted time varying parameter used to simulate random death rates (unsystematic mortality risk) and $E_{x, t}$ is the risk exposure at age $x$ and time $t$ defined as

$$
E_{x, t}=\frac{n_{x-1, t-1}+n_{x, t}}{2}
$$

in which $n_{x, t}$ is the number of living persons aged $x$ at the end of year $t$.

In order to simulate the evolution of each cohorts of policyholders in our model, we follow Brouhns et al. (2002b) who propose a transformation of (14) for simulation pourposes as follows

$$
E_{t}^{i}=\frac{-n_{t-1}^{i} q_{t}^{i}}{\ln \left(p_{t}^{i}\right)}
$$

in which $n^{i}$ is the reference population of the $i^{t h}$ cohort of policyholders and $q_{t}^{i}$ and $p_{t}^{i}$ are the (random) death and living probability given by the simulation of $\mu_{t}^{i}{ }^{25}$ Thus, the number of living individuals for each cohort is given by

$$
n_{t}^{i}=n_{t-1}^{i}-d_{t}^{i}
$$

\footnotetext{
${ }^{24}$ The term $d$ indicates the grade of cointegration of the series. For further mathematical details refer to Brockwell and Davis (2009) pp. 273-320.

${ }^{25}$ Please note that in our model we define $i$ the cohort of policyholders which is equivalent to the specification $x$ for the age of the population, since all cohorts of individuals enter the balance sheet at the same age and remain for an equal fixed period.
} 
in which $d_{t}^{i}$ is the simulated number of deaths. This is obtained by simulating a random draw from a Poisson distribution with $\lambda=E_{t}^{i} \cdot \mu_{t}^{i}$, in which $E_{t}^{i}$ is the exposure to risk of the $i^{t h}$ cohort and $\mu_{t}^{i}$ is the simulated mortality rate (see 13). To simulate $\mu$, we model different realizations of the time trend $k_{t}$ in presence of noise. Formally, this is given by the following equation

$$
k_{t}=\widehat{k}_{t}+\varepsilon_{t}
$$

in which $\widehat{k}_{t}$ is the expected time trend and $\varepsilon_{t} \sim\left(0, \sigma_{k}\right)$. The insertion of an error term allows for systematic changes in the mortality dynamics, i.e. the undiversifiable mortality risk. ${ }^{26}$

\subsubsection{Adverse Selection}

In the context of life insurance business and in particular in presence of annuity business, a well-known problem regarding the self-selection of longer living individuals has to be addressed. ${ }^{27}$ In Brouhns et al. (2002a) a model to quantify the impact of this phenomenon is presented: a Brass-type relational model defines the mortality rate of the pool of annuitants as a function of the mortality rates of the population. This is given by the following relation

$$
\ln \left[\mu_{t}^{i, a s}\right]=\phi_{1}+\phi_{2} \ln \left[\mu_{t}^{i}\right]
$$

in which the term $\phi_{2}$ reflects the speed of improvement in the mortality rates. Gatzert and Wesker (2012) insert a second term using a time index with the intent of reducing the speed of improvement as time goes by. Thus, the resulting relation is given by the following equation

$$
\ln \left[\mu_{t}^{i, a s}\right]=\phi_{1}+\phi_{2} \ln \left[\mu_{t}^{i}\right]+\phi_{3}\left(\ln \left[\mu_{t}^{i}\right] \cdot \tau_{\text {index }}\right)
$$

where $\phi_{3}<0$ and $\tau_{\text {index }}$ is a linear time index which gives more weight to coefficient $\phi_{3}$ as time goes by. Finally, in order to simulate the mortality developments of the annuitants population, we rewrite (19) as follows

$$
\ln \left[\mu_{t}^{i, a s}\right]=\phi_{1}+\phi_{2} \ln \left[\mu_{t}^{i}\right]+\phi_{3}\left(\ln \left[\mu_{t}^{i}\right] \cdot \tau_{\text {index }}\right)+\varepsilon_{t}
$$

with $\varepsilon_{x, t} \sim N\left(0, \sigma_{k}\right)$.

\subsubsection{Claims Developments}

We take a simple approach for the stochastic development of claims: we assume that they evolve according to a log-normal distribution, which is known ex-ante and remains unchanged over

\footnotetext{
${ }^{26}$ See for instance Wills and Sherris (2010), Hanewald et al. (2013) and Gatzert and Wesker (2012).

${ }^{27} \mathrm{On}$ a formal investigation of the problem, see among others Finkelstein and Poterba (2004).
} 
time. ${ }^{28}$ This simplification allows us to introduce uncertainty as well as fat tail results, both typical features of non-life claims. Thus, at every point in time $t$, claims in country $j$ are a random draw from the following distribution

$$
C^{j}(t)=\log -\mathcal{N}\left(\mu_{C}^{j}, \sigma_{C}^{j}\right)
$$

which has the following arithmetic moments

$$
\mathbb{E}\left[C^{j}\right]=e^{\mu_{C}^{j}+\frac{1}{2} \sigma_{C}^{j^{2}}} \quad \operatorname{Var}\left(C^{j}\right)=\left(e^{\sigma_{C}^{j^{2}}}-1\right) e^{2 \mu_{C}^{j}+\sigma_{C}^{j^{2}}}
$$

To be more precise, we define $C$ as an index with expected value fixed at 1 , i.e. $\mathbb{E}\left[C^{j}\right] \stackrel{!}{=} 1$ and consequently $\mu_{C}^{j}+\frac{1}{2} \sigma_{C}^{j^{2}} \stackrel{!}{=} 0$, which determines in every period the amount of cash-outflows generated by outstanding claims when multiplied by the amount of premiums collected in the previous period.

\section{$2.3 \quad$ Life Business}

We model 2 main types of business at shareholders' risk: endowment/annuity business and term life business. Both are modelled as standard contracts sold yearly to a cohort of policyholders in country $j$. Endowment/annuity business represents a traditional savings product through which policyholders accumulate funds over a pre-defined period of time and then either get a lump sum payment at the end of the period or annuitize the accumulated wealth. The contract entails i) a fixed time to maturity, ii) a minimum guaranteed rate of return, iii) a minimum profit participation, iv) yearly premiums with a loading, v) early death benefits (at discount) and vi) the opportunity for a share $\theta^{a}$ of the living policyholders at maturity to annuitize the accumulated funds and get life-long benefit payments. By contrast term life business only offers protection against early death: it entails $i$ ) a fixed time to maturity, ii) yearly premiums with loadings and iii) benefits liquidated as lump sum contingent on death.

\subsubsection{The Asset Side}

We assume that at each point in time, the insurer invests in 4 asset classes, namely sovereign bonds, corporate bonds, stocks and real estate, all kept in fixed proportions (static asset allocation), namely $\omega^{s b}, \omega^{c b}, \omega^{s}, \omega^{r e}{ }^{29}$ The asset allocation is then subject to the following conditions $\sum_{j} \omega^{j}=$ $1 \wedge \omega^{j} \geq 0$ for $j=s b, c b, s, r e$.

Bond-like asset classes are divided in sub-portfolios: 5 sub-portfolios for sovereign bonds, i.e. 1 per each of the countries considered in the model, in which each sub-portfolio comprises 20 coupons

\footnotetext{
${ }^{28}$ In the literature it is often assumed that claims develop following a GBM, see for instance Gatzert and Schmeiser (2008a) and Gatzert and Schmeiser (2008b): however, in a multi-period setting as the one in the present model, the volatility of claims that follow a GBM would tend to compound over time leading to very unstable developments with very high insolvency probabilities for insurers. Such feature would not be in line with observed claims developments.

${ }^{29}$ These represent the most common securities held by insurers, see EIOPA Stress Test (2014).
} 
(20 YTM), with residual time to maturity from 1 to 20; 4 sub-portfolios for corporate bonds, i.e. ratings from $\mathrm{AAA}$ to $\mathrm{BBB}$, in which each sub-portfolio comprises 10 coupons (10 YTM), each with residual time to maturity from 1 to 10 . This portfolio structure is chosen in order to constantly keep a fixed number of coupons in the portfolio which serve as an approximation for a weighted average of available coupons in the market. The weights associated to each coupon are chosen to match the available average modified duration data. A natural implication of this approach is the presence in the portfolio of coupons bought at different point in time, which are then marked to market and subject to changes in their market value due to movements of the term structure of interest rates. For Stock-like asset classes we follow a similar approach: the stock portfolio comprises stock returns from country specific stock indexes, which can be thought as country specific portfolios; the same holds for the real estate portfolio, which comprises real estate returns from country specific real estate indexes. Moreover, weights within portfolios are chosen to reflect home bias. ${ }^{30}$ Finally the total market value of assets at time $t$ is define as $A(t)^{l}$.

The price of a bond of the $j^{\text {th }}$ issuer with residual time to maturity $\tau$ with payoff vector $c$ which pays 1 unit at maturity is given by the following equation

$$
P_{t}^{j, \tau}=c_{t}^{j, \tau} \cdot m_{t}^{j, \tau}
$$

in which, recalling 2.2.1, $\mathrm{m}$ is the vector of stochastic discount factors; more precisely, we can express $c$ and $m$ as follows

$$
c_{t}^{j, \tau}=\left[c_{t}^{j, 1}, \ldots, c_{t}^{j, \tau}+1\right], m_{t}^{j, \tau}=\left[\begin{array}{c}
e^{-\left(r_{f(t, 1)}+\delta_{t}^{j}\right) \cdot 1} \\
\cdot \\
\cdot \\
\cdot \\
e^{-\left(r_{f(t, \tau)}+\delta_{t}^{j}\right) \cdot \tau}
\end{array}\right]
$$

Thus, the value of each bond portfolio is given by the following equation

$$
B_{t}^{s b / c b}=A(t)^{l} \cdot \underbrace{\omega_{t}^{s b / c b}}_{\text {class }} \cdot \underbrace{\sum_{j=1}^{N} \omega^{j}}_{\text {issuer }} \cdot \underbrace{\sum_{\tau=1}^{T} \omega_{t}^{j, \tau}}_{\text {time to maturity }}
$$

in which $\omega_{t}^{j, \tau}$ is the share of issuer $j$, i.e. country $j$ in the case of sovereign, rating $j$ in the case of corporate, with residual time to maturity $\tau$ which is yearly adjusted to reach the target duration. ${ }^{31}$

\footnotetext{
${ }^{30}$ When calibrating the model, we give more weight to the domestic index with respect to the indexes of the other countries, i.e. we assign a higher coefficient within the portfolio to the index representing the home country, whereas all other indices are given the same lower coefficient (see Section 3). This is a typical feature of investors, see for instance Kenneth and Poterba (1991).

${ }^{31}$ See Appendix A.4.
} 
More precisely, we can represent the relative weight of each coupon as follows

$$
(s b) \Rightarrow \omega^{j}:\left[\begin{array}{c}
\omega^{D E} \\
\omega^{F R} \\
\omega^{N L} \\
\omega^{I T} \\
\omega^{E S}
\end{array}\right],(c b) \Rightarrow \omega^{j}:\left[\begin{array}{c}
\omega^{A A A} \\
\omega^{A A} \\
\omega^{A} \\
\omega^{B B B}
\end{array}\right], \text { s.t. } \mathbf{1}^{\prime} \omega^{j}=1 \wedge \omega^{j} \geq 0, \quad j=D E, \ldots, B B B
$$

and the relative weight yearly adjusted to keep the modified duration constant

$$
\omega_{t}^{j, \tau}:\left[\begin{array}{c}
\omega_{t}^{j, d_{1}} \\
\cdot \\
\cdot \\
\cdot \\
\omega_{t}^{j, d_{n}}
\end{array}\right], \text { s.t. } \mathbf{1}^{\prime} \omega^{j, \tau}=1 \wedge \omega^{j, \tau} \geq 0, \tau=d_{1}, \ldots, d_{n}
$$

Finally, once we have the share of the portfolio we allocate to each single bond and its price, it is easy to derive the amount of notional to be bought and the relative generated cash flows. ${ }^{32}$

The stock and real estate portfolio have similar characteristics: the value of each portfolio is given by the following equation

$$
\begin{aligned}
S_{t}^{s / r e}= & A(t)^{l} \cdot \omega^{s / r e} \cdot \sum_{j=1}^{N} \omega_{t}^{j} \\
& \text { s.t. } \mathbf{1}^{\prime} \omega^{j}=1 \wedge \omega^{j} \geq 0, j=D E, \ldots, E S
\end{aligned}
$$

in which $\omega^{j}$ represents the weight allocated to issuer $j$, i.e. country. Stocks and real estate pay yearly contingent dividends/rents which are computed as follows

$$
d_{t+1}^{j, s / r e}=\psi^{s / r e} \cdot\left\{S_{t+1}^{* j, s / r e}-S_{t}^{* j, s / r e}\right\}^{+}
$$

in which $\psi^{s / r e} \leq 1$ determines how much of the marginal growth is cashed in as dividend/rent and $S^{*}$ is the index representing the dynamics of $s / r e$ of the $j$ issuer. Finally, dividends and rents are subtracted to the value of each stock-like asset class which is given by the following equation

$$
S_{t+1}^{j, s / r e}=S_{t}^{j, s / r e} \cdot e^{\left(\mu_{s / r e}^{* j}-\frac{\sigma_{s / r e}^{* j}}{2}+\sigma_{s / r e}^{* j} d W_{s / r e}^{* j, \mathbb{P}}\right)}-d_{t+1}^{j, s / r e}
$$

\footnotetext{
${ }^{32}$ For instance, given $B^{s b / c b, j}$, i.e. the value of the bond sub-portfolio $s b / c b$ issued by $j$, we know that the value allocated to each bond is given by $B^{s b / c b, j} \cdot \omega_{t}^{j, \tau}$ and therefore the quantity of unit bonds held in portfolio is given by $F^{s b / c b, j, \tau}=\frac{B^{s b / c b, j} \cdot \omega_{t}^{j, \tau}}{P^{s b / c b, j, \tau}}$ where $F$ is the notional of the bond paying the coupon $c$.
} 


\subsubsection{The Liability Side}

At each point in time a cohort of $n^{i}$ individuals aged $x$ buy a contract with annual net premium $\pi$, with an accumulation period of $T$ years and hold it until maturity. ${ }^{33}$ Thus, at each point in time the insurer has $N^{l}(t)$ cohorts of contracts in its balance sheet. On top of the net premium, i.e. the amount that gets accumulated in the policyholder's account in case of endowment/annuity products or the amount used for actuarial calculations in case of term life products, the insurer charges a loading factor $\varrho^{l} \geq 0$ which is the same for every cohort and every type of product. ${ }^{34}$ For endowment/annuity products, once the accumulation phase is terminated, a fraction $0 \leq \theta^{a} \leq 1$ of the living policyholders decide to annuitize the accumulated funds, whereas the remainder $1-\theta^{a}$ receive a lump sum payment equal to the accumulated funds. The insurer charges an additional loading factor to those who decide to annuitize: policyholders pay a loading factor out of the actuarially fair benefits, i.e. $m w=1-\varrho$ in which $m w$ is the ratio of the present discount value of the expected annuity payments to the price (Cannon and Tonks, 2008). Payments of both premiums and benefits are made in arrears, i.e. at the end of each year. In case death occurs before $T$ for endowment products, policyholders receive a fraction $\vartheta \leq 1$ of the accumulated funds, i.e. a recovery value.

We define the aggregate value of the liability side of the balance sheet as the sum of endowment policies, annuities and term life policies: $\omega_{t}^{e}, \omega_{t}^{a}$ and $\omega_{t}^{t l}$ represent the share of each type of business in the liability portfolio. ${ }^{35}$ More formally, this can be expressed as follows

$$
L(t)^{l}=\sum_{i=1}^{N^{l, e}} n^{e, i}(t) \cdot l^{e, i}(t)+\sum_{i=1}^{N^{l, a}(t)} n^{a, i}(t) \cdot l^{a, i}(t)+\sum_{i=1}^{N^{l, t l}} n^{t l, i}(t) \cdot l^{t l, i}(t)
$$

in which $l^{e, i}$ is the market value of the $i^{\text {th }}$ cohort of contracts expected to be liquidated at the end of the period (i.e. endowment policies), $l^{a, i}$ is the market value of the the $i^{\text {th }}$ cohort of contracts expected to be annuitized and $l^{t l, i}$ is the market value of term life contracts. $n^{e, i}(t)$, $n^{a, i}(t)$ and $n^{t l, i}(t)$ are the number of contracts per cohort of endowment, annuity and term life contracts, whereas $N^{l, e}, N^{l, a}(t)$ and $N^{l, t l}$ represent the total number of cohorts in the portfolio for endowment, annuity and term life respectively.

In order to compute the market value, the actuarial value of the technical reserves must also be computed at each point in time: thus, the aggregate value of the technical reserves, i.e. the

\footnotetext{
${ }^{33}$ We drop the superscript $j$ which indicates the country in order to simplify the notation.

${ }^{34}$ Operational costs are not modeled, therefore the loading factor $\varrho$ can be thought of either as a markup on top of the marginal cost of insuring (which could be a function of the market power of the company) or as a reward (risk premium) for systematic mortality risk.

${ }^{35}$ Similar to the asset portfolio, the following conditions apply: $\sum_{j} \omega^{j}=1 \wedge \omega_{t}^{j} \geq 0$ for $j=e, a, t l$.
} 
simplified book value, can be expressed as follows

$$
V(t)=\sum_{i=1}^{N^{l, e}} n^{e, i}(t) \cdot v^{e, i}(t)+\sum_{i=1}^{N^{l, a}(t)} n^{a, i}(t) \cdot v^{a, i}(t)+\sum_{i=1}^{N^{l, t l}} v^{t l, i}(t)
$$

in which $v^{e, i}, v^{a, i}$ and $v^{t l, i}$ represent the technical reserves for the contracts during the accumulation and decumulation phase (if annuitized) respectively. The amount of technical reserves is particularly important for savings products (endowments/annuities) since the computation of the amount of profits which need to be shared with policyholders every year is based on technical reserves.

\subsubsection{The Book Value of Liabilities}

\section{Endowment/Annuity business}

We first define the dynamics of the policyholders' accounts for the accumulation and decumulation phase: both endowment and annuities entail a profit sharing mechanism, through which during the accumulation phase, the distributed profits increase either the sum insured (i.e. the accumulated funds) or the yearly benefits for those who annuitize the distributed profits are liquidated every year and thereby increase the yearly benefits. Such mechanism implies that the amount of benefits to be paid out during the decumulation phase might vary according to both the dynamics of the asset return of the portfolio backing the liabilities and the dynamics of the mortality of the underwriting portfolio. Thus, the dynamics is given by the following recursive equations

$$
\left\{\begin{array}{lll}
v_{t}^{e, i}=v_{t-1}^{i}\left(1+r_{t}^{g, i}\right)+n_{t}^{i} \pi^{i}-\left(\vartheta+v^{q}(1-\vartheta)\right) v_{t-1} \cdot d_{t}^{i}, & & t:[1, T], \text { accumulation } \\
v_{t}^{e, i}=-v_{t-1}^{e, i}\left(1+r_{t}^{g, i}\right), & & t=T+1, \text { lump sum } \\
v_{t}^{a, i}=v_{t-1}^{a, i}\left(1+r^{i}\right)-b^{i} \frac{n_{t}^{i}}{n_{t-1}^{i}}, & & t:[T+1, \omega-x], \text { annuitization }
\end{array}\right.
$$

in which $b^{i}$ is the actuarially fair amount of life long benefits paid out to living policyholders, $v_{0}^{e, i}=0,{ }_{0} p_{x}=1$ and $q_{\omega}=1 .{ }^{36}$ The return yearly granted to policyholders, i.e. $r_{t}^{g, i}$ is determined by the following condition

$$
r_{t}^{g, i}=r^{i}+\left(v^{a} \cdot r_{t}^{a}-r^{i}\right)^{+}+\left(v^{q} \cdot r_{t}^{q}\right)^{+}
$$

in which $r_{t}^{a}$ is the rate of return of the insurers's asset portfolio at time $t, r_{t}^{q}$ is the rate of return stemming from the actual mortality developments and $v^{a / q} \in[0,1]$ is an exogenous constant through which the regulator forces insurers to distribute a minimum amount of financial and mortality

\footnotetext{
${ }^{36}$ See Appendix A.2 For further mathematical details see Pitacco et al. (2009), pp.8 - 16.
} 
returns to policyholders. ${ }^{37}$ More formally, $r_{t}^{a}$ is given by

$$
r_{t}^{a}=\frac{\sum_{j=1}^{N} \sum_{\tau=1}^{T} c_{t}^{j, \tau, s b}+\sum_{j=1}^{N} \sum_{\tau=1}^{T} c_{t}^{j, \tau, c b}+\sum_{j=1}^{N} d_{t}^{j, s}+\sum_{j=1}^{N} d_{t}^{j, r e}}{A_{t}^{b v}}
$$

the sum of coupons, bonds due and dividends and rents computed on the book value of assets. ${ }^{38}$ Profits from mortality developments come from two sources and can be summarized as follows

$$
\begin{cases}(1-\vartheta) \cdot v_{t-1}^{e, i}\left(\tilde{q}_{t}^{i}-\bar{q}_{t}^{i}\right), & \text { for } t \leq T, \text { accumulation } \\ v_{t}^{a, i} \cdot\left(\tilde{q}_{t}^{i}-\bar{q}_{t}^{i}\right), & \text { for } t>T, \text { decumulation }\end{cases}
$$

in which $\tilde{q}_{t}^{i}$ is the observed (stochastic) mortality of the $i^{t h}$ cohort determined as $\tilde{q}_{t}^{i}=\frac{\tilde{n}_{t-1}^{i}-\tilde{n}_{t}^{i}}{\tilde{n}_{t-1}^{i}}$ whereas $\bar{q}_{t}^{i}$ is the expected mortality probability used to compute the necessary reserves. ${ }^{39}$ The return on mortality is then computed as follows

$$
r_{t}^{q}=\frac{\sum_{i=1}^{N^{l, e}(t-1)}(1-\vartheta) \cdot v_{t-1}^{e, i} \cdot\left(\tilde{q}_{t}^{i}-\bar{q}_{t}^{i}\right)+\sum_{i=1}^{N^{l, a}(t-1)} v_{t}^{a, i} \cdot\left(\tilde{q}_{t}^{i}-\bar{q}_{t}^{i}\right)}{V_{t-1}}
$$

Finally, the book value for endowment/annuity liabilities is determined as the expected amount of funds to be paid in the future discounted at the technical interest rate $r^{i}$. More formally, for the endowment contract this is given by the following equation

$$
\begin{aligned}
\bar{v}_{t}^{e, i} & =v_{t}^{e, i} \cdot\left[\sum_{s=0}^{T-t-1}\left(\vartheta+v^{q}(1-\vartheta)\right) \cdot \frac{\left(1+r^{i}\right)^{s}{ }_{s} \bar{p}_{t}^{i} \cdot \bar{q}_{t+s}^{i}}{\left(1+r^{i}\right)^{s}}+\frac{\left(1+r^{i}\right)^{T-t} T \bar{p}_{t}^{i}}{\left(1+r^{i}\right)^{T-t}}\right] \\
& =v_{t}^{e, i} \cdot\left[\sum_{s=0}^{T-t-1}\left(\vartheta+v^{q}(1-\vartheta)\right) \cdot{ }_{s} \bar{p}_{t}^{i} \cdot \bar{q}_{t+s}^{i}+{ }_{T} \bar{p}_{t}^{i}\right]
\end{aligned}
$$

in which $v_{t}^{e, i}$ are the accumulated funds at time $t$ and $\bar{p}$ and $\bar{q}$ represent the surviving and mortality probability used for pricing purposes, with ${ }_{0} \bar{p}_{t}^{i}=1 .{ }^{40}$ It is worth remarking that the technical

\footnotetext{
${ }^{37}$ However, it is worth remarking that the way yearly returns are credited to policyholders varies across countries: some countries have strict regulations regarding the profit participation mechanism (e.g. Germany) while others do not have a specific regulation on the profit participation (e.g. the Netherlands). In particular, in many countries $v$ is set by the regulator and it represents the minimum share of profits that must be credited to the policyholders' accounts, although such share of profits might differ for financial and mortality returns. Since we calibrate the model for different countries, we take into consideration the peculiarities of each underlying local regulatory regime and we provide an overview in Appendix A.7.

${ }^{38}$ Analogously to the book value of liabilities, we also compute the book value of assets in each period: although we focus on the market value of assets, we indirectly derive historical costs by approximating the book value to the face value and update them yearly.

${ }^{39}$ It is common practice to load mortality probabilities in order to factor in potential deviations from unsystematic mortality. Thus, we load the underlying probability distribution of mortality according to the German Actuarial Association (DAV) guidelines and thereby compute the necessary reserves to hold in the balance sheet. We keep such loading equal across countries. See Table 9.

${ }^{40}$ More formally, the expression introduces the conditional surviving probability which is given by the following expression ${ }_{T} \bar{p}_{t}^{i}=\prod_{s=t}^{T} \bar{p}_{s}^{i}$, i.e. the probability that a $x+t$ year old individual survives for the next $T$ years.
} 
interest rate is indeed the guaranteed rate of return: by discounting with the rate $r^{i}$, the insurer explicitly assumes that the paid premiums will at least grow in the policyholder's account at the rate $r^{i}$ and thereby provides a minimum guaranteed rate of return. Thus the book value of the contract is approximated as the mortality weighted current level of the policyholders' account dimished by the recovery value $\vartheta$ and also by the amount of returns that are given back to policyholders $v^{q} .{ }^{41}$

Finally, for the annuity contract this is simply given by

$$
\left\{\begin{aligned}
v_{t}^{a, i} & =m w \cdot v_{t}^{e, i}, & & t=T+1 \\
v_{t}^{a, i} & =v_{t-1}^{a, i}\left(1+r^{i}\right)-b^{i} \frac{n_{t}^{i}}{n_{t-1}^{i}}, & & t>T+1
\end{aligned}\right.
$$

in which $m w$ is the money's worth ratio of the annuity contract and $b$ are the yearly benefits of the annuity. $^{42}$

\section{Term Life business}

The book value for term life liabilities is also determined as the expected amount of funds to be paid out in the future discounted at the technical interest rate $r^{i}$. More formally, this is given by

$$
v_{t}^{t l, i}=\sum_{s=0}^{T-t-1} \frac{D B^{i} \cdot{ }_{s} \bar{p}_{t}^{i} \cdot \bar{q}_{t+s}^{i}}{\left(1+r^{i}\right)^{(s+1)}}-\frac{\pi^{i} \cdot{ }_{s} \bar{p}_{t}^{i}}{\left(1+r^{i}\right)^{s}}
$$

in which $D B$ are the actuarially fair benefits. ${ }^{43}$

\subsubsection{The Market Value of Liabilities}

\section{Endowment/Annuity business}

The market value of endowment/annuity liabilities is computed using risk-neutral valuation. At time $t$, the insurer computes the best estimate of its liabilities taking into account the guaranteed rate of return, the expected profit sharing dynamics and discounts the terminal value using the risk free rate term structure. This computation is close but not equivalent to a fair valuation of the contract, which would, however, require additional distributional assumptions (i.e. simulations) regarding the evolution of the asset side return, the mortality developments and the dynamics of the risk free term structure. Thus, for computational reasons, we abstain from such stochastic valuation and rely on an approximate computation of the best estimates. ${ }^{44}$ The market consistent

\footnotetext{
${ }^{41}$ To be more precise, a $v^{q}$ share of the amount $1-\vartheta$ has to be given back to the survived policyholders, therefore the value that has to be booked as reserve in the balance sheet, i.e. paid out to policyholders in the future, is given by $\vartheta+v^{q}(1-\vartheta)$.

${ }^{42}$ See Appendix A.2.

${ }^{43}$ See Appendix A.3.

${ }^{44}$ For further details, see for instance Grosen and Løchte Jørgensen (2000), Bauer et al. (2006) or Gatzert (2008).
} 
value of the endowment contract at time $t$ is approximated by the following equation

$$
l_{t}^{e, i}=v_{t}^{e, i} \cdot\left[\sum_{s=0}^{T-t-1}\left(\vartheta+v^{q}(1-\vartheta)\right) \cdot \frac{\left(1+\left\{r^{i}, \hat{r}_{s+1}^{g}\right\}^{+}\right)^{s}{ }_{s} \bar{p}_{t}^{i} \cdot \bar{q}_{t+s}^{i}}{\left(1+r_{f(t, s+1)}\right)^{s}}+\frac{\left(1+\left\{r^{i}, \hat{r}_{s+1}^{g}\right\}^{+}\right)^{(s+1)} s+1 \bar{p}_{t}^{i}}{\left(1+r_{f(t, s+1)}\right)^{(s+1)}}\right]
$$

in which $\hat{r}_{s+1}^{g}$ is a vector containing the expected future rate of return stemming from the profit sharing mechanism which value depends on the information set available at time $t$, i.e. from the observed rate of return granted to policyholders in the past. ${ }^{45}$

For the annuity contract, the market consistent valuation has also to take the decumulation phase into consideration. Thus, the market consistent value of the annuity contract at time $t$ is approximated by the following equation

$$
l_{t}^{a, i}=l_{t}^{e, i}-\left\{l_{t}^{e, i}-\underline{b}^{i} \cdot \sum_{s=T+1}^{\omega-x} \frac{s p_{x+T}^{i}}{\left(1+r_{f(t, s)}\right)}\right\}
$$

in which $\underline{b}$ is estimated in every year and indicates the minimum amount of benefits at every point in time. Finally, the actual market value shall consider the amount of policyholders who will annuitize at the end of the accumulation period. Therefore, we rewrite the market value for both endowment and annuity products as follows:

$$
\begin{gathered}
l^{e, i}(t)=\left(1+r m^{e / a}\right) \cdot\left(1-\theta^{a}\right) \cdot l^{e, i}(t) \\
l^{a, i}(t)=\left(1+r m^{e / a}\right) \cdot \theta^{a} \cdot l^{a, i}(t)
\end{gathered}
$$

in which $\theta^{a}$ is the amount of annuitants and $r m^{e / a}$ is a deterministic risk margin.

\section{Term Life business}

The market value for term life liabilities is also computed as the risk neutral expected amount of funds to be paid out in the future. More formally, this is given by the best estimate of the contract

$$
l_{t}^{t l, i}=\sum_{s=0}^{T-t-1} \frac{D B \cdot{ }_{s} \bar{p}_{t}^{i} \cdot \bar{q}_{t+s}^{i}}{\left(1+r_{f(t, s)}\right)^{(s+1)}}-\frac{\pi^{i} \cdot{ }_{s} \bar{p}_{t}^{i}}{\left(1+r_{f(t, s)}\right)^{s}}
$$

which is then aggregated and endowed with a deterministic risk margin $\left(\mathrm{rm}^{t l}\right)$

$$
l^{t l, i}(t)=\left(1+r m^{t l}\right) \cdot n_{t}^{i} \cdot l_{t}^{t l, i}
$$

\footnotetext{
${ }^{45} \mathrm{~A}$ similar valuation setting is described among others in Grosen and Løchte Jørgensen (2000) and Bacinello (2003). For further details on the future returns granted to policyholders, see Appendix A.5.
} 


\subsection{Non-Life Business}

We model a stylized generic property/liability protection contract with a fixed yearly maturity, in which premiums (including loadings) and claims are yearly cashed in and liquidated respectively.

\subsubsection{The Asset Side}

The investment portfolio has a similar structure as the portfolio presented in 2.3.1: we assume that the insurer only invests in bonds which have the same temporal horizon as the contracts they replicate, i.e. 1 year time to maturity. In addition, we assume that the insurer does not undertake any stock and real estate investments. Thus, the market value of assets $A(t)^{n l}$ at time $t$ is the simple sum of the share of sovereign bonds $\left(\omega_{t}^{s b}\right)$ and corporate bonds $\left(\omega_{t}^{c b}\right){ }^{46}$

\subsubsection{The Liability Side}

We define the market value of the liability side as follows ${ }^{47}$

$$
L(t)^{n l}=\frac{N^{n l} \cdot \pi^{i} \cdot\left(1+r m^{n l}\right)}{1+r_{f(t, 1)}}
$$

in which $N^{n l}$ represents the number of contracts, $\pi^{i}=k \cdot \mathbb{E}[C]$ is the premium per single contract with $k$ being simply a constant to adjust the magnitude of the premium, and $r m^{n l}$ is a deterministic risk margin. In order to determine the number of contracts, we assume that within the group the amount of non-life business reserves represents a share $\omega^{n l}$ of the total reserves at market value, which implies that $L(t)^{n l}=\frac{L(t)^{l}}{1-\omega^{n l}} \cdot \omega^{n l}$. Thus, by fixing the value of $\pi^{i}$ and rearranging terms, we obtain the following

$$
N^{n l}=\frac{\left(1+r_{f(t, 1)}\right) \cdot L(t)^{l} \cdot \omega^{n l}}{\pi^{i} \cdot\left(1+r m^{n l}\right) \cdot\left(1-\omega^{n l}\right)} .
$$

Finally, the value of claims to be paid at time $t$ is given by the following expression

$$
\Psi_{t}^{n l}=N^{n l} \cdot \pi^{i} \cdot \widetilde{C}(t)
$$

and since we assume $\mathbb{E}\left[\widetilde{C}^{j}\right] \stackrel{!}{=} 1$, it follows that $\mathbb{E}[\Psi]=N^{n l} \cdot \pi^{i}$.

\footnotetext{
${ }^{46}$ Similarly to the asset side for life business, the following conditions apply: $\sum_{j} \omega^{j}=1 \wedge \omega^{j} \geq 0$ with $j=s b, c b$.

${ }^{47}$ We drop the superscript $j$ which indicates the country in order to simplify the notation.
} 


\subsection{The Free Cash Flow}

\subsubsection{Life Business}

The free cash flow for the life business before dividends to shareholders is defined as follows

$$
F C F_{t^{-}}^{l}=\underbrace{R_{t}^{a, l}}_{\text {coupons/dividends }}+\underbrace{F_{t}^{l}}_{\text {bonds due }}+\underbrace{\Pi_{t}^{l}}_{\text {premiums }}-\underbrace{\Psi_{t}^{l}}_{\text {benefits paid to PHs }}
$$

in which

$$
R_{t}^{a, l}=\sum_{j=1}^{N} \sum_{\tau=0}^{T-1} c_{t}^{s b, j, \tau}+\sum_{j=1}^{N} \sum_{\tau=0}^{T-1} c_{t}^{c b, j, \tau}+\sum_{j=1}^{N} d_{t}^{j, s}+\sum_{j=1}^{N} d_{t}^{j, r e}
$$

is the return on assets as sum of coupons and dividends.

$$
F_{t}^{l}=\sum_{j=1}^{N} F_{t}^{s b, j, 0}+\sum_{j=1}^{N} F_{t}^{c b, j, 0}
$$

is the sum of maturing bonds, i.e. notionals; premiums are given by the following expression

$$
\Pi_{t}^{l}=\sum_{i=1}^{N^{l, e}} n_{t}^{e, i} \pi^{i}\left(1+\varrho^{l}\right)+\sum_{i=1}^{N^{l, t l}} n_{t}^{t l, i} \pi^{i}\left(1+\varrho^{l}\right)
$$

and finally, benefits paid to policyholders are given by

$$
\begin{aligned}
\Psi_{t}^{l} & =\left(1-\theta^{a}\right) \cdot v_{t}^{1, e} \cdot n_{t}^{l, 1}+ \\
& +\sum_{i=1}^{N^{l, e}} v_{t-1}^{i} \cdot \vartheta \cdot \frac{n_{t}^{e, i}}{n_{t-1}^{e, i}}+\sum_{i=1}^{N^{l, a}(t)} b^{i}+v_{t-1}^{a, i} \cdot\left(1+\left\{r^{g, i}-r^{i}\right\}^{+}\right) \cdot \frac{n_{t}^{a, i}}{n_{t-1}^{a, i}}+ \\
& +\sum_{i=1}^{N^{l, t l}} D B^{i} \cdot d_{t}^{t l, i}
\end{aligned}
$$

in which (56) is the amount liquidated as lump sum to the matured cohort, (57) is the amount paid to early death individuals and to annuitants and (58) is the amount liquidated to policyholders who died during the year. The decision to pay out dividends to shareholders is taken by considering the minimum amount of capital the insurer must hold in order to comply with regulation, i.e. the solvency capital requirement as per S II (SCR). ${ }^{48}$ Thus, the amount of dividends is computed as follows

$$
R_{t}^{s h, l}=\left\{\min \left\{A\left(t^{-}\right)^{l}+F C F_{t^{-}}^{l}-L(t)^{l}-S C R(t)^{l}, r_{\text {target }}^{s h} \cdot O F^{l}(t-1)\right\}\right\}^{+}
$$

in which $A\left(t^{-}\right)^{l}$ is the total market value of assets before reinvestment, i.e. bonds which did not mature, stocks and real estate, $F C F_{t^{-}}^{l}$ is the free cash flow before dividends, $S C R(t)^{l}$ is the

\footnotetext{
${ }^{48}$ For the computation of the SCR, see Appendix A.6.
} 
regulatory capital and $r_{\text {target }}^{\text {sh }}$ is a maximum amount of dividends that can be paid out as ratio of the capital available (i.e. invested) in the previous period $O F(t-1)^{l}$. Finally, the cash to be actually reinvested, i.e. $F C F_{t}^{l}$, is computed as follows

$$
F C F_{t}^{l}=F C F_{t^{-}}^{l}-R_{t}^{s h, l}
$$

The asset portfolio is then yearly rebalanced towards the initial allocation and towards the target duration.

\subsubsection{Non-Life Business}

The free cash flow for the non-life business before dividends to shareholders is defined as follows

$$
F C F_{t^{-}}^{n l}=\underbrace{R_{t}^{a, n l}}_{\text {coupons/dividends }}+\underbrace{F_{t}^{n l}}_{\text {bonds due }}+\underbrace{\Pi^{n l}}_{\text {premiums }}-\underbrace{\Psi_{t}^{n l}}_{\text {claims paid to PHs }}
$$

in which

$$
R_{t}^{a, n l}=\sum_{j=1}^{N} c_{t}^{j, s b}+\sum_{j=1}^{N} c_{t}^{j, c b}
$$

is the return on assets as sum of coupons and

$$
F_{t}^{n l}=\sum_{j=1}^{N} F_{t}^{j, s b}+\sum_{j=1}^{N} F_{t}^{j, c b}
$$

is the sum of maturing bonds, i.e. notionals; finally, premiums are given by the following expression $\Pi^{n l}=N^{n l} \cdot \pi^{i} \cdot\left(1+\varrho^{n l}\right)$. The decision to payout dividends to shareholders is taken by considering the minimum amount of capital the insurer must hold in order to comply with regulation, i.e. the solvency capital requirement as per S II (SCR). ${ }^{49}$ Thus, the amount of dividends is computed as follows

$$
R_{t}^{s h, n l}=\left\{\min \left\{F C F_{t^{-}}^{n l}-L(t)^{n l}-S C R(t)^{n l}, r_{\text {target }}^{s h} \cdot O F^{n l}(t-1)\right\}\right\}^{+}
$$

in which $F C F_{t^{-}}^{n l}$ is the free cash flow before dividends, $S C R(t)^{n l}$ is the regulatory capital and $r_{\text {target }}^{\text {sh }}$ and $r_{\text {target }}^{s h}$ is a maximum amount of dividends that can be paid out as ratio of the capital available (i.e. invested) in the previous period $O F(t-1)^{n l}$. Finally, the cash to be reinvested, i.e. $F C F_{t}^{n l}$, is computed as follows

$$
F C F_{t}^{n l}=F C F_{t^{-}}^{n l}-R_{t}^{s h, n l} .
$$

The asset portfolio is then yearly rebalanced towards the initial allocation and towards the target duration.

\footnotetext{
${ }^{49}$ For the computation of the SCR, see Appendix A.6.
} 


\subsection{Group Consolidation}

The group balance sheet is simply the sum of the balance sheets of the subsidiaries, that is

$$
\begin{gathered}
A(t)^{g}=A(t)^{l}+A(t)^{n l} \\
L(t)^{g}=L(t)^{l}+L(t)^{n l} \\
O F^{g}(t)=A(t)^{g}-L(t)^{g} .
\end{gathered}
$$

The function of the holding company in the model is to collect dividends coming from the subsidiaries and pay them to shareholders. In addition, it has the power to transfer capital from a subsidiary which has excessive capital (CE) to a subsidiary which has capital shortage (CS). Subsidiaries can have capital excess when

$$
\begin{aligned}
C E^{l / n l}(t) & =A(t)^{l / n l}+F C F(t)^{l / n l}-\left(L(t)^{l / n l}+S C R(t)^{l / n l}\right)>0 \\
& \Longleftrightarrow A(t)^{l / n l}+F C F(t)^{l / n l}>L(t)^{l / n l}+S C R(t)^{l / n l}
\end{aligned}
$$

or capital shortage when

$$
\begin{aligned}
C S^{l / n l}(t) & =L(t)^{l / n l}+S C R(t)^{l / n l}-\left(A(t)^{l / n l}+F C F(t)^{l / n l}\right) \geq 0 \\
& \Longleftrightarrow A(t)^{l / n l}+F C F(t)^{l / n l} \leq L(t)^{l / n l}+S C R(t)^{l / n l} .
\end{aligned}
$$

Thus, there can be capital transfers in only 2 cases, i.e. case (1): $C E^{l}>0 \wedge C S^{n l}>0$ or case (2) $C E^{n l}>0 \wedge C S^{l}>0$. The amount of capital that is transferred is given by the following equations

$$
\text { case (1): }\left\{\begin{array}{l}
A(t)^{l}+F C F(t)^{l}-\min \left\{C E^{l}(t), C S^{n l}(t)\right\}-L(t)^{l}=O F^{l}(t) \\
A(t)^{n l}+F C F(t)^{n l}+\min \left\{C E^{l}(t), C S^{n l}(t)\right\}-L(t)^{n l}=O F^{n l}(t),
\end{array}\right.
$$

and

$$
\text { case (2): }\left\{\begin{array}{l}
A(t)^{l}+F C F(t)^{l}+\min \left\{C E^{n l}(t), C S^{l}(t)\right\}-L(t)^{l}=O F^{l}(t) \\
A(t)^{n l}+F C F(t)^{n l}-\min \left\{C E^{n l}(t), C S^{l}(t)\right\}-L(t)^{n l}=O F^{n l}(t) .
\end{array}\right.
$$

In addition, total dividends are re-computed as follows

$$
\text { case (1): }\left\{\begin{array}{l}
R_{t}^{s h, l}=\min \left\{C E^{l}(t)-C S^{n l}(t)^{+}, r_{\text {target }}^{s h} \cdot O F^{l}(t-1)\right\} \\
R_{t}^{s h, n l}=0
\end{array}\right.
$$

and

$$
\text { case (2): }\left\{\begin{array}{l}
R_{t}^{s h, l}=0 \\
R_{t}^{s h, n l}=\min \left\{C E^{n l}(t)-C S^{l}(t)^{+}, r_{\text {target }}^{s h} \cdot O F^{n l}(t-1)\right\} .
\end{array}\right.
$$

Finally, the marginal investment will include the capital transfer. 


\section{Calibration}

\subsection{Stochastic Processes}

We simulate 1000 iterations for the financial market developments and 1000 iterations for the mortality developments. All balance sheets are calibrated as per end of 2014. For each iteration, we consider a 10 years horizon and, thus, we look at the evolution of solvency and profitability until year $2024 .^{50}$

\subsubsection{Financial Markets Dynamics}

To conduct a forward-looking cross-country assessment of the resilience of insurers balance sheets to different financial market developments, in particular the resilience to a protracted period of low interest rates, we define 3 scenarios: the baseline scenario foresees an interest rate level for the 10YTM German sovereign bond with convergence level to about $2 \%$, coupled with the reversion to pre-crisis levels of corporate bonds spreads, stocks and real estate returns; the adverse scenario and the severely adverse scenario foresee a lower level of interest rates, with convergence level for the 10YTM German sovereign bond to about 1\%. Moreover, under the adverse scenario corporate bond spreads, stocks and real estate returns revert to pre-crisis levels, whereas under the severely adverse scenario the calibration also encompasses a substantial increase in the volatility of the corporate bonds spreads, stocks and real estate returns as it occurred during the financial crisis. We calibrate the parameters $k$ and $\sigma_{r}$ of the Vasicek model on the data of the EONIA between January 2008 and December 2014 following (Brigo et al., 2009) to ensure a stronger mean reversion. ${ }^{51}$ Moreover, we set the market price of risk at a relatively high level (i.e. $\lambda=1$ ) to ensure a concavity of the yield curve close to the one typically observed in the markets. Had we set $\lambda$ to a more common range of values, e.g. 0.05, the Vasicek model would generate rather flat yield curves due to the low interest rates foreseen by the assumed scenarios. ${ }^{52}$. Table 1 reports the estimated parameters for the 3 scenarios whereas table 2 reports the correlation coefficients through which the processes are correlated. In addition, Figures 7 - 12 depict the results of simulations under the 3 scenarios.

\subsubsection{Mortality Dynamics}

Table 3 reports the estimated parameters for the Lee-Carter model at country level. In addition, an adverse selection correction was estimated by means of the results presented in Gatzert and Wesker (2012). Indeed, it is well known that, in presence of annuities, a self-selection of people

\footnotetext{
${ }^{50}$ To simulate all processes for financial markets we follow Brigo et al. (2009) and we use an Euler scheme to discretize the equations.

${ }^{51}$ We chose such period for a more practical reason, i.e. the level of mean reversion we obtain allows for a stronger mean reversion compared using the EONIA data between January 1999 and December 2014 leads to a lower mean reversion.

${ }^{52}$ See analogous considerations in Berdin and Gründl (2015)
} 
with higher than the average life expectancy may arise. ${ }^{53}$ Thus, we distinguish between the general population and the population who buys endowment/annuity products and we assume that the latter displays a mortality dynamics corrected for adverse selection as presented in table 3. Moreover, we assume that the population who buys term life products follows the general population. ${ }^{54}$ This assumption is also reflected in the premium calculation and therefore taken into consideration by the management. ${ }^{55}$

\subsubsection{Claims Development}

For the calibration of the claims development we follow a simple approach. More specifically, we assume that claims develop in the same fashion in every country and that they do not grow in expected value. In other words we assume that the collected premiums remain constant over time and that the business does not grow. ${ }^{56}$ Moreover, we assume that deviations from the expected amount of claims occur. In particular, we set the standard deviation to $10 \%$, which is a more conservative figure than those presented among others in Gatzert and Schmeiser (2008a) or Gatzert and Schmeiser (2008b). The relatively low level of risk chosen for the development of claims is justified by the fact that combined ratios tend to be rather stable over time. ${ }^{57}$ Thus, by assuming fair pricing with loadings and a relatively moderate deviation from the expected value, we ensure a relatively stable combined ratio over time. ${ }^{58}$ Table 4 reports the calibration of the model for the claim developments.

\subsection{Asset and Liability Portfolios}

The selected asset allocation for life business is reported in Figure 5, whereas for non-life business it is reported in Figure 6. The asset allocation for life business is shaped as to match both data available on the relative weight of single asset classes within the asset portfolio and the modified duration data as reported in EIOPA Stress Test (2014). For the sovereign bond portfolio, we assume that the holdings of other sovereign bonds are equally distributed among the remaining countries. Table 5 reports in column (2) the relative weights of single sub-portfolios within the same asset class. ${ }^{59}$ Moreover, in order to match the modified durations reported by EIOPA Stress Test (2014),

\footnotetext{
${ }^{53}$ See for instance Finkelstein and Poterba (2004).

${ }^{54}$ There is no reason why the mortality dynamics of policyholders who buy term life products should be identical to the mortality dynamics of the general population and thereby do not display any adverse selection behaviour. However, for the sake of simplicity we do not apply a correction term to this share of the business.

${ }^{55}$ Loading factors are applied to the mortality assumptions used to compute premiums (loaded probabilities). This is in line with international practice, see for example Von Gaudecker and Weber (2004).

${ }^{56}$ This is a simplifying assumption: in fact one could introduce both for the life and non-life business, a growth rate for premiums at least in line with general inflation, which however is not modelled in the present framework.

${ }^{57} \mathrm{~A}$ simplified combined ratio is computed as follows: $C R=\frac{\text { losses }+ \text { expenses }}{\text { premiums }}$.

${ }^{58}$ Further sensitivity analyses could test for different scenarios in which volatility is higher or pricing is subject to tougher competition and thereby profit margins tend to be low.

${ }^{59}$ For instance, for Germany we use the data reported by EIOPA Stress Test (2014) on home sovereign holdings while the remainder of all sovereign holdings are equally distributed among French, Italian, Dutch and Spanish
} 
we apply the duration matching strategy presented in Section 2.3.1. More specifically, we select the last 20 YTM during the last 20 years as to be representative of the coupons simultaneously held in the portfolio: each coupon has a different expected time to maturity, i.e. the oldest coupon in portfolio is due in 1 year, whereas the youngest is due in 20 years. Then, in order to match the modified duration of the sub-portfolios, weights were chosen following the algorithm presented in Appendix A.4. We apply the same strategy also to corporate bond portfolios. In this context, the breakdown by credit quality is fixed across countries and the expected time to maturity for corporate bonds is 10. Therefore, the oldest coupon in the portfolio is due in 1 year whereas the youngest in 10 years. Weights are then assigned to each coupon to match the duration data reported by EIOPA Stress Test (2014) by applying the algorithm illustrated in Appendix A.4. Finally, for stocks and real estate sub-portfolios, due to data limitation, we apply a simpler approach. ${ }^{60}$ In order to reproduce a plausible home bias, we assume that $60 \%$ of the stock and real estate portfolio is held in domestic assets while the remainder is equally distributed among the other countries. Table 5 reports the composition of stocks and real estate portfolios. The guaranteed rate of returns held in portfolio and the asset and liability durations are key drivers in the model. In particular, they are relevant for the endowment/annuity portfolio which is the most sensitive to interest rate changes. Table 6 reports the composition of the endowment/annuity portfolio at the beginning of the simulation (i.e. end of 2014). In this context, we apply the same methodology as in Berdin and Gründl (2015), i.e. we accumulate cohorts of contracts using available past data and assuming a fixed time to maturity for the contracts over time. We then allow for an additional rate of return based on the available data from EIOPA Stress Test (2014) or based on the sovereign yields at country level. By doing so, we are able to reproduce the typical situation that life insurers face, i.e. the co-existence of different cohorts of contracts with different guaranteed rate of returns and different time horizons in portfolio. Moreover, this strategy also allows us to compute the modified duration of the endowment/annuity portfolio which is the most vulnerable to interest rate changes and which is reported in Table 7 . The endowment/annuity portfolio is then matched by the asset portfolio and the difference between the duration of the 2 portfolios is reported in table 7 as well. The interpretation of the duration mismatch is the following: the higher the difference between the duration of the liability portfolio and the duration of the asset portfolio, the higher is the exposure to reinvestment risk and, therefore, the higher the sensitivity of the own funds to the movement of the term structure of interest rates. Finally, it is worth remarking that the presence of term life business and annuity business does change the duration mismatch in the balance sheet, as the modified duration of term life products is typically shorter than the modified duration of endowment products, whereas the modified duration of annuities is typically higher than the modified duration of endowment products. However, reserves allocated to term life and annuities in Europe are typically modest, thereby making the figures presented in Table 7 highly representative.

sovereign bonds. We follow the same approach for all countries, as we do not dispose of more detailed data on sovereign holdings at country level.

${ }^{60}$ Indeed, we do not dispose of the geographical breakdown of stocks and real estate holdings 


\subsection{Specifications}

We test 4 balance sheet compositions (i.e. specifications) in terms of business model: specification (1) foresees only endowment business, specification (2) foresees endowment business and term life business, specification (3) foresees endowment business, term life business and annuity business, whereas specification (4) introduces life and non-life business. Table 8 reports the different specifications and the relative weights of the different lines of business. This is an important aspect since traditionally endowment and annuity business tend to be very sensitive to interest rate risk and more in general to financial risk, whereas term life business and non-life business are rather insensitive to capital markets developments. Against this background, insurers have the possibility to diversify their liability portfolio and thereby increase resilience in case of adverse financial market conditions. Such resilience clearly depends on the relative weight of each line of business within the portfolio, which ultimately determines the solvency position and the profitability of the insurer. Since we do not dispose of detailed data on the amount of reserves allocated to each line of business, i.e. endowment, term life and annuity business, and since we want to maintain a certain degree of comparability across countries, we define the different portfolio composition to be as realistic as possible given the data limitation (Table 8$).{ }^{61}$

\subsection{Other Balance Sheet Parameters}

Table 9 reports the remaining parameters of the model. The share of reserves allocated to endowment/annuities is set to $95 \%$, term life and the share of annuitants is set to $5 \%$. We use data provided by BaFin for German life insurers (BaFin, 2013), in particular data on the amount of reserves allocated to term-life business, and we assume these figures are representative also for other countries. ${ }^{62}$ By contrast, data for annuity business is very limited and not directly available from publicly available statistics. However, in general, annuities still represent a small business in continental Europe and, therefore, we assume $5 \%$ as to be a purely indicative figure. The split between life and non-life business at group level is calibrated using the data by the national insurance associations or by the local regulator in each country. ${ }^{63}$ The number of cohorts of contracts held in portfolio is a crucial variable as it allows to determine the time to maturity structure of the liability side. Unfortunately, we do not dispose of sufficiently detailed data to estimate the expected time to maturity of typical endowment and term life contracts. However, based on the data on the duration of liabilities reported in the EIOPA Stress Test (2014), we

\footnotetext{
${ }^{61}$ The availability of more granular data could allow clustering companies according to their business portfolios and thereby allowing for a more precise analysis.

${ }^{62}$ We rely on German data to determine the relative weight of each line of business due to the lack of data and for comparability reasons.

${ }^{63}$ The German Insurance Association (GDV) and Federal Financial Supervisory Authority (BaFin), the French Insurance Association (FFSA) and the Prudential Supervisory Authority (ACPR), the Italian Insurance Association (ANIA) and the Insurance Supervisory Authority (IVASS), the Dutch Insurance Association (VVV) and the Dutch Central Bank (DNB) and finally the Spanish Insurance Association (UNESPA) and the Ministry of Economy and Finance, DG for Insurance and Pension Funds.
} 
can approximately infer the expected time to maturity of each cohort of contracts. In addition, to allow for comparability, we fix the expected time to maturity of term life contracts equal across countries. The money's worth ratio is based on data for Germany reported by Von Gaudecker and Weber (2004), whereas the loading factor for life premiums is fixed to $1 \%$ and for non-life to $5 \%$ : the difference between loading factors is justified by the fact that the non-life business displays fat tails in claim developments and therefore it requires higher premiums in order to hedge unexpected results. ${ }^{64}$ The loading factor for mortality are taken from the German Actuarial Association and kept constant across countries. ${ }^{65}$ Also premiums are computed using German data and kept constant across countries. ${ }^{66}$ Finally, the recovery value introduces an additional loading factor in case of early termination of the contract, the minimum share of $r^{a}$ and $r^{q}$ are taken from national regulations (if existent) and the risk margins are taken from EIOPA QIS5 (2010).

The dividend payout target and the initial (i.e. at the beginning of the simulation period) solvency ratio are 2 crucial parameters. The dividend payout ratio is a key variable in the model as it determines how much of the profits generated every year is cashed out to shareholders. To set this parameter, we refer to the statistical data released by EIOPA. ${ }^{67}$ In particular, we compute yearly averages at country level of the profit or losses realized over the year divided by the available solvency margin. In order to ensure comparability, we keep the average across country as reference parameter in every specification and for every country in the model. Moreover, we assume it to be fixed at group level. ${ }^{68}$ The initial solvency ratio is also a crucial figure. Due to the lack of data availability and due to the need of ensuring comparability, we assume that all countries start the simulation period with the same solvency ratio, i.e. 165\%. This value corresponds to the average European solvency ratio as reported in the EIOPA QIS5 (2010). ${ }^{69}$

\section{Results}

Figures 13 - 17 report the results of the simulations for the baseline scenario, Figures $18-22$ report the results of the simulations for the adverse scenario, whereas Figures 23 - 27 report the results of the simulations for the severely adverse scenario. For each country we look at 3 main variables which characterize the profitability and solvency dynamics over time: i) return on assets (computed at book values) which provides a measure of both the return policyholders expect on

\footnotetext{
${ }^{64}$ Similar figures for loadings are reported for instance in Gründl et al. (2006).

${ }^{65}$ The German Actuarial Association publishes a mortality tables including loading factors both for annuity business, i.e. DAV 2004R, and for term life business, i.e. DAV 2008T.

${ }^{66}$ Following the data reported by BaFin (2013), we extrapolate an approximate proportion among premiums for different insurance contracts.

${ }^{67}$ EIOPA Statistics - EU/EEA (re)insurance statistics 2005-2013.

${ }^{68}$ The data suggest that there is a slightly higher propensity to generate profits in the non-life business, i.e. $8.3 \%$ compared to $7 \%$ in the life business. For the sake of simplicity we assume a unique dividend policy at group level.

${ }^{69}$ The figure refers to both solo undertakings life and non-life, and insurance groups. In general we would expect non-life business to have a much higher solvency ratio compared to life, due to fat tails of the underlying risks: unfortunately the availability of data on SII ratios is scarce, therefore, we relied on an average figure for both lines of business and across countries, which in turn allow for greater comparability of results.
} 
their accounts and the amount of cash generated from insurers financial assets ${ }^{70}$, ii) return on equity measured as the ratio between the dividends paid out and the amount of own funds and iii) the solvency ratio as the most direct risk metrics.

\subsection{The Baseline Scenario}

Under specification 1 (Figure 13) ${ }^{71}$, we observe a steady decline in the return on assets across all countries and across all specifications: this is the direct effect of the adjustment of the bond portfolios to the prevailing interest rate regime. More specifically, assuming an average duration spanning between 6 and 8 years, we might expect the asset portfolio to have completely turned around by the end of the simulation and, therefore, all available coupons to be in line with market rates. The return on equity displays a generalized decrease over time across all countries, except for Italy. The decrease in dividends is direct consequence of the solvency situation, which appears to be negatively affected in most countries. Indeed in our model, as soon as the solvency ratio approaches $100 \%$ (i.e. when own funds are close to the minimum regulatory amount), the management reduces the amount of dividends paid out to shareholders in order to increase the capital of the firm. The solvency ratio decreases dramatically in Germany as direct consequence of the high level of guarantees and the lower amount of profits generated from endowment business. ${ }^{72}$ In fact, the solvency ratio decreases very rapidly, thus forcing the management to stop paying out dividends. France also displays a reduction in the amount of dividends paid out to shareholders justified by the relatively surprising decrease in the solvency ratio. Although the level of outstanding guarantees is substantially lower compared to Germany, this sharp reduction is mainly explained by the calibration of the asset portfolio. Indeed, based on our data, the asset portfolio foresees a relatively high exposure to stock-like asset classes which do not generate sufficient cash inflows to keep up with the liability portfolio. ${ }^{73}$ The Netherlands and Spain display similar dynamics with respect to the return on equity, although for the Netherlands the situation improves along with the simulation, whereas for Spain the amount of dividends tends to zero by the end of the simulation. Both countries also display a reduction in their solvency position at the beginning, however consistently with the dynamics of the dividends, the situation improves for the Netherlands whereas it deteriorates further for Spain. Italy is a remarkable exception. Indeed, the dividend payout ratio does not seem to be strongly affected under this scenario, so is not the solvency

\footnotetext{
${ }^{70}$ We do not take capital gains/losses into considerations since changes in market values directly affect the solvency ratio and, therefore, are better captured by the solvency ratio dynamics.

${ }^{71}$ Specification 1 only includes endowment business.

${ }^{72}$ It is worth stressing that for a portfolio of endowment business, additional source of return such as mortality profits are very small since the company has very limited exposition to mortality and, therefore, does not make profits out of mortality developments. For instance in Berdin and Gründl (2015), results for Germany look substantially different due to the deterministic inclusion of mortality gains (as much as $1 \%$ of outstanding reserves) which are indeed an important source of profit for life insurers. Thus, specification 2, in which term life business adds substantial profits, features a remarkable improve of the solvency situation.

${ }^{73}$ The share of stocks in France appears to be substantially higher compared to other countries, better data could help in understanding if insurers actually hold a high portion of stocks in their general account or part of these holdings are attributable to separate accounts.
} 
ratio, although over the medium term we observe a moderate reduction. Such difference compared to other countries can be explained in part by the moderate duration mismatch, and in part by regulation: indeed Italian insurers are heavily exposed to Italian sovereign debt, which provides higher returns with moderate solvency capital requirements, thus improving the overall solvency situation.

Under specification 2 (Figure 14$)^{74}$, we can observe a generalized improvement across all countries of both profitability (in terms of return on equity) and solvency when compared to the results obtained under specification 1. However, the German balance sheet still displays a marked reduction in the solvency position over time, although less rapid than under specification 1: the reduction in the solvency position in turn reduces the amount of dividends paid out to shareholders, thus, highlighting how the German business model under a protracted period of low rates present vulnerabilities both in terms of profitability and solvency. France and Spain only show a minor reduction in their solvency positions towards the end of the simulation period, whereas Italy and the Netherlands appear to be in a better position.

This generalized improvement is essentially due to the diversification of the business portfolio. The inclusion of the term life business (corresponding to $5 \%$ of total liabilities) increases the free cash flow and, thereby, allows the insurer to pay out more dividends and to remain compliant with the solvency regulation. Indeed, the term life business generates about $25 \%$ of the total income premium although its share, appears moderate. ${ }^{75}$ In addition, the pricing for the term life business is conducted with loaded mortality probabilities and additional loading on premiums which allow the insurer to collect on average more premiums than the benefits it has to liquidate. ${ }^{76}$ Thus, a more diversified portfolio has a beneficial effect on both profitability and solvency, which however heavily depend on the pricing of the products and more generally on the competitive stance of the market. ${ }^{77}$

Under specification 3 (Figure 15) ${ }^{78}$, consistently with the results observed in specification 2, we note a further improvement of the insurers financial conditions. In fact, adding annuity business allows the insurer to smooth cash outflows over time and to increase expected profits via pricing. However, this occurs at the cost of taking other risks, in particular longevity risk. This combined effect of smoothing cash outflows and higher profits due to pricing, offsets the valuation effect due to the higher expected duration of the liability side. This is a particularly relevant aspect since under S II, insurers have the possibility of discounting liabilities using the ultimate forward rate,

\footnotetext{
${ }^{74}$ Specification 2: Endowment and Term Life Business includes endowment and term-life business.

${ }^{75}$ This figure is the average across countries: depending on the accumulated endowment liabilities, the amount of collected premiums changes, as the number of contracts sold yearly is calibrated to match the share of liabilities at market value.

${ }^{76}$ Clearly, the results are dependent on the underlying calibration which might be arbitrary. Indeed, we could expect lower profit margins as markets increase in competition. Therefore, further sensitivity analyses could shed additional light on the role of technical margins.

${ }^{77}$ For instance, selling products at lower prices could increase the demand for such products but at the same time it would expose the insurer to higher risks.

${ }^{78}$ Specification 3: Endowment, Term Life and Annuity Business includes endowment, term-life business and annuity business.
} 
which in turn decreases the market value of liabilities compared to the theoretical marked-to-market valuation and thereby boosts its solvency position and its expected dividend payouts. Results once again heavily depends on the pricing of products, i.e. for annuities on the coefficient $m w$. Indeed, the higher is $m w$, the lower is the expected profit of the insurer and the higher is the exposure to longevity risk, which, however, materializes very slowly in the balance sheet and, therefore, it is hard to detect within the time horizon we consider. ${ }^{79}$ Thus, with a more diversified portfolio insurers can better cope with a persistent low interest rate environment, although in the case of Germany we still observe a reduction in the solvency situation towards the end of the simulated period, with a consequent mild reduction in the dividend payout ratio.

Finally, specification 4 (Figures 16 and 17) introduces the group diversification and the possibility to redistribute capital within the group. Results are essentially similar to specification 3, however, a few caveats are necessary. The model we present for non-life business is highly stylized and does not feature some fundamental specificities of this business. Nevertheless, upon proper calibrations, the model allows for testing the resilience of an insurance group to different claims developments and different competitive stances of the market, and thereby to identify critical levels of capitalization. In general, we observe that the level of the asset return for non-life is much lower and the volatility much higher compared to life. This is due to the fact that we assume a very short duration, i.e. 1 year, for the asset allocation of the non-life business. Indeed, this assumption implies that the financial returns are exposed to the higher volatility of the short term rates. In addition, the volatility of the solvency ratio is much higher compared to life. This is due to the calibration of the claims distribution: indeed the deviation from the expected claims is substantial (refer to Table 5) and it results in marked changes in the solvency ratio. Moreover, the median level of the solvency ratio grows for all countries over time, implying that the business generates sufficient free cash flows to pay out dividends and increase the value of the own funds. The solvency ratio of the life business remains substantially unchanged compared to specification 3 , thus, excluding capital redistributions from the life business towards non-life business.

In conclusion, we can say that a scenario in which interest rates converge towards $2 \%$ in the long run and in which spreads, stocks and real estate developments return to pre-crisis level, would still represent a threat to those companies more exposed to financial guarantees, in particular in those markets in which contracts have long maturities and local regulation is more stringent in terms of profit participation.

\subsection{The Adverse Scenario}

Under specification 1 (Figure 18), we observe a generalized worsening of both profitability and solvency across almost all countries. Indeed, a lower level of interest rates has a profound impact

\footnotetext{
${ }^{79}$ For instance Koijen and Yogo (2015) provide evidence of sales at discount in the U.S. market during the financial crisis as a means to boost cash inflows in time of (potential) distress. The authors identify negative mark-ups, i.e. $m w>1$, during the financial crisis, with picks of $m w>1.15$ for 30 years term annuities.
} 
on the valuation of both asset and liabilities, in which the latter increase more due to the higher duration. Such effect is particularly strong for Germany, which displays the higher outstanding levels of guarantees and (together with the Netherlands) the longest maturities. Thus, a higher value of expected future liabilities reduces the solvency ratio and thereby forces the management to reduce the dividend payouts, consistently with the results observed under the baseline scenario. Adding term life business (Figure 19) results in a generalized improvement for all countries but Germany. Indeed, Germany still experiences a strong reduction in the return on equity due to the lower solvency ratios, which in almost half of the simulated paths results below minimum requirements. Consistently with the results observed under calibration 1, adding term life and annuity business (Figure 20) improves the situation both for profitability and solvency across all countries. However, Germany still appears to be vulnerable even after the business diversification.

Finally, in specification 4 which feature both the life and non-life business (Figure 21), we can observe that the median solvency ratio for the non-life business has substantially decreased compared to the baseline scenario: such effect is mostly due to the lower return on assets that under the adverse scenario the assets allocated to the non-life business can achieve. In fact as the duration of the asset allocation is 1 year, the effect of low rates is immediately transmitted into the balance sheet, which results in lower cash inflows from coupons and thereby lower growth of own funds. In Figure 28 we report the relative decrease of the median solvency ratios for non-life business under the adverse scenario compared to the baseline scenario: it can be noted that the decrease ranges from $20 \mathrm{pp}$ for Germany and Spain to almost $40 \mathrm{pp}$ for France, Italy and Netherlands. Such difference is on the one hand due to the higher median solvency ratio under the baseline scenario, which then translates into a stronger drop under the adverse scenario, and on the other hand it is due to the idiosyncrasy in the asset allocation across countries and consequently in the different solvency capital requirements.

Capital transfers do not seem to play a role, meaning that the solvency level in the life business does not drop sufficiently to negatively affect the solvency position of the non-life business. Thus, we can conclude that lower rates may also reduce the solvency level of non-life insurers assuming an unchanged premium income. The speed of the transmission into the balance sheet of such effect clearly depends on the time to maturity structure of the asset allocation.

\subsection{The Severely Adverse Scenario}

Under specification 1 (Figure 23), we observe even worse results compared to the adverse scenario. This is mainly the effect of the higher volatility in financial markets, which substantially increases the volatility of the solvency ratio. This is particularly evident for Italy and Spain, which under the severely adverse scenario experience a high volatility of their sovereign debt and severely adverse stock and real estate market developments. This higher volatility has a detrimental effect on the solvency ratio for both markets. In particular, Italy, which never displays downside risks with respect to low interest rates, seems to be especially exposed to the volatility of its sovereign 
debt due to the strong home bias on bond investments. The higher volatility in financial markets decreases profitability across all markets as direct consequence of the reduce solvency ratio. By diversifying the liability portfolio, we can observe a generalized improvement (Figures 24 and 25). Overall, Germany and Spain seem to be the most exposed to this scenario, with both important reductions in profitability and solvency position.

Likewise to the adverse scenario, under specification 4 , we can observe also a reduction in the median solvency ratio of the non-life business across all countries, although the reduction is less pronounced compared to the adverse scenario, especially for France, Italy and the Netherlands. Such result is due to 2 related phenomena: on the one hand, the higher volatility provides higher asset returns which are immediately visible in the balance sheet due to the short duration of the asset side; on the other hand, the short duration prevents the volatility to influence the solvency ratio since all bonds mature within the year and therefore capital gains and losses are not visible in the balance sheet. This is clearly a particular feature of the model: in fact a higher duration of the asset side would result in a higher volatility of the solvency ratio. However, such result does not hold for Spain and Germany: in fact, in Figure 28 we can observe how the drop in the median solvency ratio for the Spanish non-life business in the severely adverse scenario compared to the baseline is very strong in the first years of the simulation. Also for Germany we can observe a similar development, although less pronounced compared to Spain. This is the direct effect of the capital redistribution within the group: as the life business is exposed to high volatility and low interest rates, it drags capital from the non-life business and thereby reduces the solvency position of the non-life business. Once more this is an interesting development, since capital transfers within a group may be a potential source of interconnection and therefore spill overs across business lines.

\section{Conclusion}

In this paper, we present a forward-looking model for the assessment of solvency and profitability in insurance companies. We model the balance sheet of both life and non-life insurance business, which we then project under stochastic capital markets, stochastic mortality and stochastic claims. In our framework, we are able to test the resilience of insurance companies under different capital market scenarios, with particular focus on a protracted period of low interest rates. Our evidence suggests that there are insurance markets which appear to be particularity exposed to downside risks due to their peculiarities and to their specific regulation. We observe that diversification of the business portfolio has a strong positive effect, which however depends very much on a number of factors that are key to the analysis. Those factors include pricing, the competitive stance, the demand for new contracts and the lapse ratio which all strongly determine the outcome of the model. Moreover, we can observe that low rates may also affect the solvency level of the non-life business through lower return on assets and also through capital redistribution within groups, which may represent a potentially negative spillover. This is a relevant aspect, in particular in light of 
the ongoing low interest rate environment in which life insurers are exposed to downside risks and might have need for additional capital in the future.

However, it is worth remarking that results should be taken with caution. Indeed the high number of inputs necessary for the model make the results dependent on the calibration whose quality in turn depends on the availability of data. ${ }^{80}$ Nevertheless, the results presented in this paper confirm some previous findings on the weaknesses of the life insurance industry in certain markets, in particular in Germany, and provide an additional warning on the potential threats to its stability that could derive by a protracted period of low interest rates. Further analyses could spark additional light on the policy measures necessary to prevent future crises. In conclusion, our research is one of the first attempts to create an analytical framework for assessing financial stability in the insurance sector. Our model not only allows to stress-test the balance sheet of an insurance group under different capital market developments, but it also allows considering other key aspects of the insurance business. In fact, the portfolio diversification, the role of pricing and the competitive stance are examples of influencing factors, which can be further analyzed for policy purposes. Moreover, our model provides a multi-period perspective, which is a relevant aspect in the insurance industry, as risks tend to accumulate over time. In particular, we think that it is essential for policy authorities to dispose within their macro-prudential mandate of rigorous instruments, which allow for timely interventions in this sector. Finally, further research is necessary, especially on more general equilibrium aspects of the analysis, such as policyholders' behavior and asset allocation dynamics. Indeed, such features could be introduced in our framework and could potentially spark additional light on the underlying economics of the insurance business.

\footnotetext{
${ }^{80}$ Indeed, more precise and granular data could of course increase the quality and reliability of results.
} 


\section{References}

Antolin, P., Schich, S., and Yermo, J. (2011). The Economic Impact of Protracted Low Interest Rates on Pension Funds and Insurance Companies. OECD Journal: Financial Markets Trends, 2011(1).

Bacinello, A. R. (2003). Fair Valuation of a Guaranteed Life Insurance Participating Contract Embedding a Surrender Option. Journal of Risk and Insurance, 70(3):461-487.

BaFin (2013). Statistik der Bundesanstalt fr Finanzdienstleistungsaufsicht Erstversicherungsunternehmen und Pensionsfonds. BaFin Statistics.

Bauer, D., Kiesel, R., Kling, A., and Ruß, J. (2006). Risk-Neutral Valuation of Participating Life Insurance Contracts. Insurance: Mathematics and Economics, 39(2):171-183.

Berdin, E. (2016). Interest Rate Risk, Longevity Risk and the Risk taking Behaviour of Life Insurers. ICIR \& SAFE Working Paper Series (forthcoming).

Berdin, E. and Gründl, H. (2015). The Effects of a Low Interest Rate Environment on Life Insurers. The Geneva Papers on Risk and Insurance-Issues and Practice.

Berdin, E., Kok, C., Mikkonen, K., Pancaro, C., and Vendrell Simon, J. M. (2015). Euro Area Insurers and the Low Interest Rate Environment. ECB Financial Stability Review - November 2015.

Björk, T. (2004). Arbitrage Theory in Continuous Time. Oxford University Press.

Borel-Mathurin, F., Darpeix, P.-E., Guibert, Q., and Loisel, S. (2015). Main Determinants of Profit Sharing Policy in the French Life Insurance Industry. PSE Working Papers n 2015-16.

Brigo, D., Dalessandro, A., Neugebauer, M., and Triki, F. (2009). A Stochastic Processes Toolkit for Risk Management: Geometric Brownian Motion, Jumps, GARCH and Variance Gamma Models. Journal of Risk Management in Financial Institutions, 2(4):365-393.

Brigo, D. and Mercurio, F. (2006). Interest Rate Models - Theory and Practice: with Smile, Inflation and Credit. Springer.

Brockwell, P. J. and Davis, R. A. (2009). Time Series: Theory and Methods. Springer Science \& Business Media.

Brouhns, N., Denuit, M., and Vermunt, J. K. (2002a). A Poisson Log-Bilinear Regression Approach to the Construction of Projected Lifetables. Insurance: Mathematics and Economics, 31(3):373393. 
Brouhns, N., Denuit, M., Vermunt, J. K., et al. (2002b). Measuring the Longevity Risk in Mortality Projections. Bulletin of the Swiss Association of Actuaries, 2:105-130.

Cannon, E. and Tonks, I. (2008). Annuity Markets. Oxford University Press.

Domanski, D., Shin, H. S., and Sushko, V. (2015). The Hunt for Duration: Not Waving but Drowning? BIS Working Paper.

EIOPA (2015). Financial Stability Report - December 2015. (2).

EIOPA QIS5 (2010). Quantitative Impact Study 5. Technical report, EIOPA.

EIOPA Stress Test (2014). EIOPA Insurance Stress Test 2014. Technical report, EIOPA.

European Central Bank (2015). Macro-Financial and Credit Environment. ECB Financial Stability Review - November 2015.

Finkelstein, A. and Poterba, J. (2004). Adverse Selection in Insurance Markets: Policyholder Evidence from the UK Annuity Market. Journal of Political Economy, 112(1):183-208.

Gatzert, N. (2008). Asset Management and Surplus Distribution Strategies in Life Insurance: An Examination with Respect to Risk Pricing and Risk Measurement. Insurance: Mathematics and Economics, 42(2):839-849.

Gatzert, N. and Schmeiser, H. (2008a). Combining Fair Pricing and Capital Requirements for Non-Life Insurance Companies. Journal of Banking 86 Finance, 32(12):2589-2596.

Gatzert, N. and Schmeiser, H. (2008b). The Influence of Corporate Taxes on Pricing and Capital Structure in PropertyLiability Insurance. Insurance: Mathematics and Economics, 42(1):50-58.

Gatzert, N. and Wesker, H. (2012). Mortality Risk and its Effect on Shortfall and Risk Management in Life Insurance. Journal of Risk and Insurance.

Grosen, A. and Løchte Jørgensen, P. (2000). Fair Valuation of Life Insurance Liabilities: The Impact of Interest Rate Guarantees, Surrender Options, and Bonus Policies. Insurance: Mathematics and Economics, 26(1):37-57.

Gründl, H., Post, T., and Schulze, R. N. (2006). To Hedge or not to Hedge: Managing Demographic Risk in Life Insurance Companies. Journal of Risk and Insurance, 73(1):19-41.

Hanewald, K., Piggott, J., and Sherris, M. (2013). Individual Post-Retirement Longevity Risk Management Under Systematic Mortality Risk. Insurance: Mathematics and Economics, 52(1):87-97.

Hull, J. (2010). Options, Futures, and Other Derivatives, 7 edition. Pearson Education.

Insurance Europe (2015). European Insurance - Key Facts. Insurance Europe Statistical Publications. 
Joyce, M., Liu, Z., and Tonks, I. (2014). Institutional Investor Portfolio Allocation, Quantitative Easing and the Global Financial Crisis. Bank of England, Working Paper No. 510.

Kenneth, R. F. and Poterba, J. M. (1991). Investor Diversification and International Equity Markets. The American Economic Review, 81(2):222-226.

Koijen, R. S. J. and Yogo, M. (2015). The Cost of Financial Frictions for Life Insurers. American Economic Review, 105(1):445-75.

Lee, R. D. and Carter, L. R. (1992). Modeling and Forecasting US Mortality. Journal of the American statistical association, 87(419):659-671.

Macaulay, F. R. (1938). Some Theoretical Problems Suggested by the Movements of Interest Rates, Bond Yields and Stock Prices in the United States Since 1856. NBER Books.

Pitacco, E., Denuit, M., Haberman, S., and Olivieri, A. (2009). Modelling Longevity Dynamics for Pensions and Annuity Business. Oxford University Press.

Rajan, R. G. (2005). Has Financial Development Made the World Riskier? National Bureau of Economic Research, Working Paper 11728.

Schlütter, S. and Gründl, H. (2012). Who Benefits from Building Insurance Groups\&quest; A Welfare Analysis of Optimal Group Capital Management. The Geneva Papers on Risk and Insurance-Issues and Practice, 37(3):571-593.

Shreve, S. E. (2004). Stochastic Calculus for Finance II: Continuous-time Models, volume 11. Springer Science \& Business Media.

Swiss Re (2012). Facing the Interest Rate Challange. Sigma Series, 2012(4).

Tower, I. and Impavido, G. (2009). How the Financial Crisis Affects Pensions and Insurance and Why the Impacts Matter (EPub). (9-151).

Vasicek, O. (1977). An Equilibrium Characterization of the Term Structure. Journal of Financial Economics, 5(2):177-188.

Von Gaudecker, H.-M. and Weber, C. (2004). Surprises in a Growing Market Niche: An Evaluation of the German Private Life Annuities Market. Geneva Papers on Risk and Insurance. Issues and Practice, pages 394-416.

Wedow, M. and Kablau, A. (2011). Gauging the Impact of a Low-Interest Rate Environment on German Life Insurers. Deutsche Bundesbank Discussion Papers No. 02/2011.

Wills, S. and Sherris, M. (2010). Securitization, Structuring and Pricing of Longevity Risk. Insurance: Mathematics and Economics, 46(1):173-185. 


\section{A Appendix}

\section{A.1 Correlation of Stochastic Processes}

All stochastic processes are correlated through a Cholesky decomposition. More formally, this is given by the following equations

$$
\begin{aligned}
d W_{r}^{\mathbb{P}}(t) & =d \widetilde{W_{r}}(t) \\
d W_{g / c}^{j, \mathbb{P}}(t) & =\rho_{r, g / c} d \widetilde{W_{r}}(t)+\sqrt{1-\rho_{r, g / c}^{2}} d \widetilde{W_{g / c}^{j}}(t) \\
d W_{s / r e}^{j, \mathbb{P}}(t) & =\rho_{r, s / r e} d \widetilde{W}_{r}(t)+\rho_{g / c, s / r e} d \widetilde{W_{g / c}^{j}}(t)+\sqrt{1-\rho_{r, s / r e}^{j}{ }^{2}-\rho_{g / c, s / r e}^{j}} d \widetilde{W_{s / r e}^{j}}(t)
\end{aligned}
$$

in which the correlation coefficient $\rho$ satisfies $d W_{r}^{\mathbb{P}}(t) \cdot d W_{g / c}^{j, \mathbb{P}}(t)=\rho_{g / c}^{j} d t, d W_{r}^{\mathbb{P}}(t) \cdot d W_{s / r e}^{j, \mathbb{P}}(t)=$ $\rho_{s / r e}^{j} d t, d W_{g / c}^{j, \mathbb{P}}(t) \cdot W_{s / r e}^{j, \mathbb{P}}(t)=\rho_{g / c, s / r e}^{j} d t$ with $\widetilde{W_{r}} \perp \widetilde{W_{g / c}} \perp \widetilde{W_{s / r e}}$. For further mathematical details, see, for instance, Hull (2010) or Björk (2004).

\section{A.2 Actuarially Fair Annuity Benefits}

The actuarially fair yearly benefits are computed according to the following equivalence principle in which the present value of the inflow of premiums and return from reserves, i.e. the guaranteed return and the additional profit participation, is set equal to the present value of the outflow of benefits. At the inception for a single annuitant the equivalence is expressed as follows

$$
\underbrace{\sum_{t=1}^{T} \frac{\pi^{i} \cdot{ }_{t} p_{x}^{i}}{\left(1+r^{i}\right)^{t}}}_{\text {accumulation }} \stackrel{!}{=} \underbrace{\underline{b}^{i} \sum_{t=T+1}^{\omega-x} \frac{t p_{x}^{i}}{\left(1+r^{i}\right)^{t}}}_{\text {decumulation }}
$$

in which $\underline{b}^{i}$ is the minimum actuarially fair benefits granted to the annuitant and ${ }_{t} p_{x}$ is the survival probability of the annuitant, i.e. the probability that an individual aged $x$ survives the next $t$ years. When a loading factor is applied, i.e. the annuity is not fairly priced, benefits are computed as follows $^{81}$

$$
\underline{b}_{t}^{i} \stackrel{!}{=} \frac{m w \cdot v_{t}^{e, i}}{\sum_{s=T+1}^{\omega-x} s p_{t}^{i}\left(1+r^{i}\right)^{s}}
$$

in which the money's worth ratio is assumed to be $m w<1$. This is a typical setting for annuity providers which is justified by both the need of charging a risk premium for unhedgeable risks and

\footnotetext{
${ }^{81}$ For more details see for instance Pitacco et al. (2009) and Cannon and Tonks (2008).
} 
market power.

\section{A.3 Actuarially Fair Mortality Benefits}

The actuarially fair death benefits are computed as follows ${ }^{82}$

$$
D B^{i}=\sum_{s=0}^{T-1} \frac{\left(1+r^{i}\right)^{(s+1)}}{{ }_{s} \bar{p}_{x}^{i} \cdot \bar{q}_{x+s}^{i}} \cdot \frac{\pi_{s}^{i} \bar{p}_{x}^{i}}{\left(1+r^{i}\right)^{s}} .
$$

\section{A.4 Duration Matching Strategy}

We develop a simple algorithm which enables us to keep the duration of the asset portfolio unchanged over time. Since in the portfolio there coexist a fixed number of coupons with fixed time to maturity, it is necessary to impose a certain relation among coupons, otherwise there would be infinite solutions. Thus, portfolio weights for each bond portfolio are computed following this algorithm:

$$
\left\{\begin{array}{l}
\omega_{1} \cdot d_{1}+\ldots+\omega_{n} \cdot d_{n}=\bar{D} \\
\omega_{1}+\omega_{2}+\ldots+\omega_{n}=1 \\
\omega_{1}=k \cdot \omega_{2} \\
\omega_{2}=k \cdot \omega_{3} \\
\cdot \\
\cdot \\
\omega_{n-2}=k \cdot \omega_{n-1} \\
\omega_{n-1}=k \cdot \omega_{n} .
\end{array}\right.
$$

in which $d_{j}$ are the mod. durations given by the coupons available and the chosen TtM structure (e.g. 1 bucket has 1 year $T t M, \ldots, 1$ bucket has 20 years $T t M$ ) and $\bar{D}$ is the target for the portfolio mod. duration. finally, the system is solved for $k$, which determines the relation between each pair of adjacent coupons. Then it is straightforward to compute the weight to each single bucket of bonds.

\section{A.5 Projection of Future Profit Distributions}

The vector containing the expected future rate of return stemming from the profit sharing mechanism is a simple linear projection based on the information available at time $t$. More formally, $\mathbb{E}\left(r_{t^{+}: T}^{g} \mid \mathscr{F}_{t}\right)$ is estimated by extrapolating a trend on the set of observed past returns. The model is given by the following expression

$$
\hat{r}_{t+1}^{g}=\phi_{0}+\sum_{i=1}^{p} \phi_{i} r_{t-i}^{g}+\varepsilon_{t}
$$

\footnotetext{
${ }^{82}$ See for instance Gatzert and Wesker (2012).
} 
from which a drift is extrapoleted in every period and used to project the expected future profit distribution. ${ }^{83}$ The idea is to take into account at least part of the value of future profit distributions in the computation of the market value of liabilities, thereby valuing the option embedded in the product. Such valuation method is on the one hand computationally fast, but on the other it tends to neglect the complex path dependence dynamics of with profit participation policies. A more sophisticated approach should indeed include a stochastic component which would require the use of nested Monte Carlo simulations. However for the sope of the present work and for computational reasons, we abstain from the stochastic valuation of liabilities.

\section{A.6 Solvency Capital Requirements}

\section{A.6.1 Life Business}

We adopt a simplified version of the Standard Formula proposed under S II: in particular we compute at each point in time the capital requirements for the market module and the life module: under the market module we consider the following sub-modules:

- Interest rate $\Rightarrow$ for both Assets and Liabilities;

- Equity $\Rightarrow$ for the stock investment, i.e $S^{s}$;

- Property $\Rightarrow$ for the real estate investment, i.e $S^{r e}$;

- Spread $\Rightarrow$ for corporate bonds investment, i.e $B^{c b}$;

whereas under the life module we consider the following sub-modules

- Mortality $\Rightarrow$ for term life business, i.e. $L^{t l}$;

- Longevity $\Rightarrow$ for endowment/annuity business, i.e. $L^{e / a}$.

The 2 modules are then aggregated by means of given correlation coefficients.

\section{A.6.2 Non-Life Business}

For the non-life business we abstain from the standard formula under S II when computing the non-life sub-module, since we do not know all the information we would need in order to compute it as required. However, since we know the distribution of the claims over the next period, we can apply the $\operatorname{VaR}_{0.995}$ (i.e. $\mathbb{P}\left\{O F_{t+1}<0\right\} \leq 0.005$ ) which is the risk measure adopted under S II. The non-life sub-module is then computed as follows

$$
S M^{n l}=N^{n l} \cdot \pi^{i} \cdot\left(e^{\mu_{C}+z \sigma_{C}}-1\right)
$$

\footnotetext{
${ }^{83}$ We fix $p=10$, i.e. we consider always the last 10 observations.
} 
in which $z=2.58$, i.e. the coefficient taken from the standard normal distribution equivalent to

$99.5 \%$. Finally, $S C R^{n l}$ is the sum of the non-life sub-module and the market sub-module aggregated by means of given correlation coefficients.

\section{A.7 National Regulation}

We report the main features of national regulations, i.e. maximum allowed guaranteed return and profit participation or other specific requirements.

\section{A.7.1 The German Regulation}

- maximum allowed guaranteed return: the regulator computes a reference interest rate $\left(r_{t}^{r e f}\right)$, which is the 10 year moving average of the 10 year Bund yield. It then consider $60 \%$ of it and reacts to the changes in interest rates as follows:

$$
\begin{cases}r_{t+1}^{i}=r_{t}^{i}-\xi, & \text { if } \quad 60 \% \cdot r_{t}^{r e f} \leq r_{t}^{i} \\ r_{t+1}^{i}=r_{t}^{i}+\xi, & \text { if } \quad 60 \% \cdot r_{t}^{r e f} \geq r_{t}^{i}+\xi \\ r_{t+1}^{i}=r_{t}^{i}, & \text { otherwise }\end{cases}
$$

where $r_{t}^{i}$ is the maximum allowed guaranteed rate of return at time $t$ and $\xi$ is the marginal change decided by the regulator. For Germany this is fixed to $0.5 \mathrm{pp}$;

- profit participation: the profit sharing mechanism is given by the following equation

$$
r_{t}^{g, i}=r^{i}+\left\{\max \left[\left(r_{t}^{a}-r^{i}\right)^{-}, v \cdot r_{t}^{a}-r^{i}\right]+\left(v \cdot r_{t}^{q}\right)^{+}\right\}^{+}
$$

in which $v=90 \%$ (financial results and technical results).

- other specific requirements: there are additional mandatory requirements in the German market, such as an additional reserve in case of lower market rates and mandatory distribution of hidden reserves; we introduce it as in Berdin and Gründl (2015).

\section{A.7.2 The French Regulation}

- maximum allowed guaranteed return: the regulator computes a reference interest rate $\left(r_{t}^{r e f}\right)$, which is the 1 year moving average of the 10 year OAT yield. It then consider $60 \%$ of it and reacts to the changes in interest rates accordingly (source: Banque de France). More specifically, the basic rate for computation is given by the following

$$
T M E_{t}=\frac{1}{30} \sum_{t_{i}}^{30} r_{\left(t_{i}, 10\right)}^{F R}+0.05 \%
$$


then the reference rate is derived as follows

$$
r_{t}^{r e f}=\frac{1}{6} \sum_{h=0}^{5} T M E_{t-h}
$$

and finally the maximum allowed guaranteed return (or technical rate) is computed as follows

$$
r_{t}^{i}=\max \left(60 \% \cdot r_{t}^{r e f}, 3.5 \%\right)
$$

However, in order to comply with market practices in France, we assume that all new contracts issued after year 2000 are set to 0, i.e. $r_{t}^{i}=0$;

- profit participation: the profit sharing mechanism is given by the following equation

$$
r_{t}^{g, i}=r^{i}+\left(v^{a} \cdot r_{t}^{a}-r^{i}\right)^{+}+\left(v^{q} \cdot r_{t}^{q}\right)^{+}
$$

in which $v^{a}=85 \%$ (financial results) and $v^{q}=90 \%$ (technical results).

For a brief but precise description of the French regulation, see for instance Borel-Mathurin et al. (2015).

\section{A.7.3 The Italian Regulation}

- maximum allowed guaranteed return: the regulator computes a reference interest rate $\left(r_{t}^{\text {ref }}\right)$, which is the 1 year moving average of the 10 year BTP yield. It then consider $60 \%$ of it and reacts to the changes in interest rates accordingly. More specifically, the basic rate for computation is given by the following

$$
T M O_{t}=\frac{1}{30} \sum_{t_{i}}^{30} r_{\left(t_{i}, 10\right)}^{I T}+0.05 \%
$$

then the reference rate is derived as follows

$$
r_{t}^{r e f}=\frac{1}{3} \sum_{h=0}^{2} T M O_{t-h}
$$

and finally the maximum allowed guaranteed return (or technical rate) is computed as follows

$$
r_{t}^{i}=\max \left(60 \% \cdot r_{t}^{r e f}, 4 \%\right)
$$

- profit participation: the profit sharing mechanism is given by the following equation

$$
r_{t}^{g, i}=r^{i}+\left(v^{a} \cdot r_{t}^{a}-r^{i}\right)^{+}
$$


in which $v^{a}=80 \%$ (financial results). However, there is no specific regulation regarding $v^{a}$ which is usually agreed at inception in the contract. Thus $80 \%$ reflects the common practice in the Italian market and not a specific regulation.

\section{A.7.4 The Dutch Regulation}

- maximum allowed guaranteed return: no specific regulation applies;

- profit participation: the regulator publishes a reference interest rate through which companies can compute the amount of return to be transferred to policyholders. The reference rate is a weighted average of Dutch sovereign yields and it is computed as follows

$$
u^{\text {yield }}=0.1 * \frac{\sum_{\tau=1}^{5} r_{(t, i)}^{N L}}{5}+0.65 * \frac{\sum_{\tau=6}^{10} r_{(t, i)}^{N L}}{5}+0.25 * \frac{\sum_{\tau=11}^{15} r_{(t, i)}^{N L}}{5}
$$

and then the the profit sharing mechanism is given by the following equation

$$
r_{t}^{g, i}=r^{i}+\left(u^{\text {yield }}-r^{i}\right)^{+}
$$

\section{A.7.5 The Spanish Regulation}

Due to limited information, we assume for the Spanish market the same underlying regulation as for the Italian market due to their similarities. 


\section{B Figures}

Figure 3: Time to maturity structure: the figure depicts the time to maturity structure of both assets, i.e. cohorts of bonds, and liabilities, i.e. cohorts of insurance contracts. $T^{A}$ and $T^{L}$ represent the expected (fixed) time to maturity of bonds and insurance contracts in years: the structure implies that yearly, a cohort of bonds and a cohort of insurance contracts mature, and are replaced with a new cohort. In the model, on the asset side as well as on the liability side, there exist different asset classes as well as different life of business: each of them have the same time to maturity structure, in which the expected (fixed) time to maturity varies.

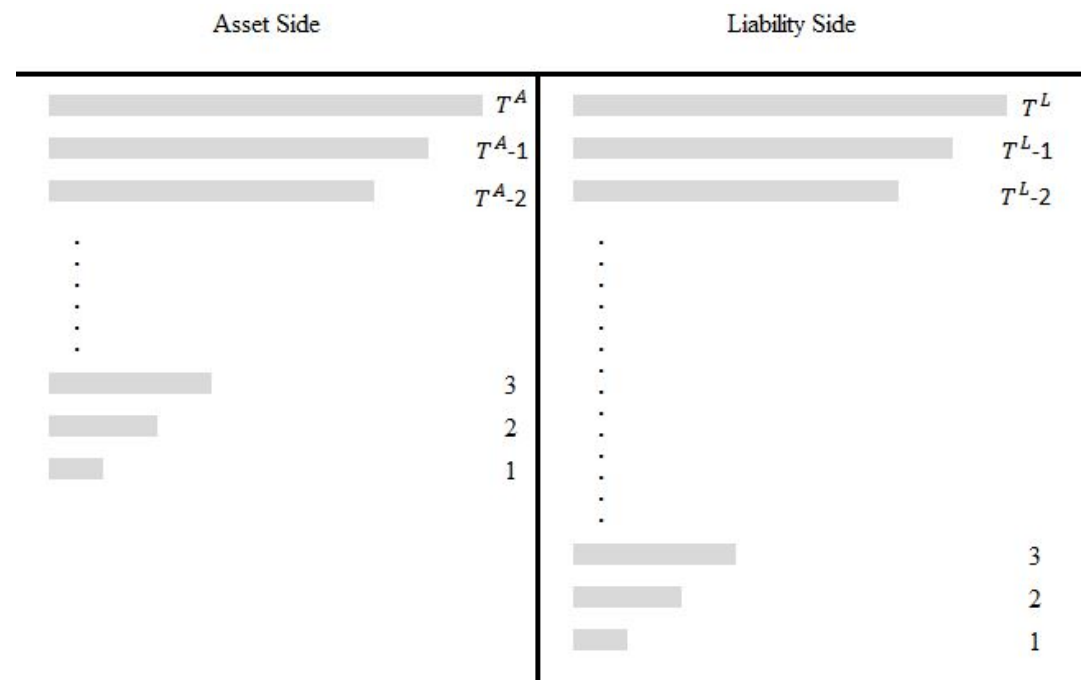

Figure 4: Model mechanics: the figure depicts the consolidation of the subsidiaries within the holding company, through which capital transfers can take place.

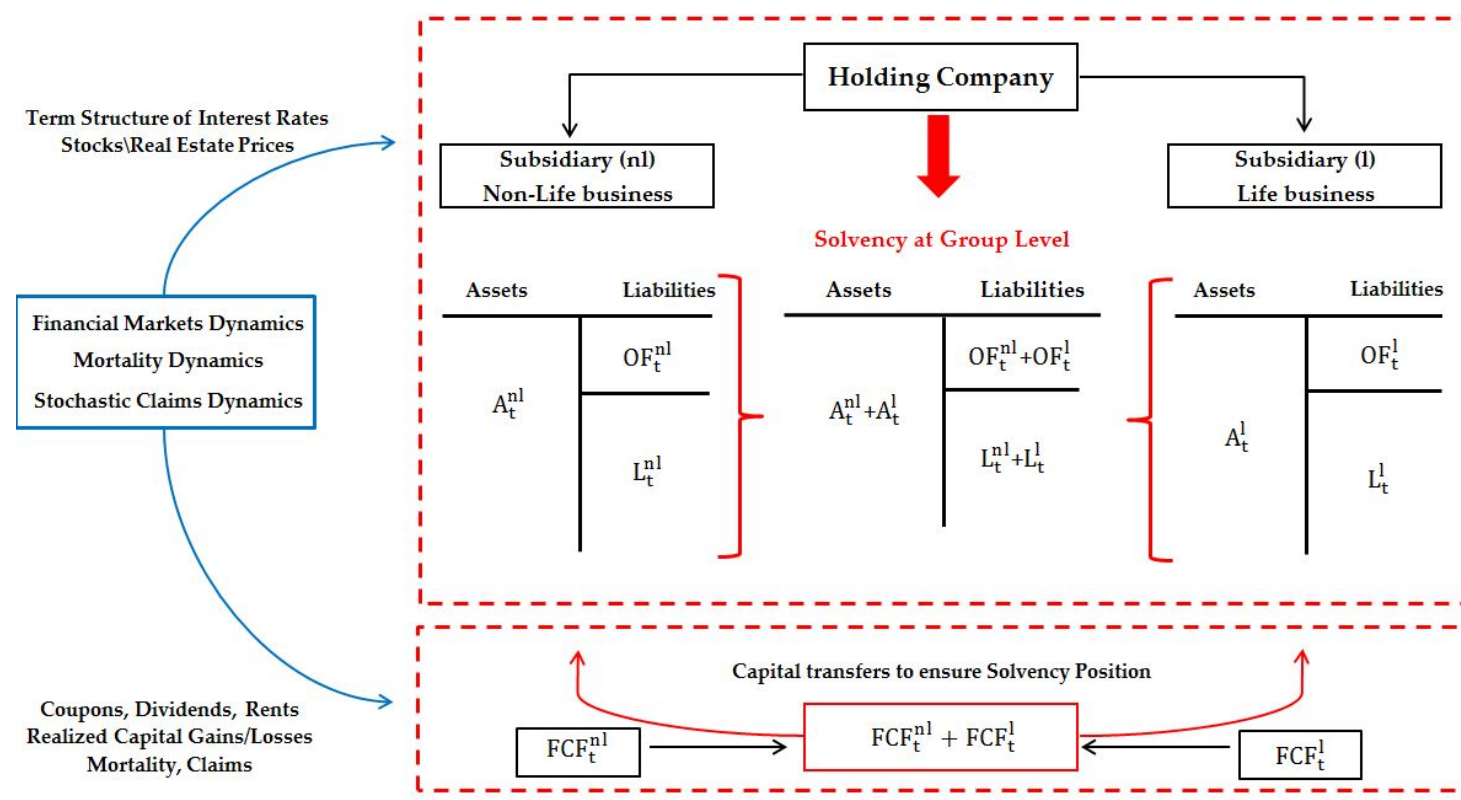

Stocks

Marked-to-Market

Valuation

Flows

BooklMarket Results 
Figure 5: Asset Allocation Life Business: country level data have been retrieved from EIOPA Stress Test (2014), from national authorities and from national insurance associations.
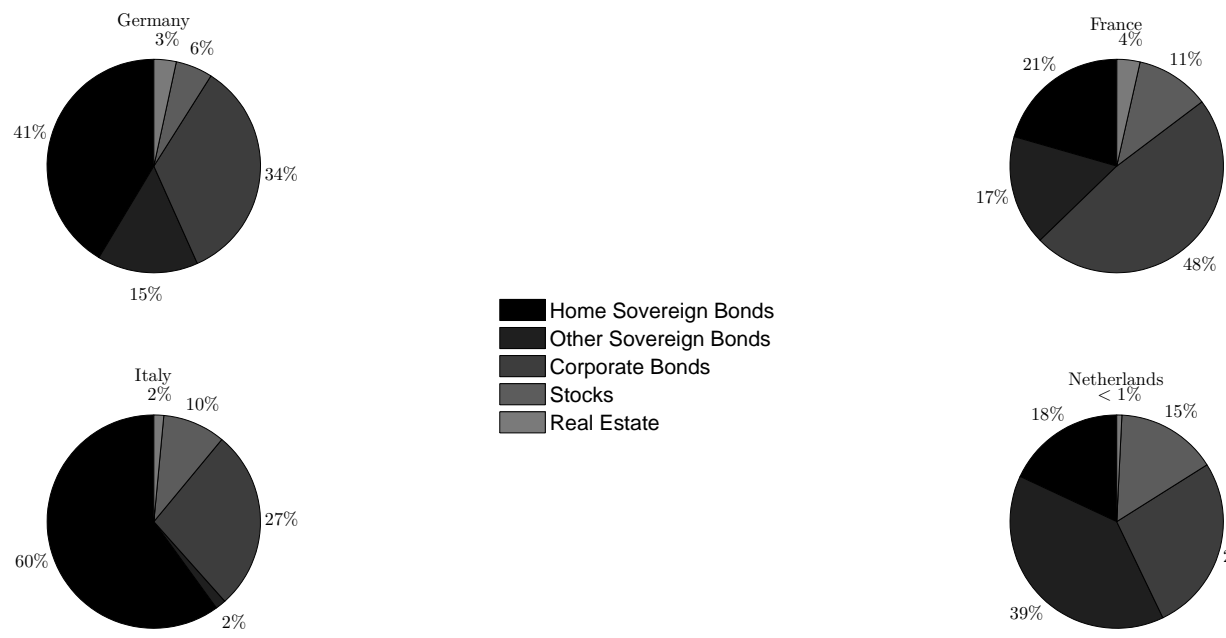

Home Sovereign Bonds

Other Sovereign Bonds

Corporate Bonds

Stocks

Real Estate
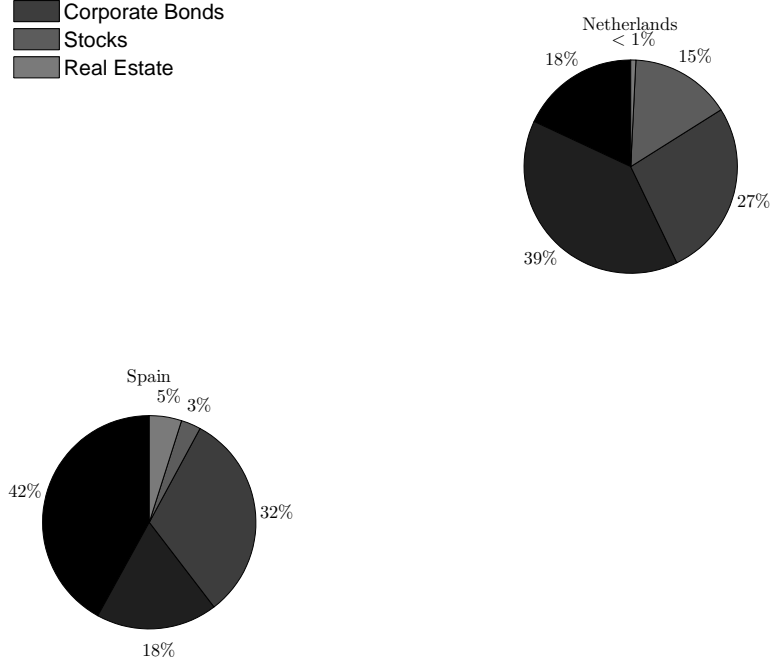

Figure 6: Asset Allocation Non-Life Business: the portfolio only includes bonds, sovereign and corporate which are held in same proportions as in the life business asset portfolio.
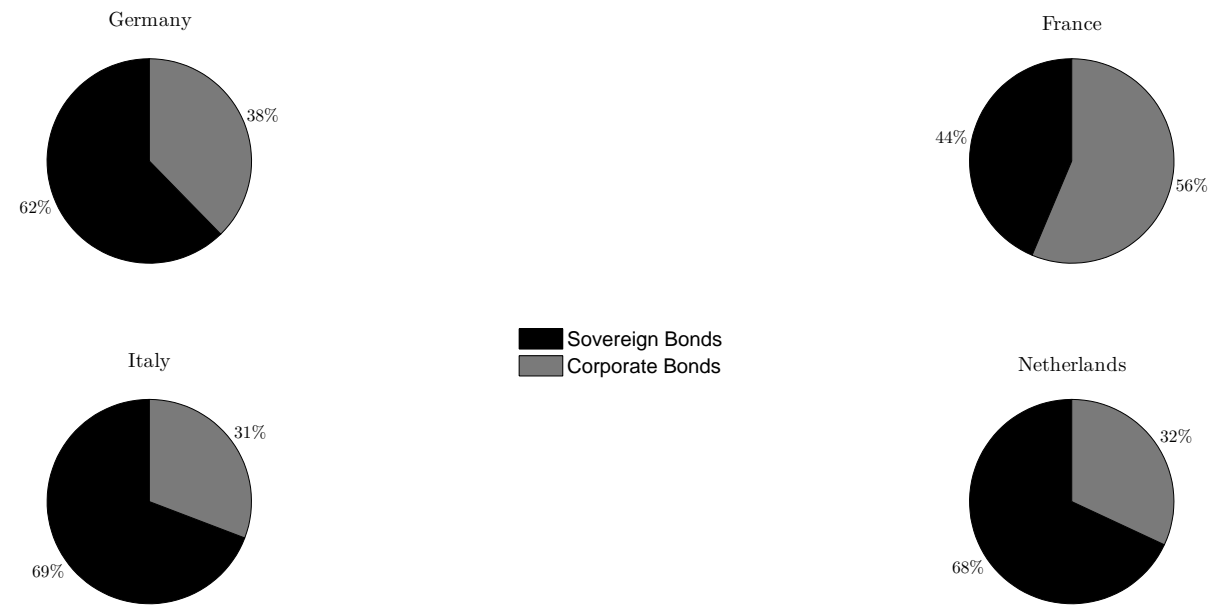

Sovereign Bonds Corporate Bonds
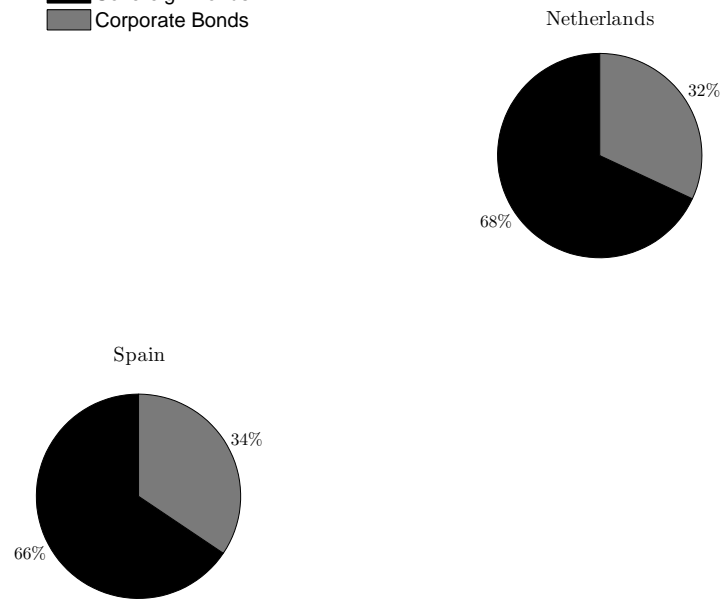
Figure 7: Baseline Scenario - 10 YTM Sovereign Bonds Yields

The graphs show the distribution of the simulation: the central red mark is the median, the edges of the box are the 25 th and 75th percentiles respectively, the whiskers extend to the most extreme data points not considered outliers whereas outliers are plotted individually.
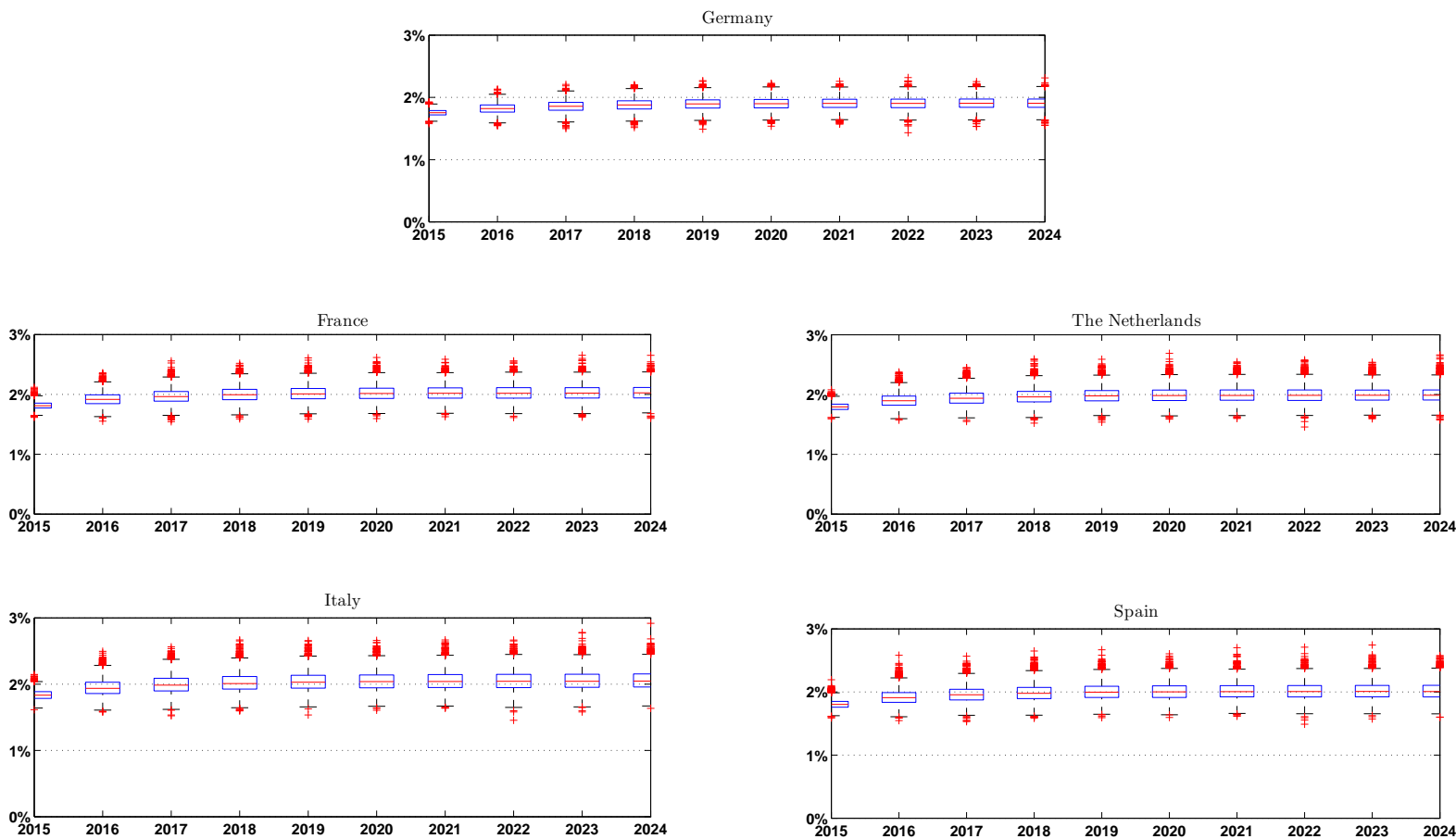

Baseline Scenario - 10 YTM Corporate Bonds Yields
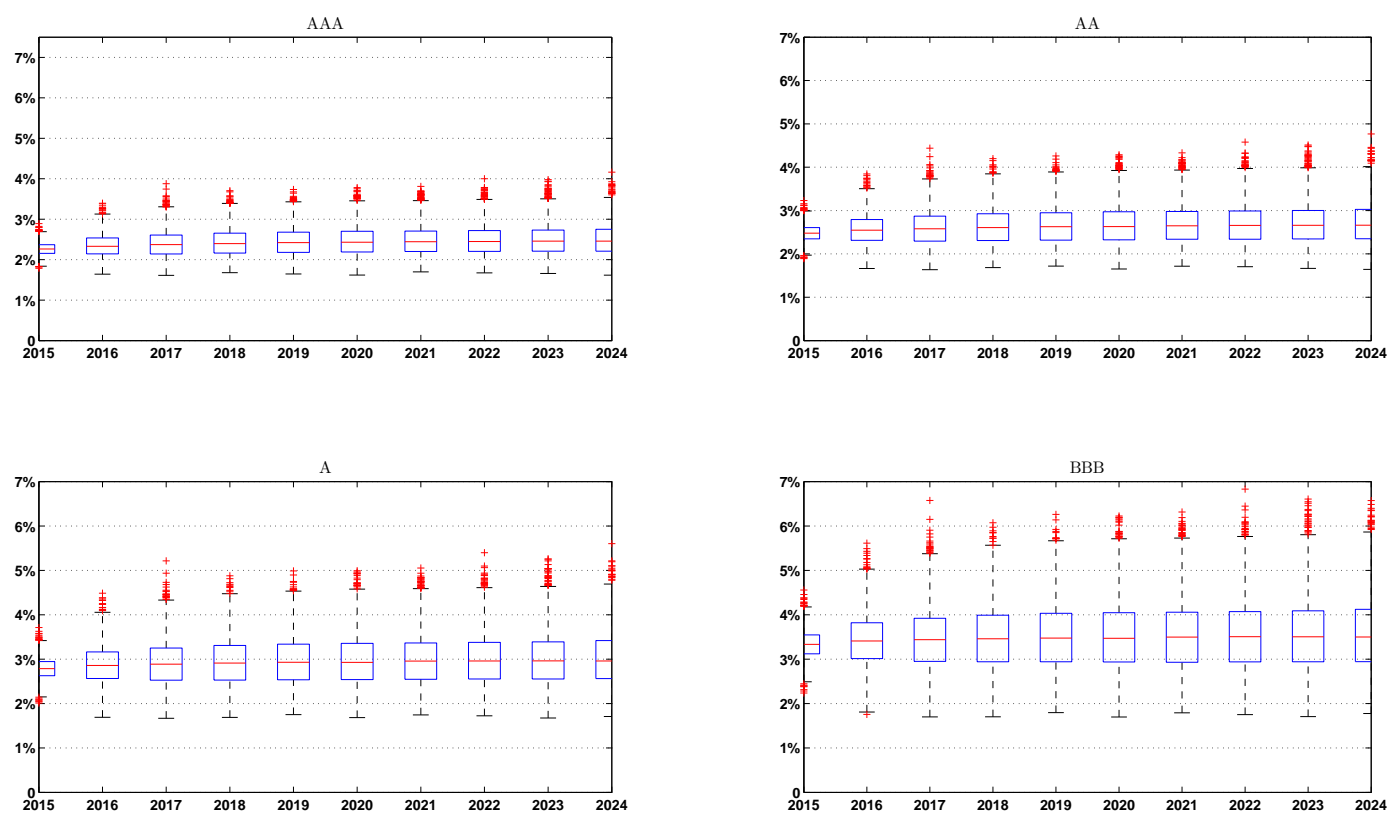
Figure 8: Baseline Scenario - Stock Indices:

The graphs show the distribution of the simulation: the central red mark is the median, the edges of the box are the 25 th and 75th percentiles respectively, the whiskers extend to the most extreme data points not considered outliers whereas outliers are plotted individually.
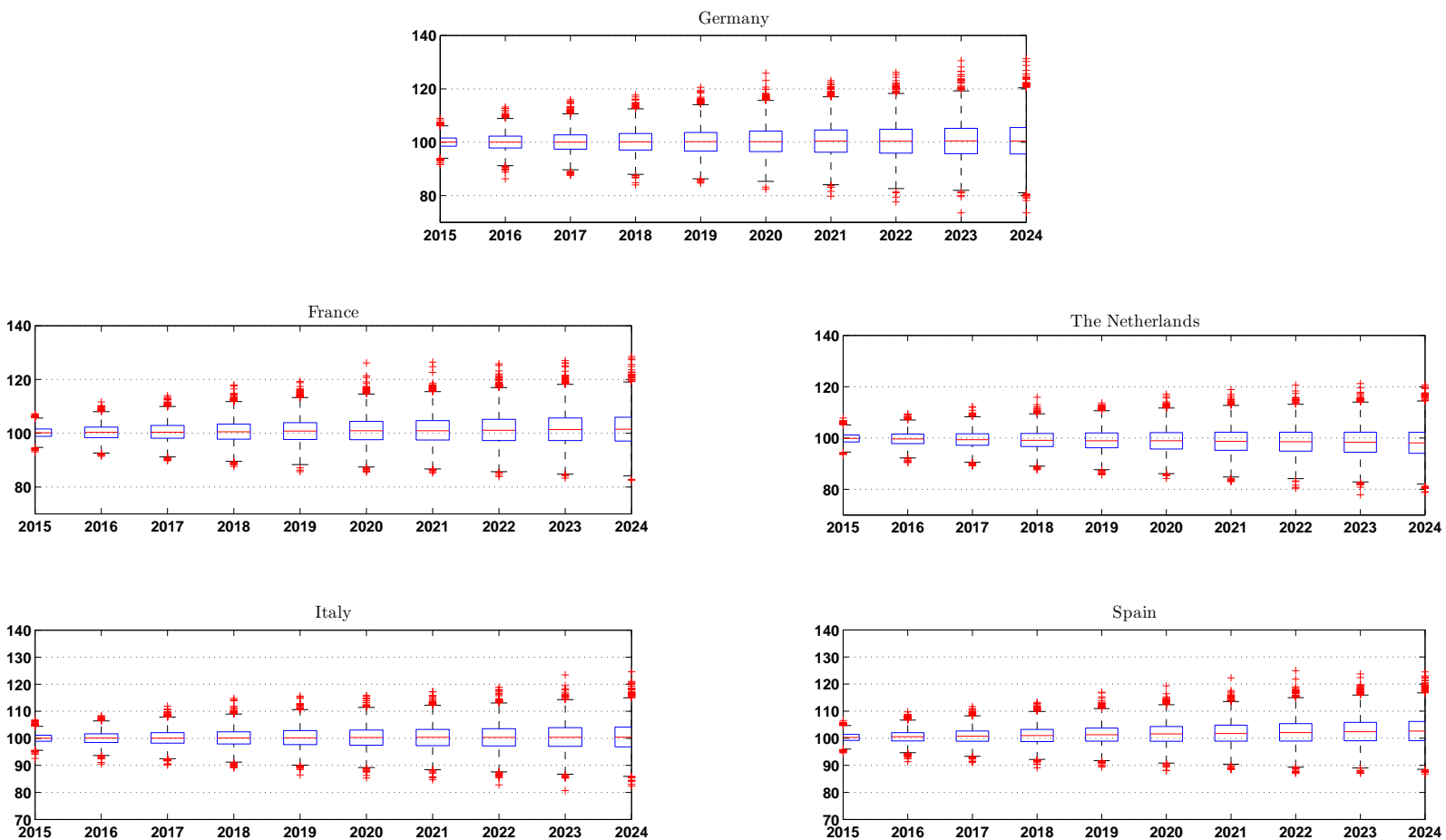

Baseline Scenario - Real Estate Indices
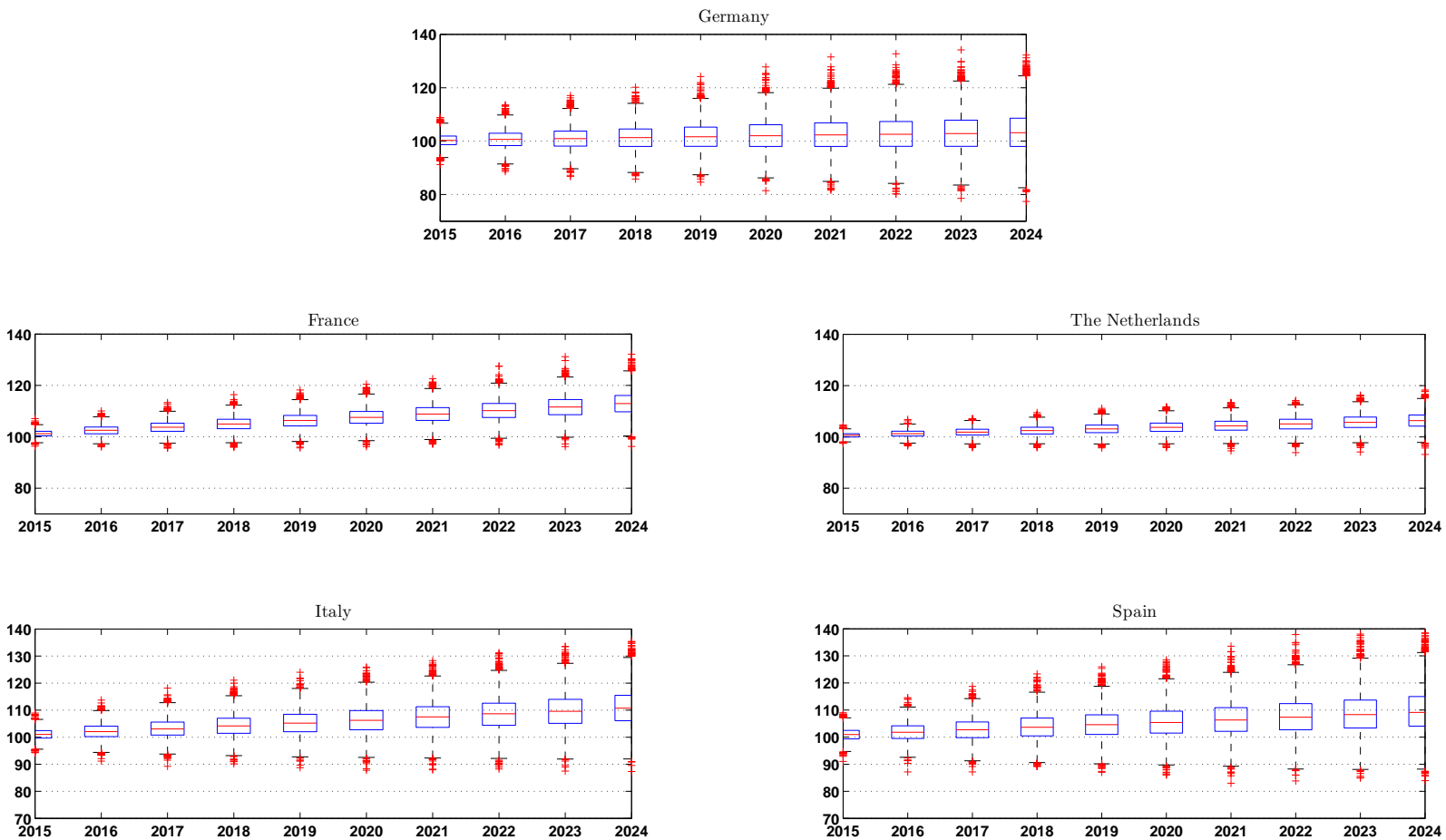
Figure 9: Adverse Scenario - 10 YTM Sovereign Bonds Yields:

The graphs show the distribution of the simulation: the central red mark is the median, the edges of the box are the 25th and 75th percentiles respectively, the whiskers extend to the most extreme data points not considered outliers whereas outliers are plotted individually.
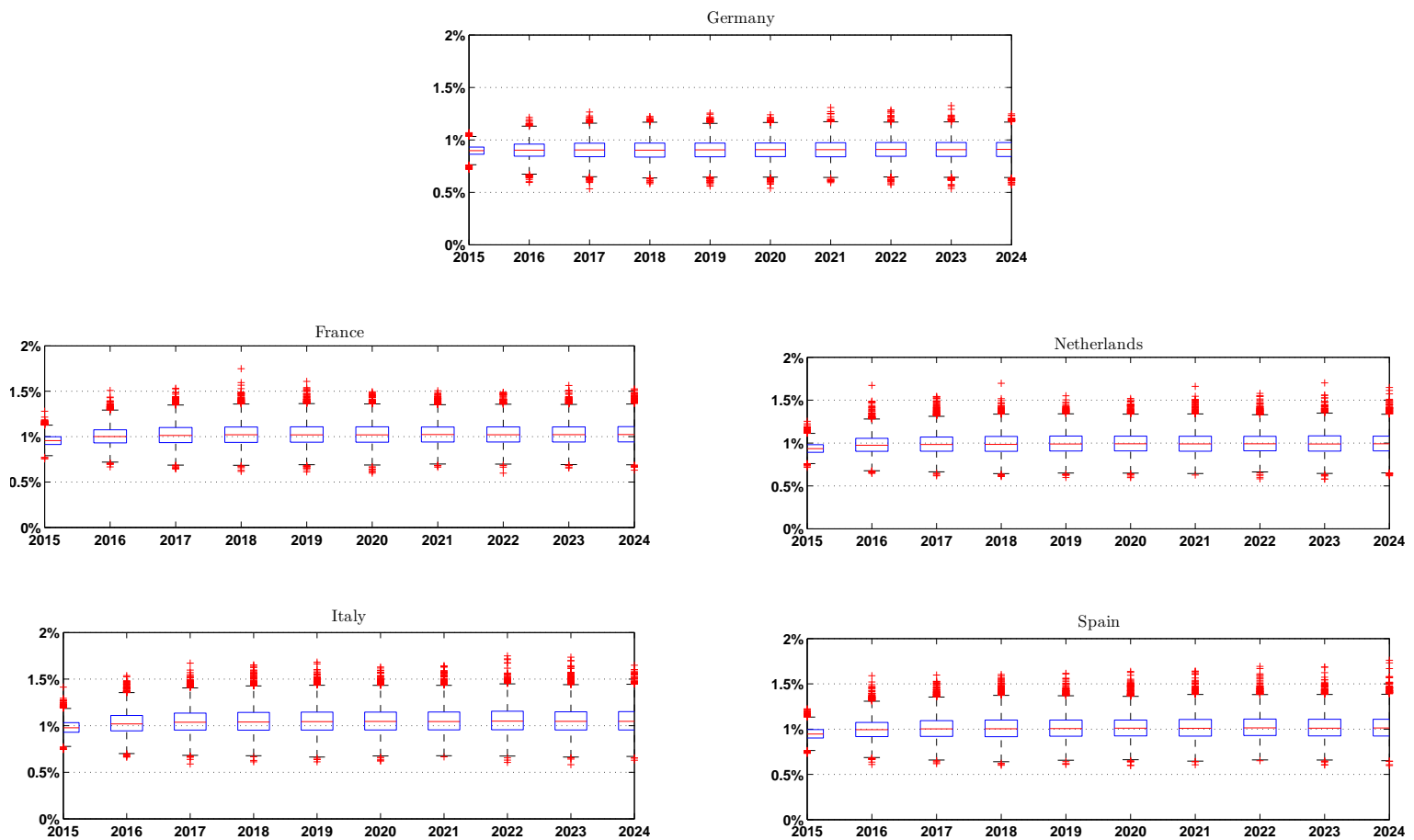

Adverse Scenario - 10 YTM Corporate Bonds Yields
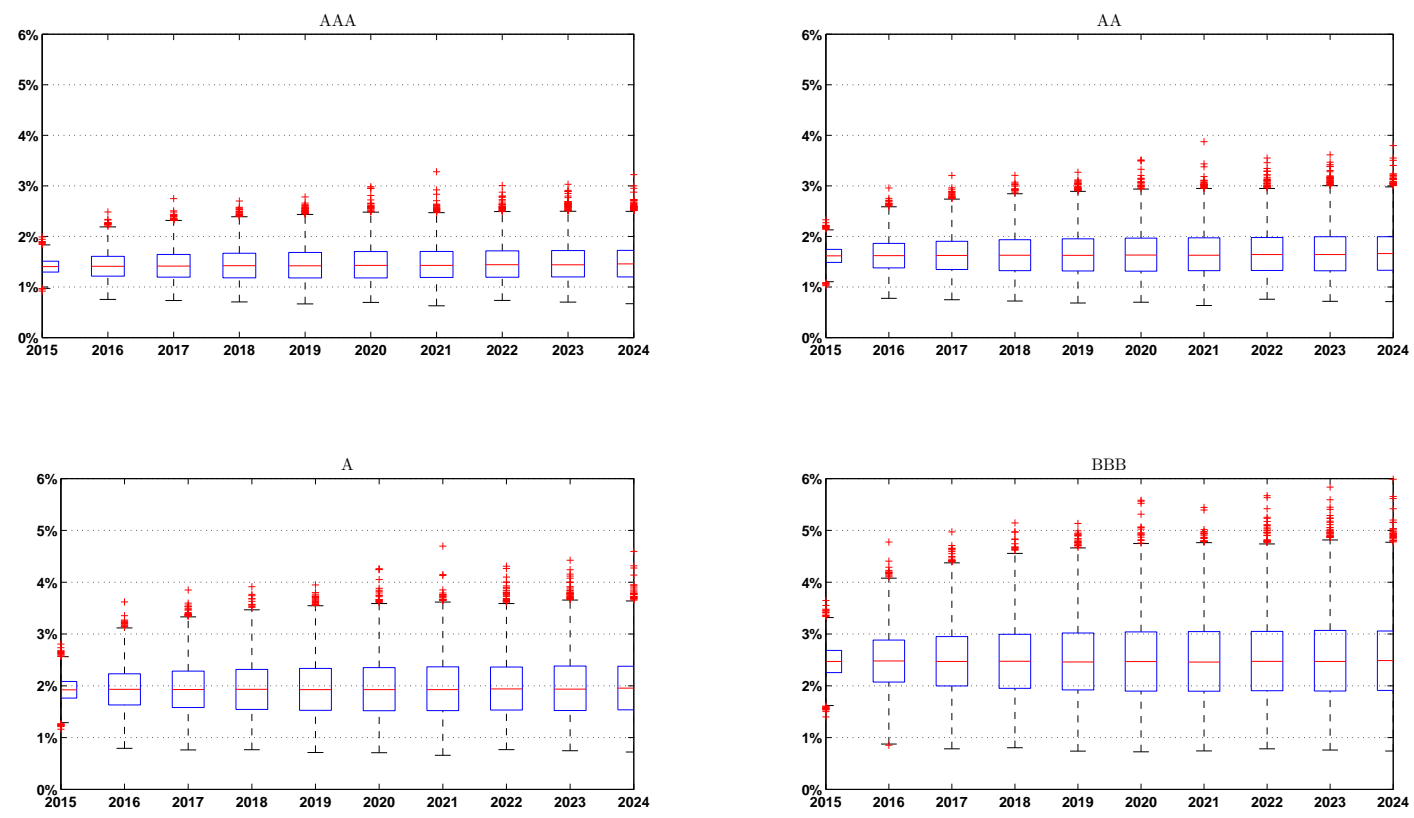
Figure 10: Adverse Scenario - Stock Indices:

The graphs show the distribution of the simulation: the central red mark is the median, the edges of the box are the 25th and 75th percentiles respectively, the whiskers extend to the most extreme data points not considered outliers whereas outliers are plotted individually.
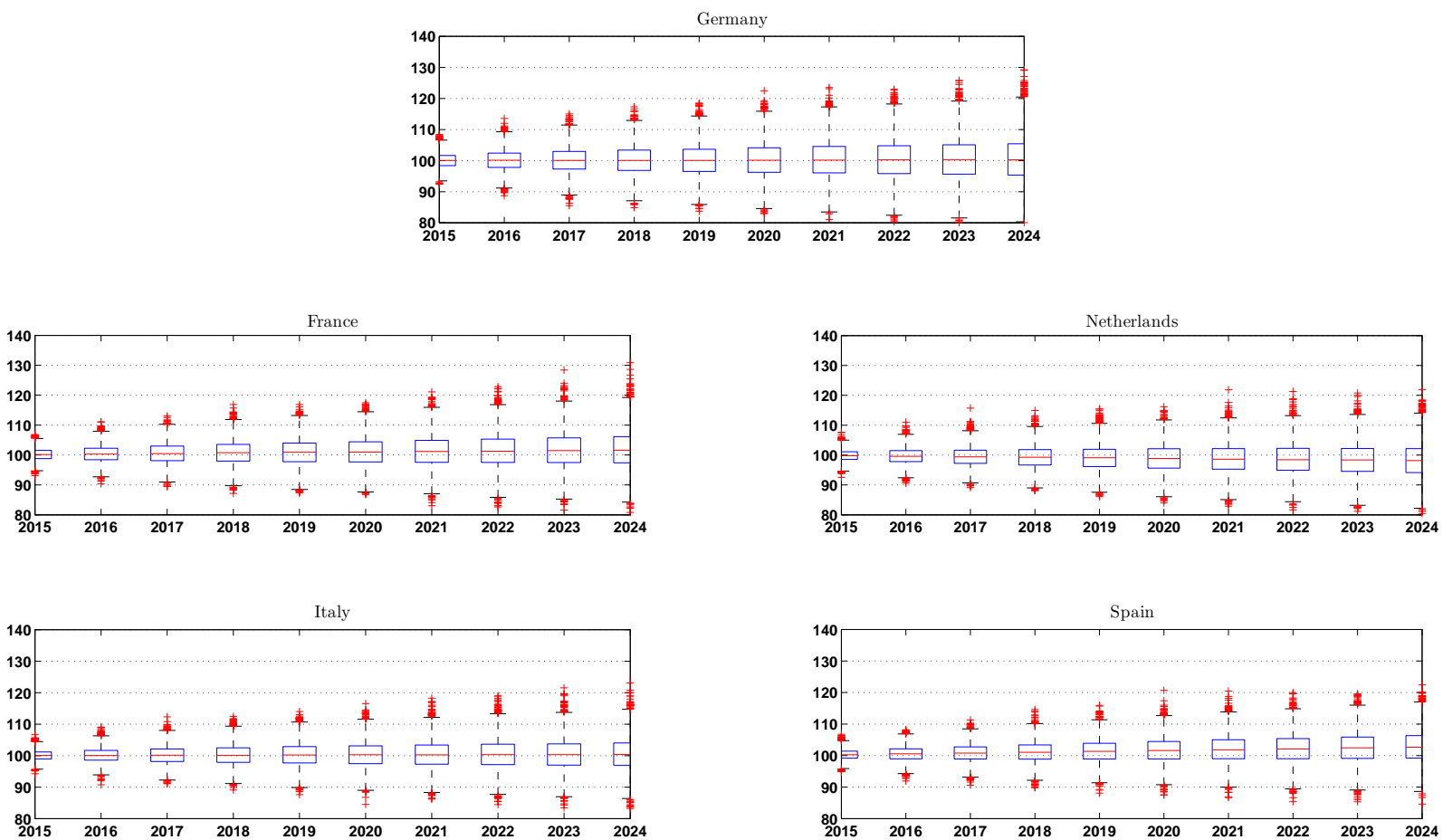

Adverse Scenario - Real Estate Indices
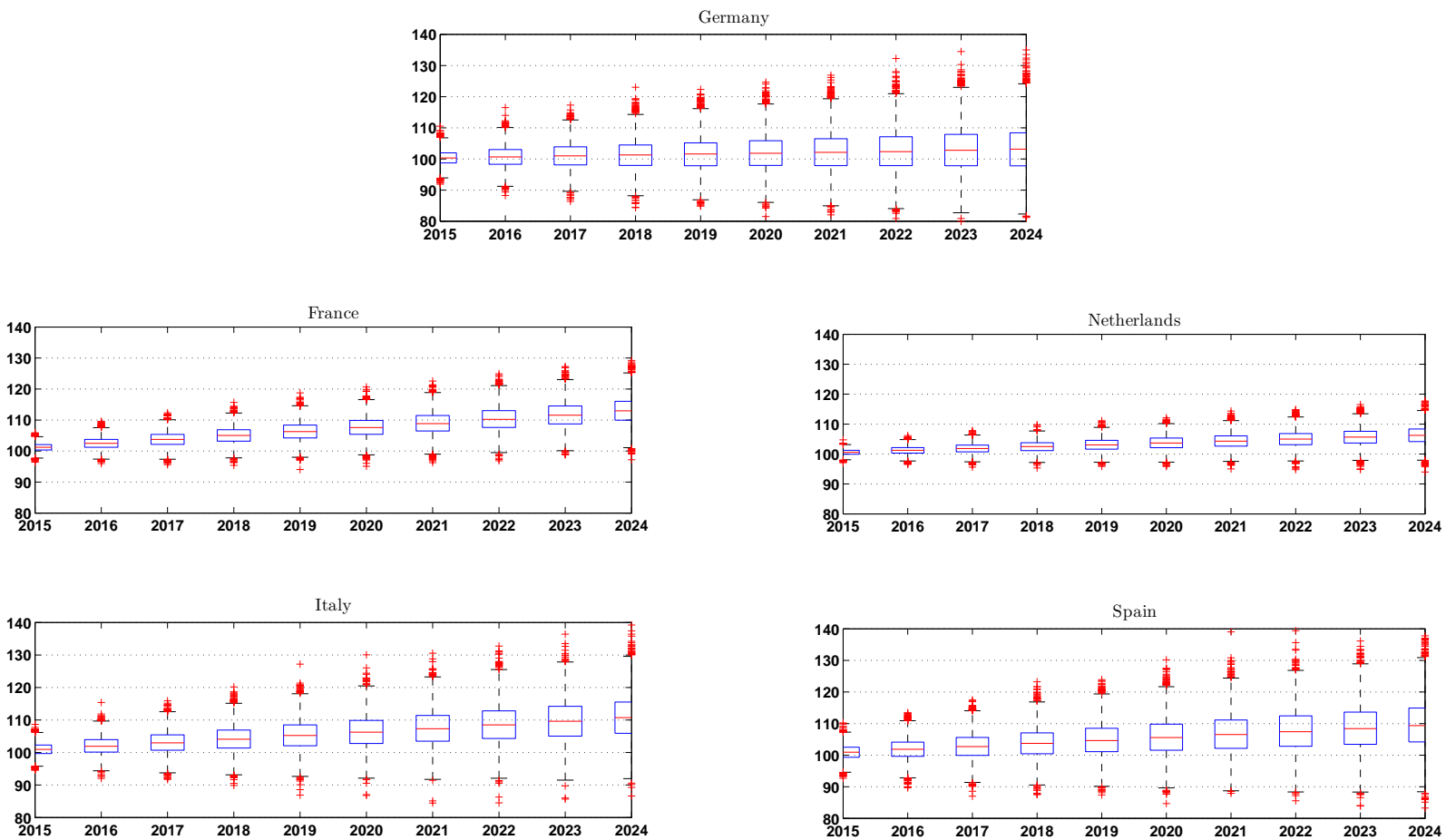
Figure 11: Severely Adverse Scenario - 10 YTM Sovereign Bonds Yields:

The graphs show the distribution of the simulation: the central red mark is the median, the edges of the box are the 25th and 75th percentiles respectively, the whiskers extend to the most extreme data points not considered outliers whereas outliers are plotted individually.
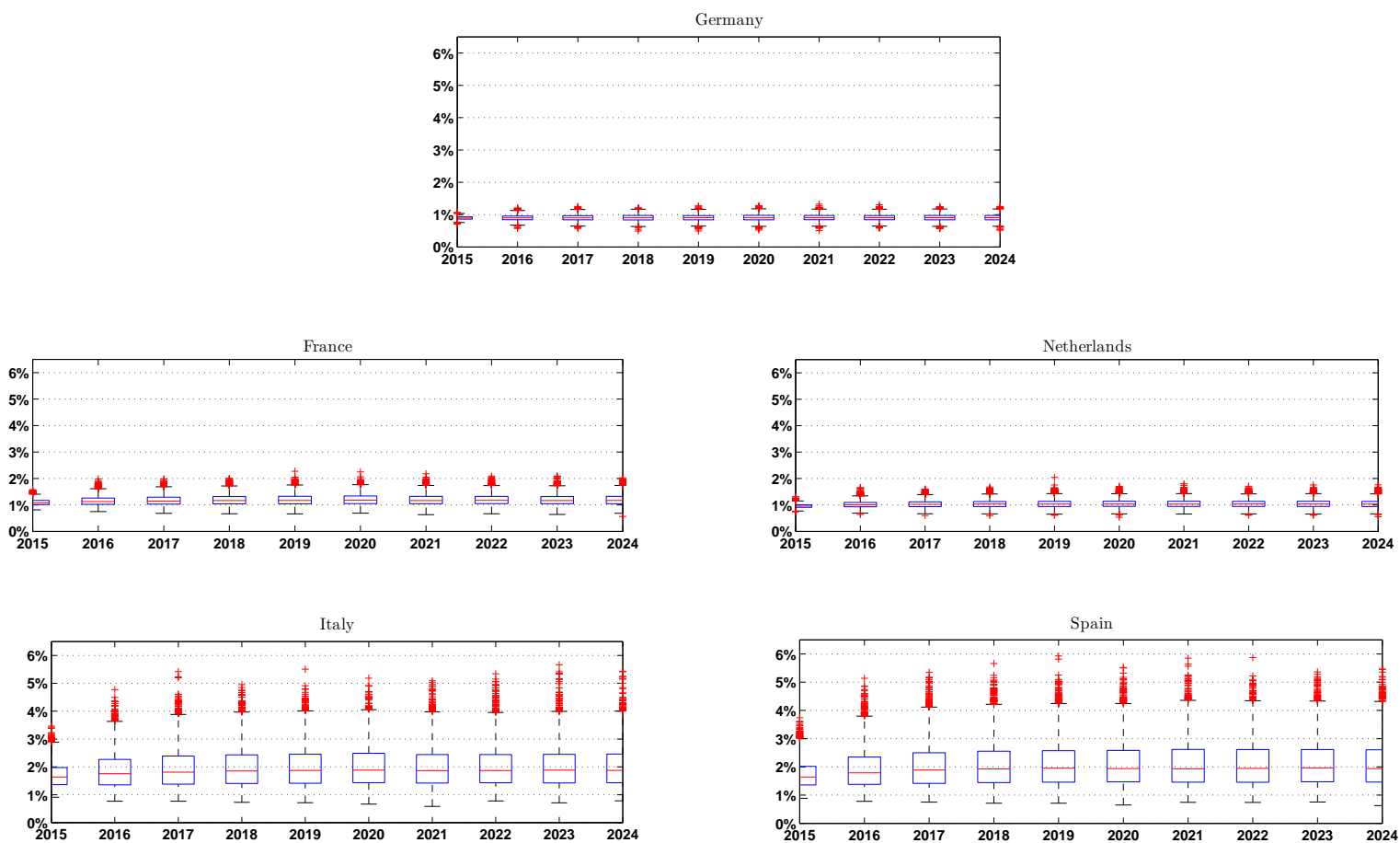

Severely Adverse Scenario - 10 YTM Corporate Bonds Yields
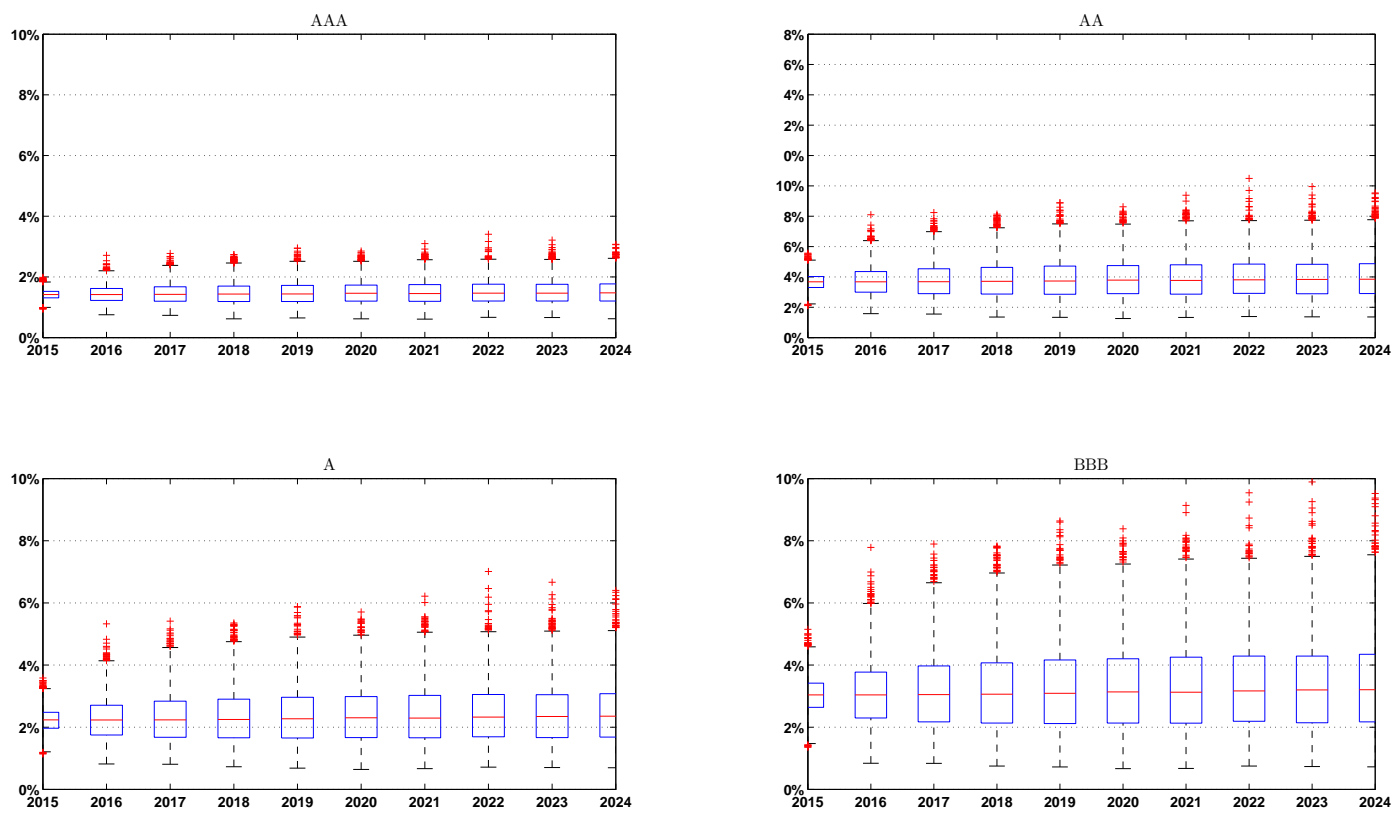
Figure 12: Severely Adverse Scenario - Stock Indices:

The graphs show the distribution of the simulation: the central red mark is the median, the edges of the box are the 25th and 75th percentiles respectively, the whiskers extend to the most extreme data points not considered outliers whereas outliers are plotted individually.
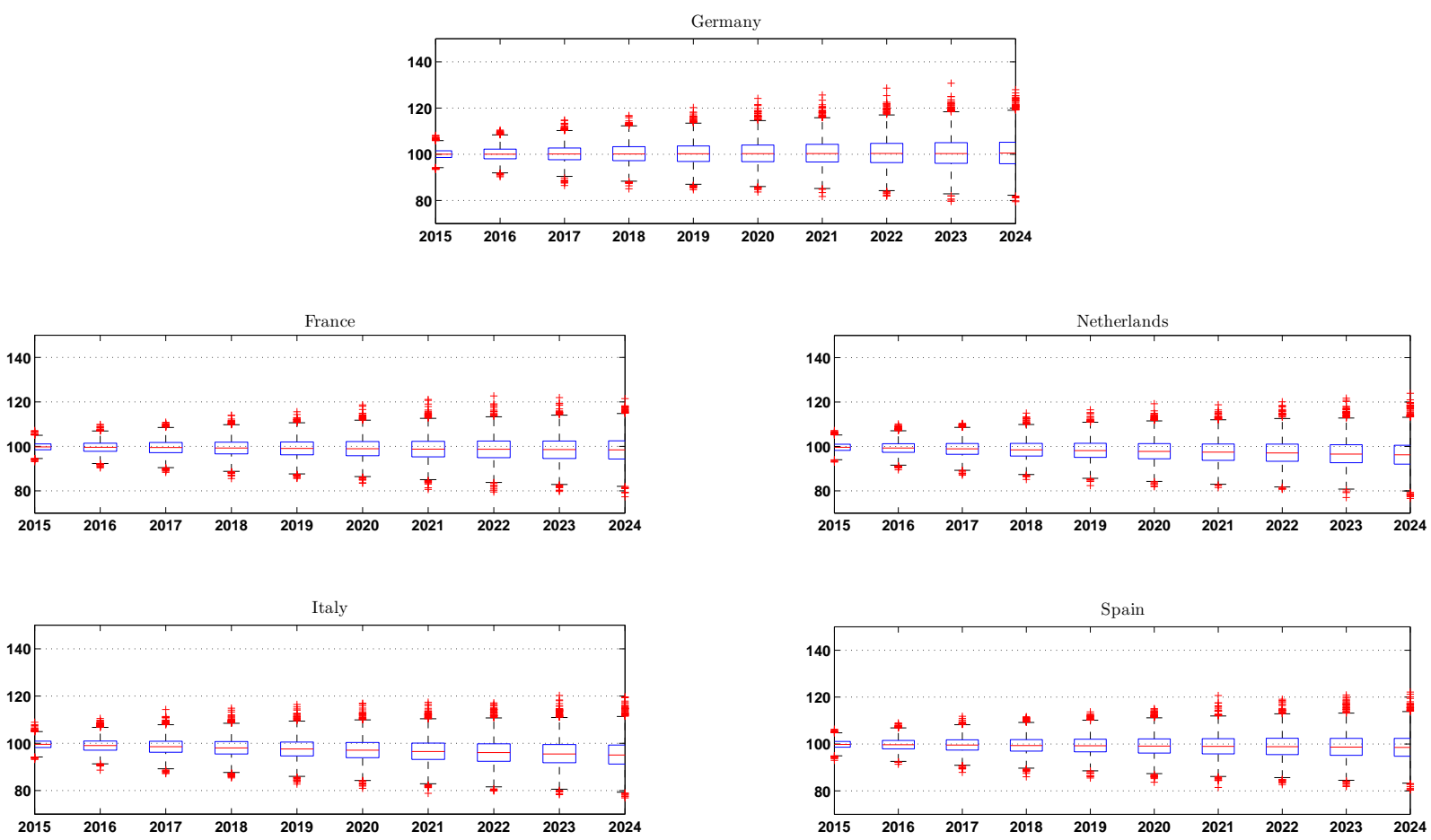

Severely Adverse Scenario - Real Estate Indices
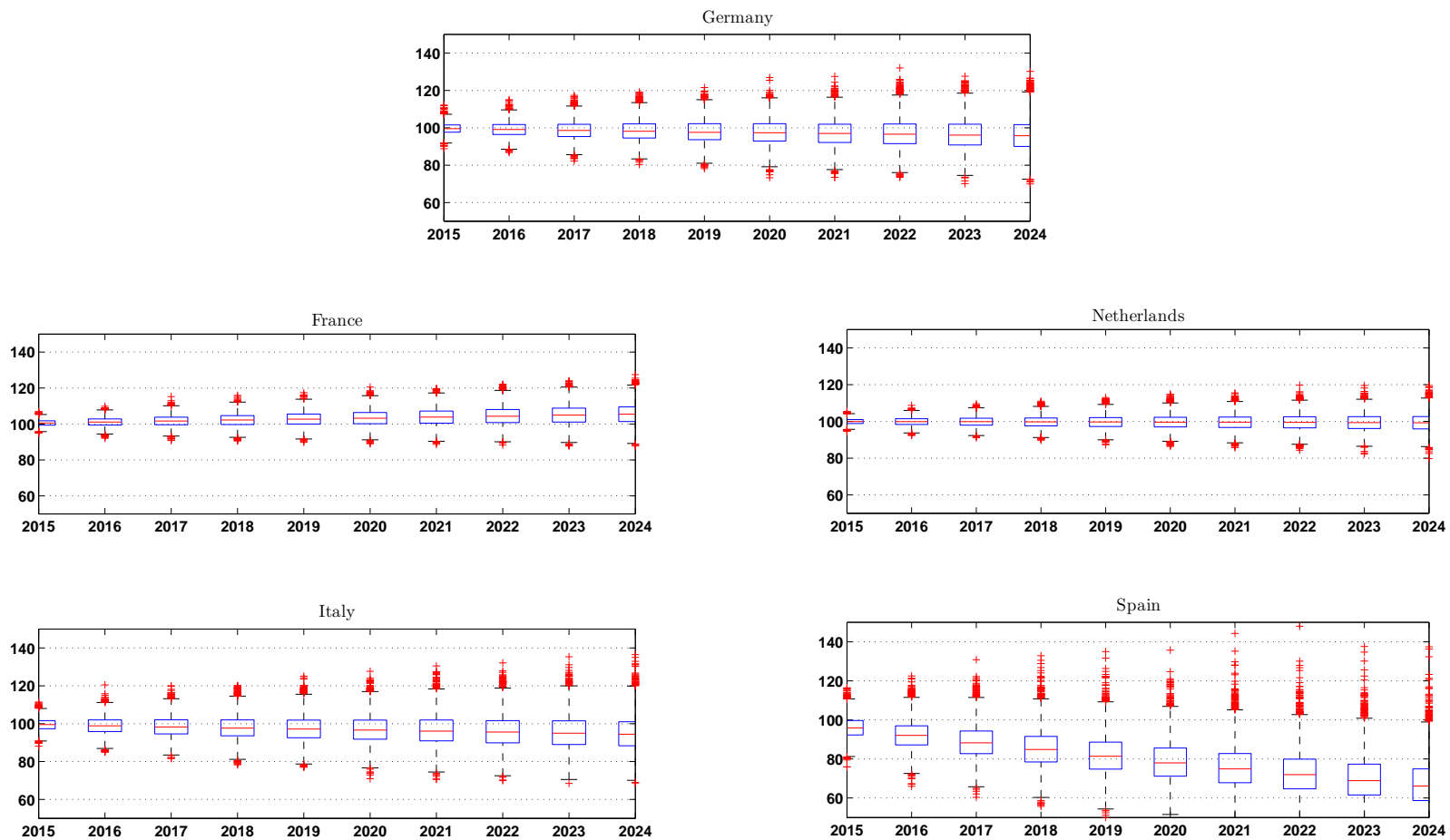
Figure 13: Results - Baseline Scenario - Specification 1: Endowment Business.

The Graphs show the return on assets, the return on equity (Dividends $/ O F_{t-1}$ ) and the solvency ratio; for the return on assets and for the solvency ratio we report the $95 \%$ confidence interval (shaded area) and the median (dotted line), whereas for the return on equity we only report the mean.
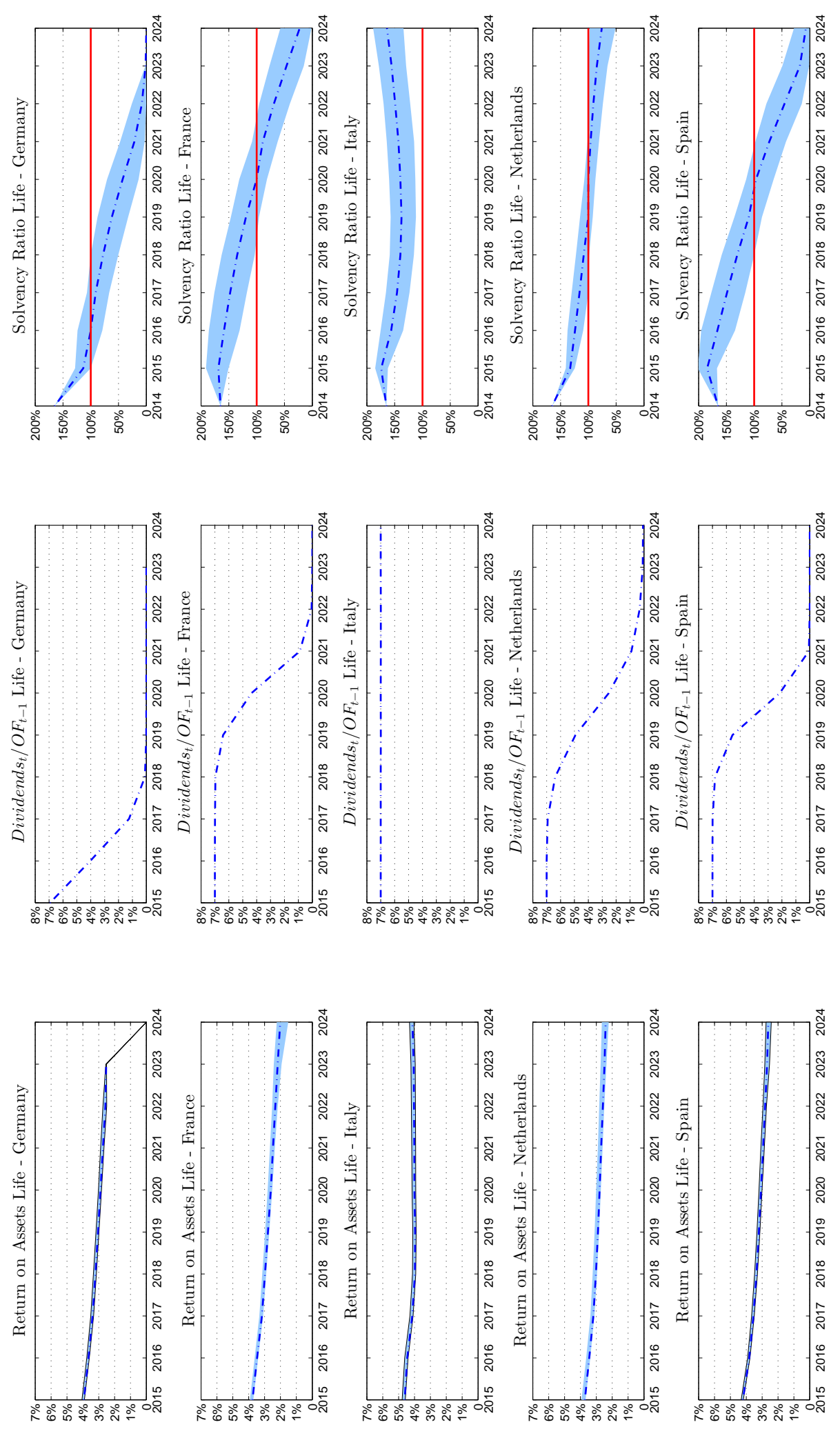
Figure 14: Results - Baseline Scenario - Specification 2: Endowment and Term Life Business.

The Graphs show the return on assets, the return on equity (Dividends $/ O F_{t-1}$ ) and the solvency ratio; for the return on assets and for the solvency ratio we report the $95 \%$ confidence interval (shaded area) and the median (dotted line), whereas for the return on equity we only report the mean.
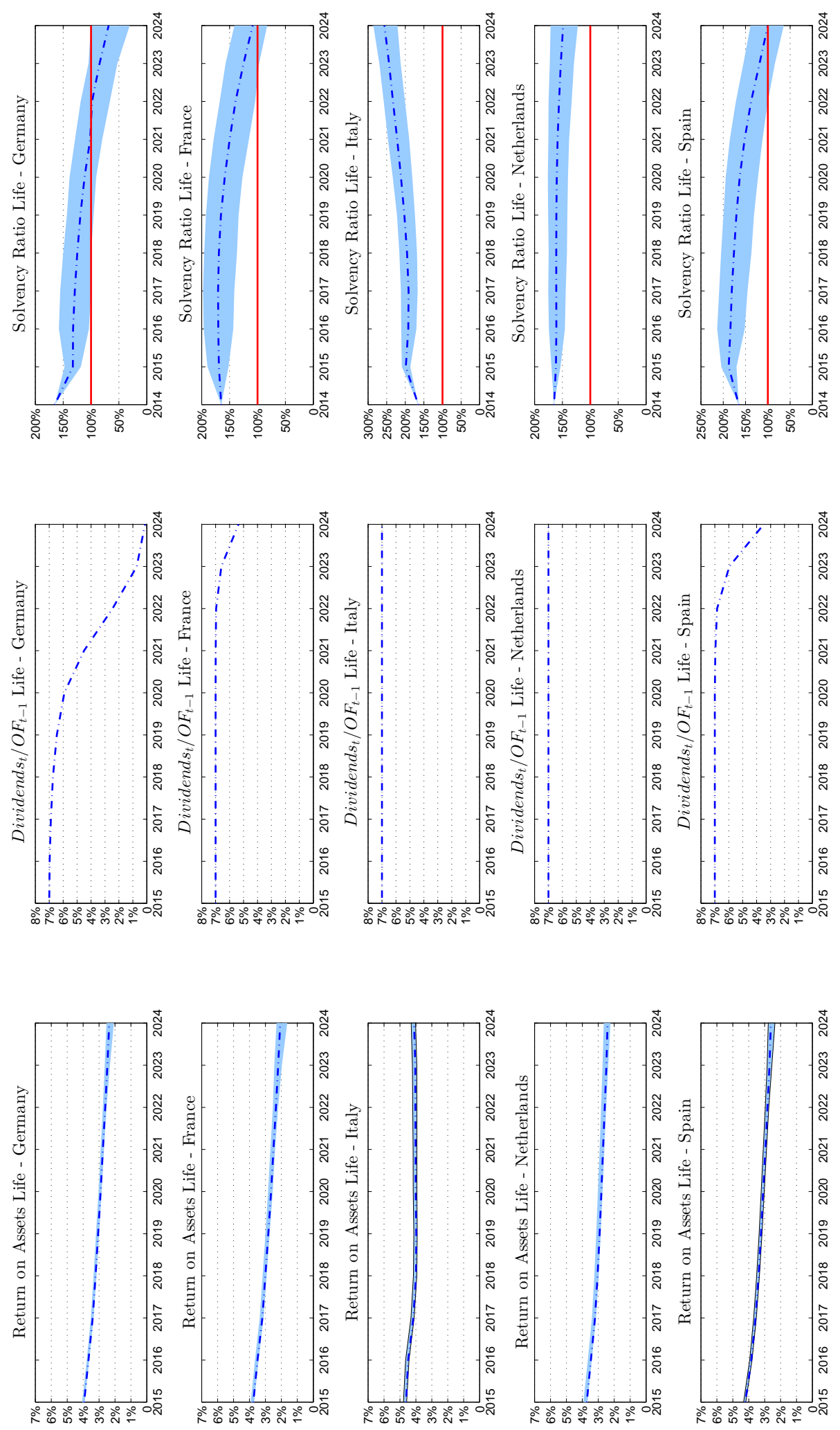
Figure 15: Results - Baseline Scenario - Specification 3: Endowment, Term Life and Annuity Business. The Graphs show the return on assets, the return on equity (Dividends $/ O F_{t-1}$ ) and the solvency ratio; for the return on assets and for the solvency ratio we report the $95 \%$ confidence interval (shaded area) and the median (dotted line), whereas for the return on equity we only report the mean.
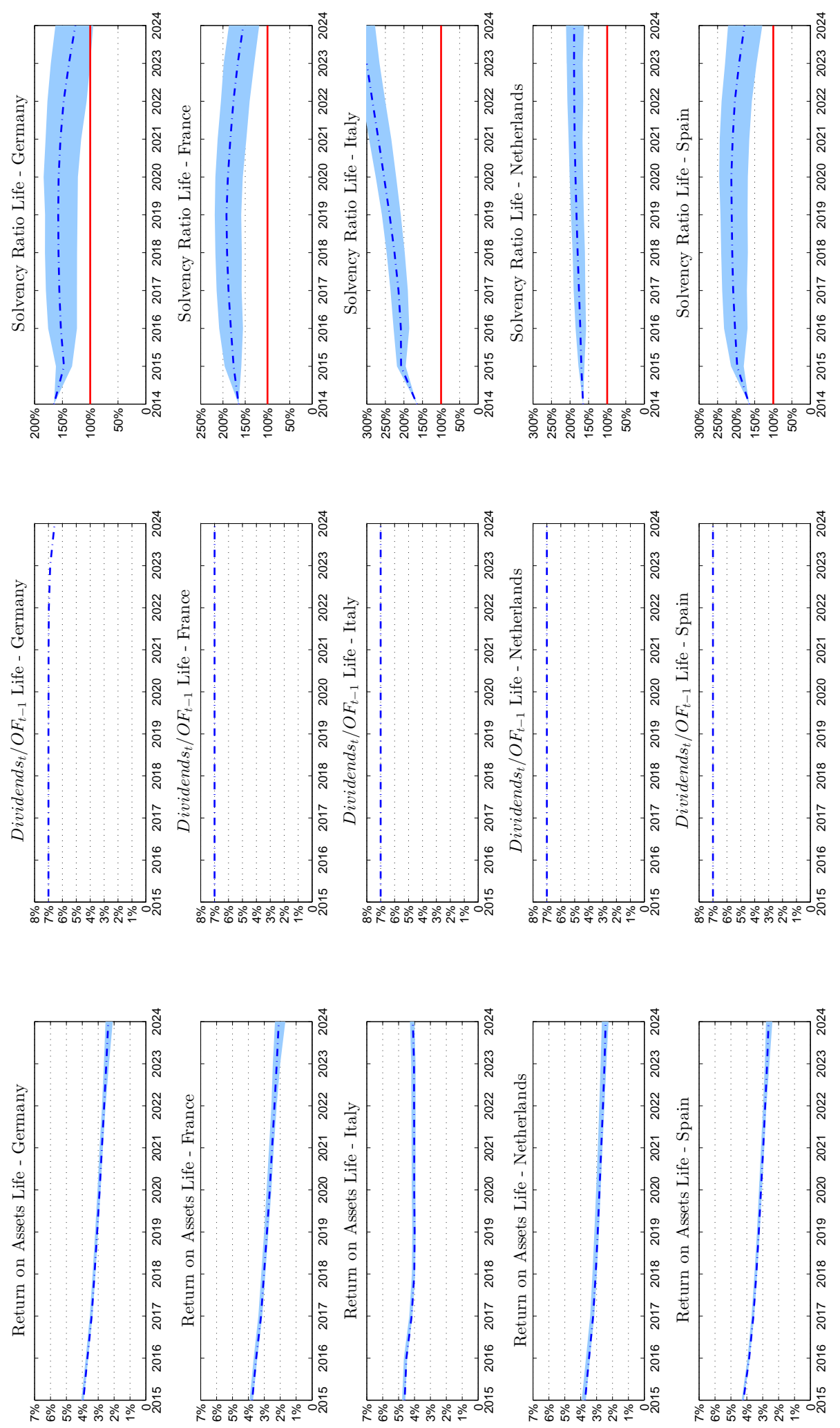
Figure 16: Results - Baseline Scenario - Specification 4: Endowment, Term Life, Annuity and Non-Life Business. The Graphs show the return on assets, the return on equity (Dividends $/ O F_{t-1}$ ) and the solvency ratio both for life an non-life; for the return on assets and for the solvency ratio we report the $95 \%$ confidence interval (shaded area) and the median (dotted line), whereas for the return on equity we only report the mean.
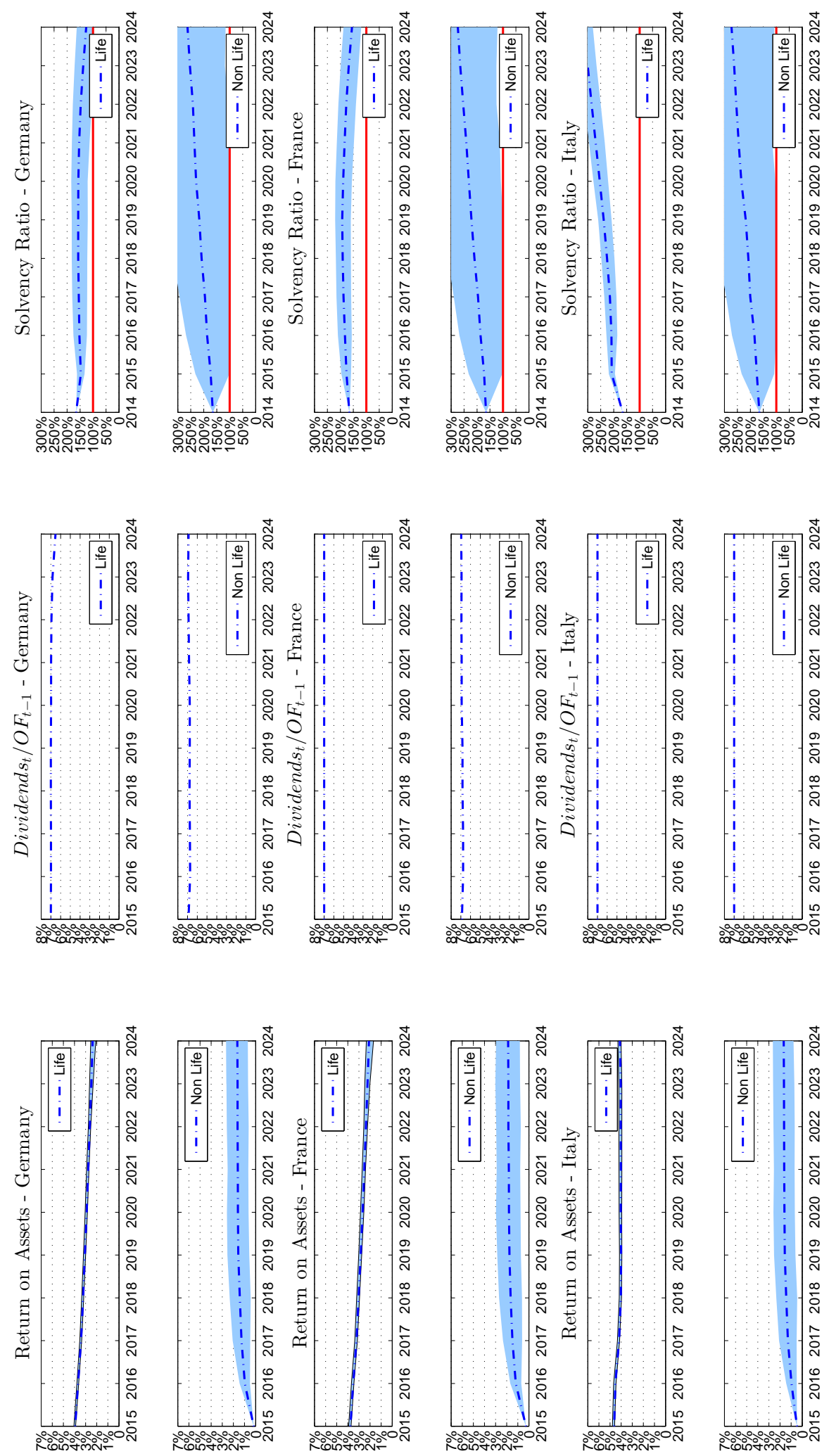
Figure 17: Results - Baseline Scenario - Specification 4: Endowment, Term Life, Annuity and Non-Life Business. The Graphs show the return on assets, the return on equity (Dividends $/ O F_{t-1}$ ) and the solvency ratio both for life an non-life; for the return on assets and for the solvency ratio we report the $95 \%$ confidence interval (shaded area) and the median (dotted line), whereas for the return on equity we only report the mean.
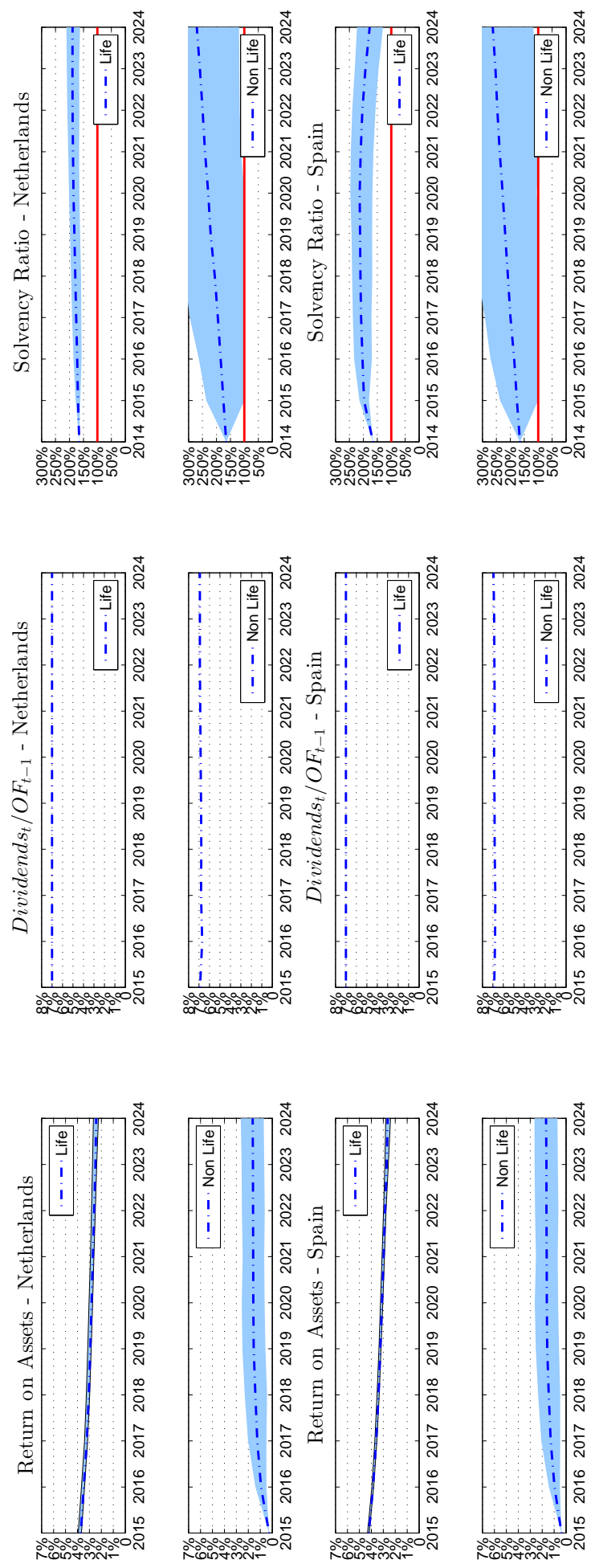
Figure 18: Results - Adverse Scenario - Specification 1: Endowment Business.

The Graphs show the return on assets, the return on equity (Dividends $/ O F_{t-1}$ ) and the solvency ratio; for the return on assets and for the solvency ratio we report the $95 \%$ confidence interval (shaded area) and the median (dotted line), whereas for the return on equity we only report the mean.
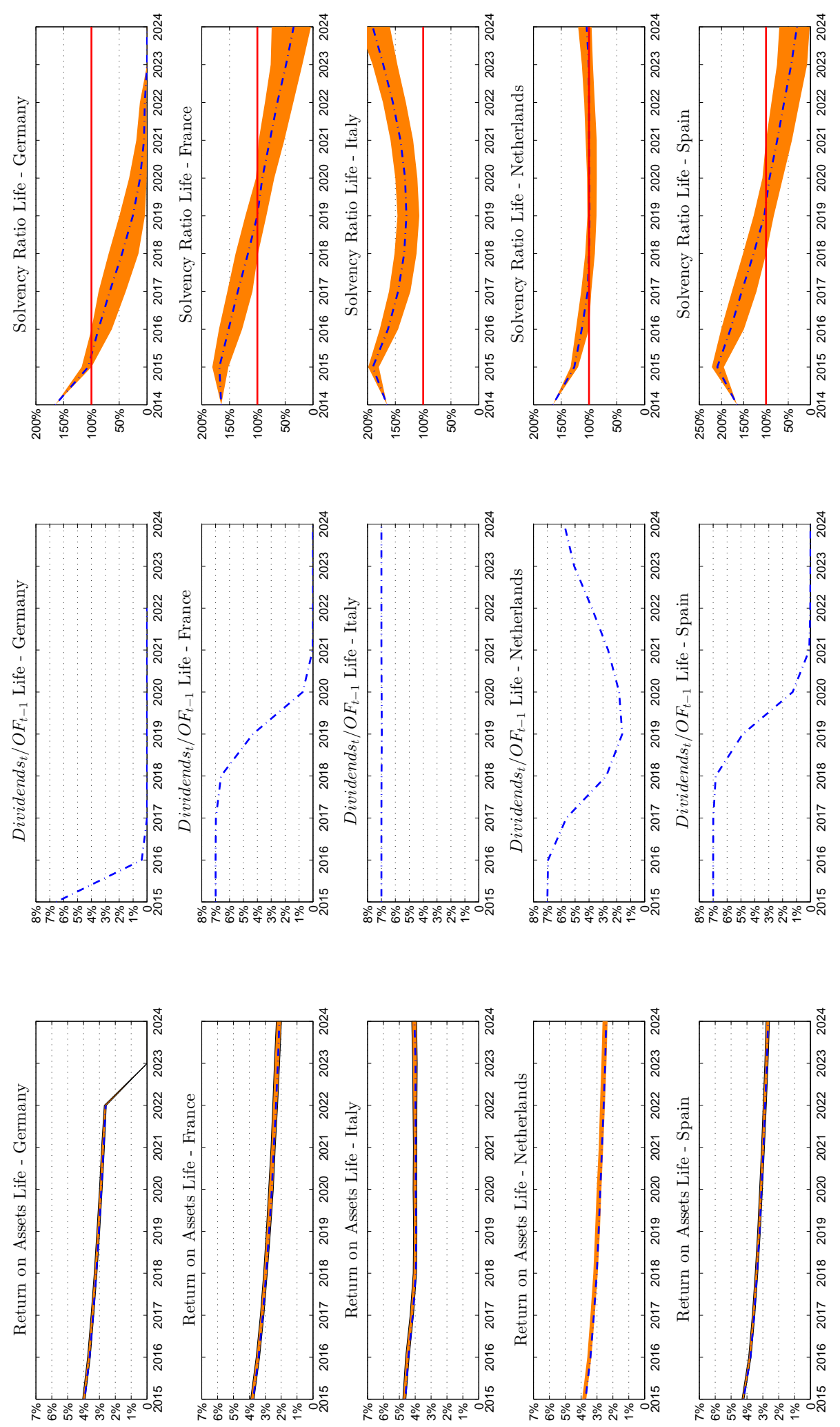
Figure 19: Results - Adverse Scenario - Specification 2: Endowment and Term Life Business.

The Graphs show the return on assets, the return on equity (Dividends $/ O F_{t-1}$ ) and the solvency ratio; for the return on assets and for the solvency ratio we report the $95 \%$ confidence interval (shaded area) and the median (dotted line), whereas for the return on equity we only report the mean.
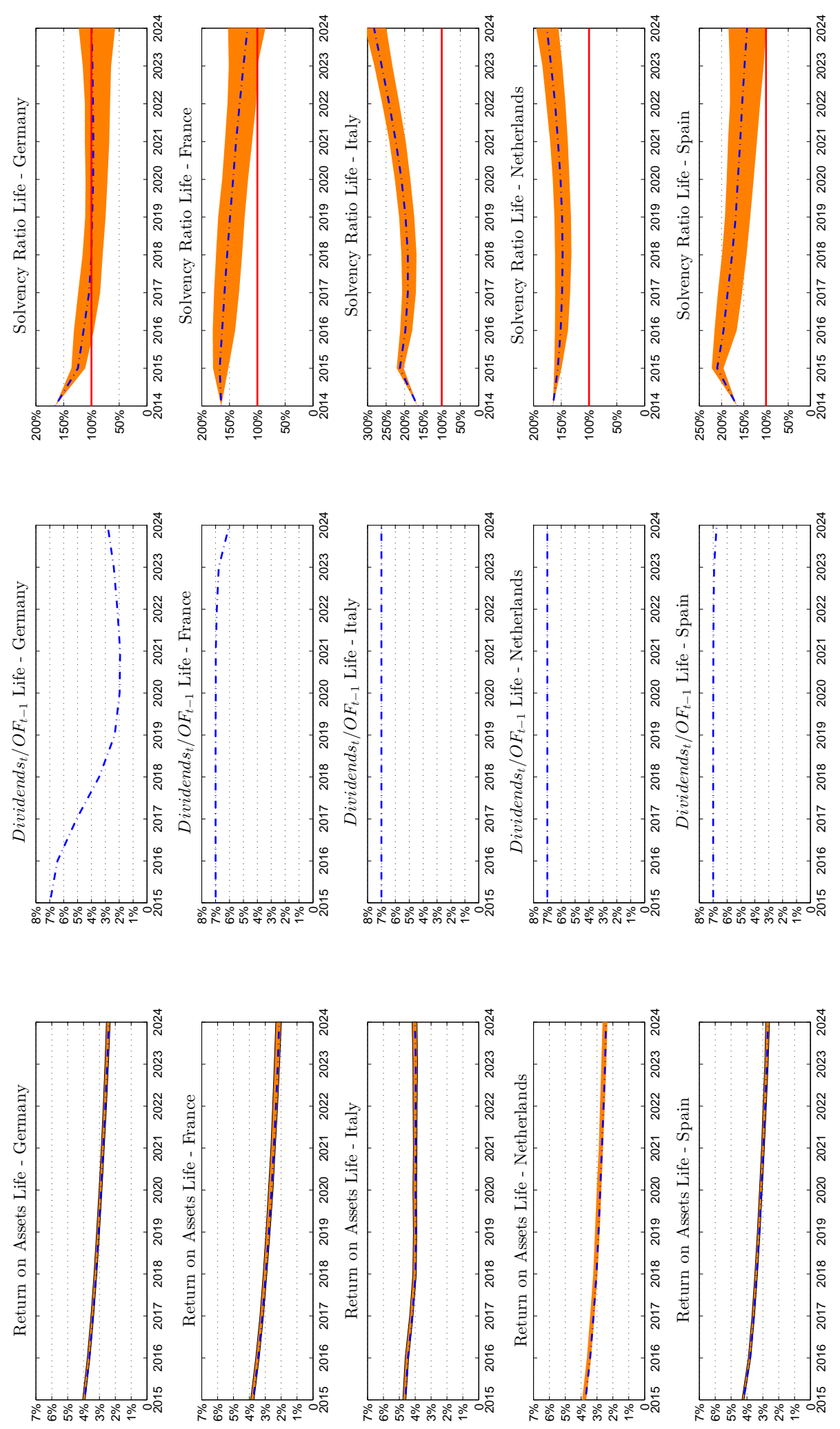
Figure 20: Results - Adverse Scenario - Specification 3: Endowment, Term Life and Annuity Business. The Graphs show the return on assets, the return on equity (Dividends $/ O F_{t-1}$ ) and the solvency ratio; for the return on assets and for the solvency ratio we report the $95 \%$ confidence interval (shaded area) and the median (dotted line), whereas for the return on equity we only report the mean.
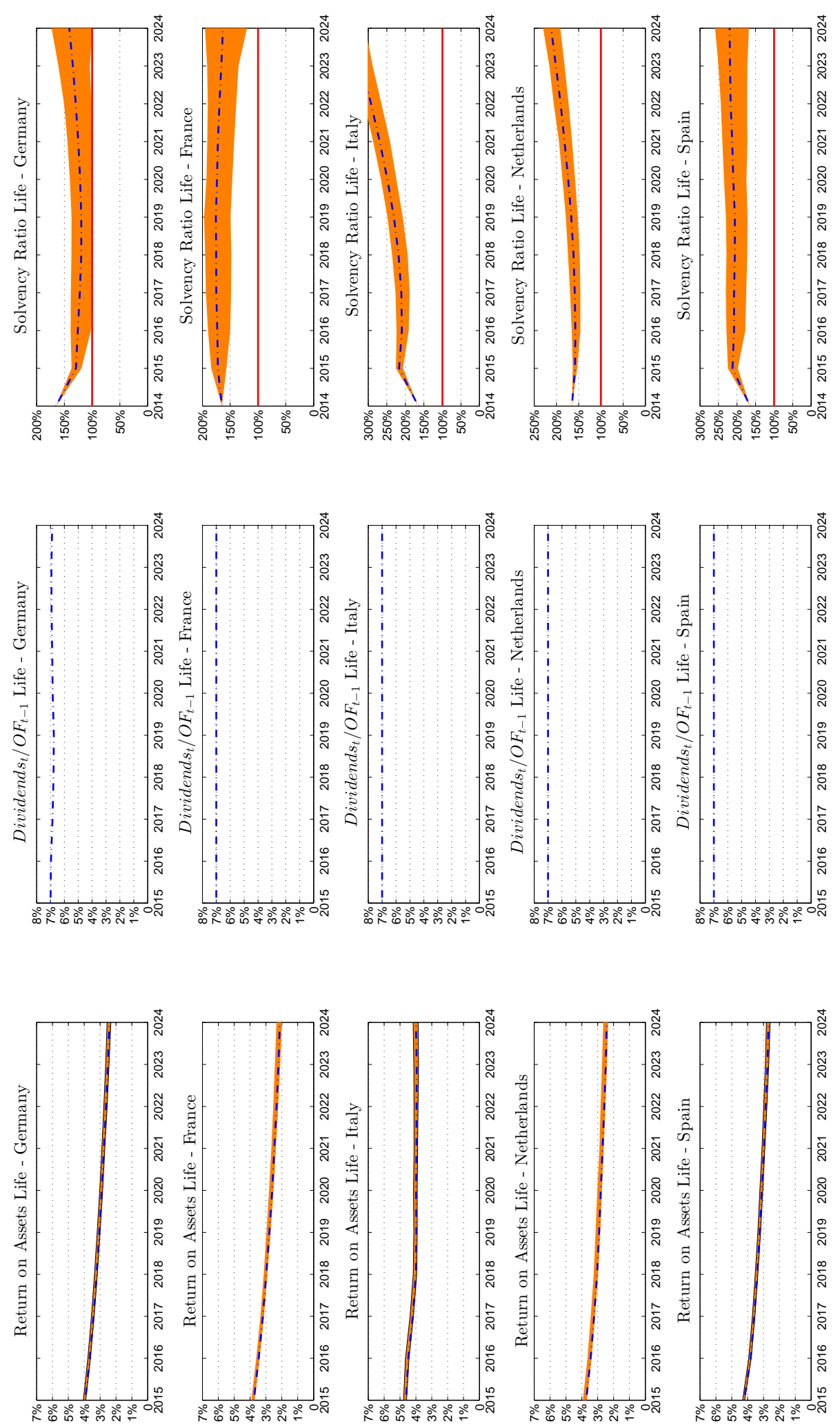
Figure 21: Results - Adverse Scenario - Specification 4: Endowment, Term Life, Annuity and Non-Life Business. The Graphs show the return on assets, the return on equity (Dividends $/ O F_{t-1}$ ) and the solvency ratio both for life an non-life; for the return on assets and for the solvency ratio we report the $95 \%$ confidence interval (shaded area) and the median (dotted line), whereas for the return on equity we only report the mean.
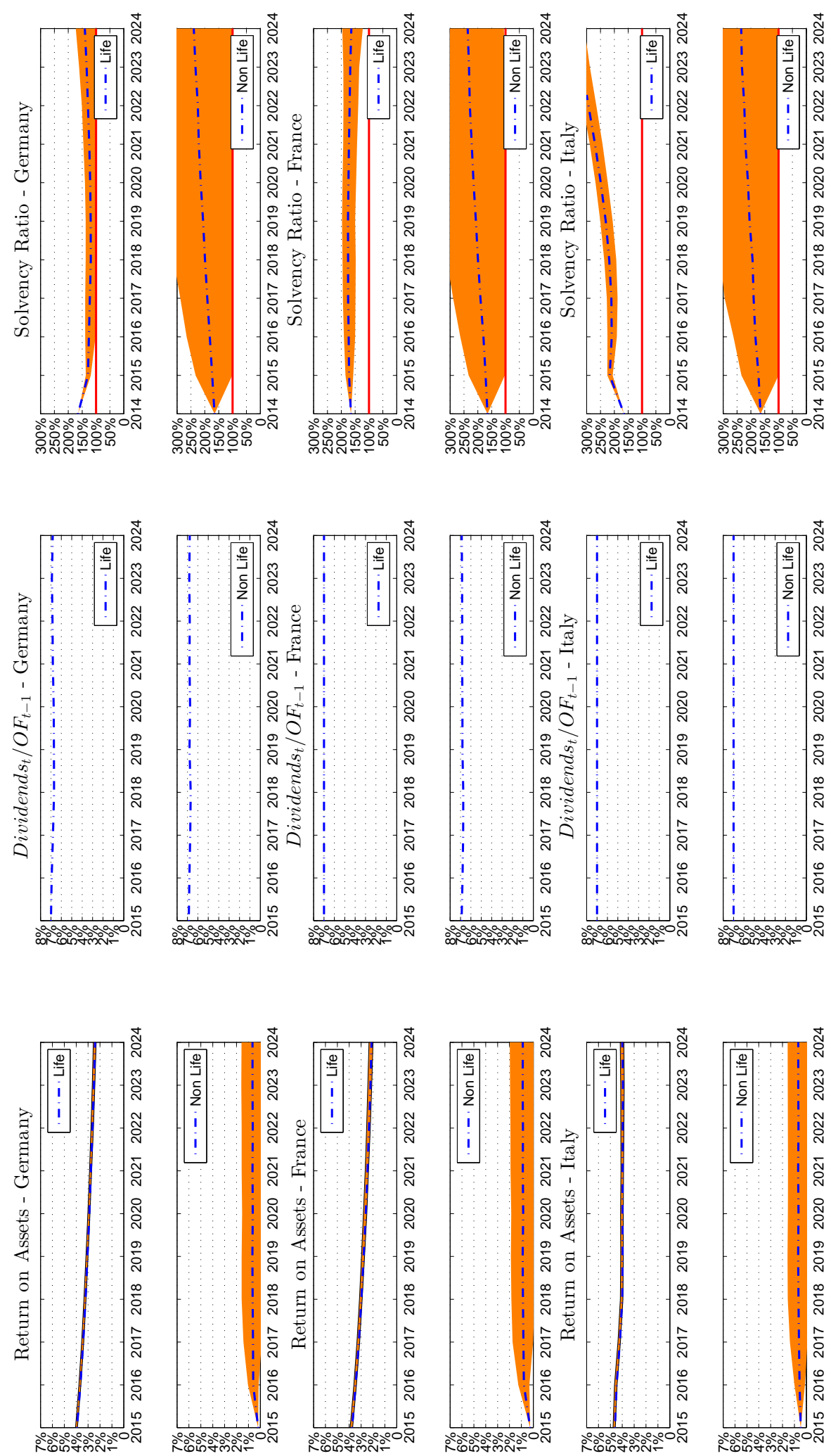
Figure 22: Results - Adverse Scenario - Specification 4: Endowment, Term Life, Annuity and Non-Life Business. The Graphs show the return on assets, the return on equity (Dividends $/ O F_{t-1}$ ) and the solvency ratio both for life an non-life; for the return on assets and for the solvency ratio we report the $95 \%$ confidence interval (shaded area) and the median (dotted line), whereas for the return on equity we only report the mean.
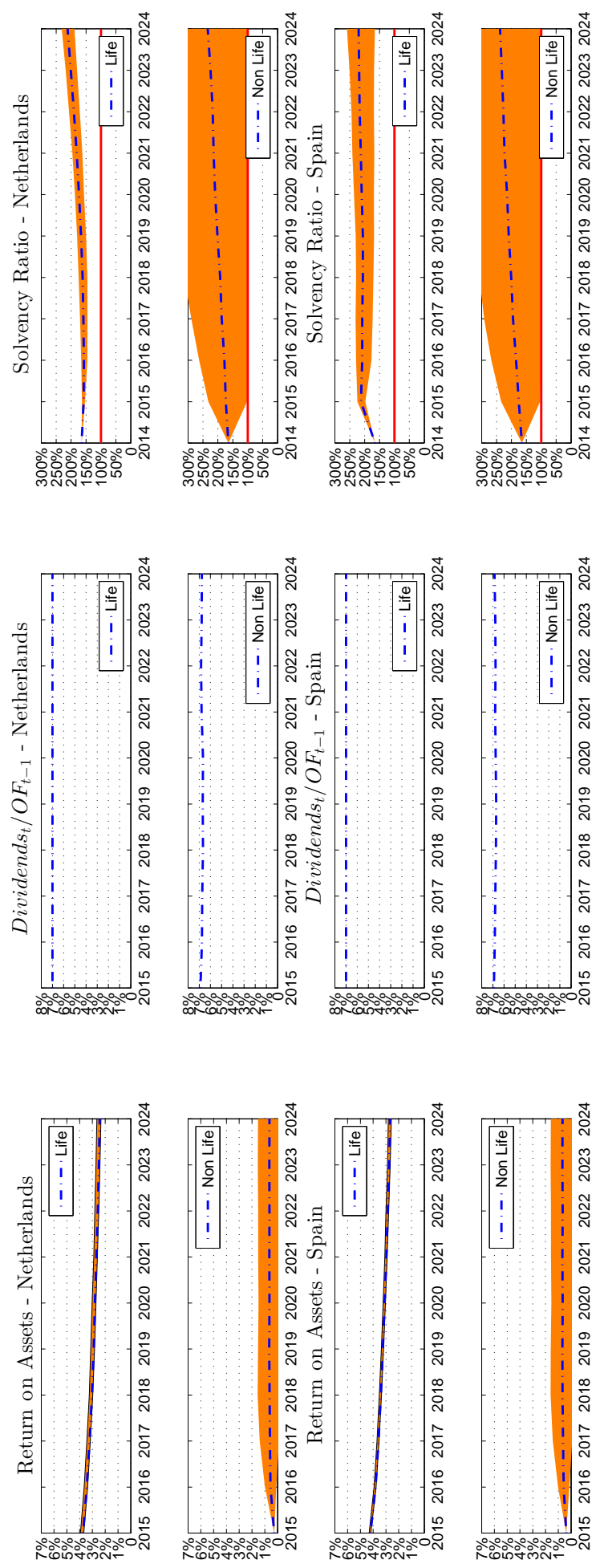
Figure 23: Results - Severely Adverse Scenario - Specification 1: Endowment Business.

The Graphs show the return on assets, the return on equity (Dividends $/ O F_{t-1}$ ) and the solvency ratio; for the return on assets and for the solvency ratio we report the $95 \%$ confidence interval (shaded area) and the median (dotted line), whereas for the return on equity we only report the mean.
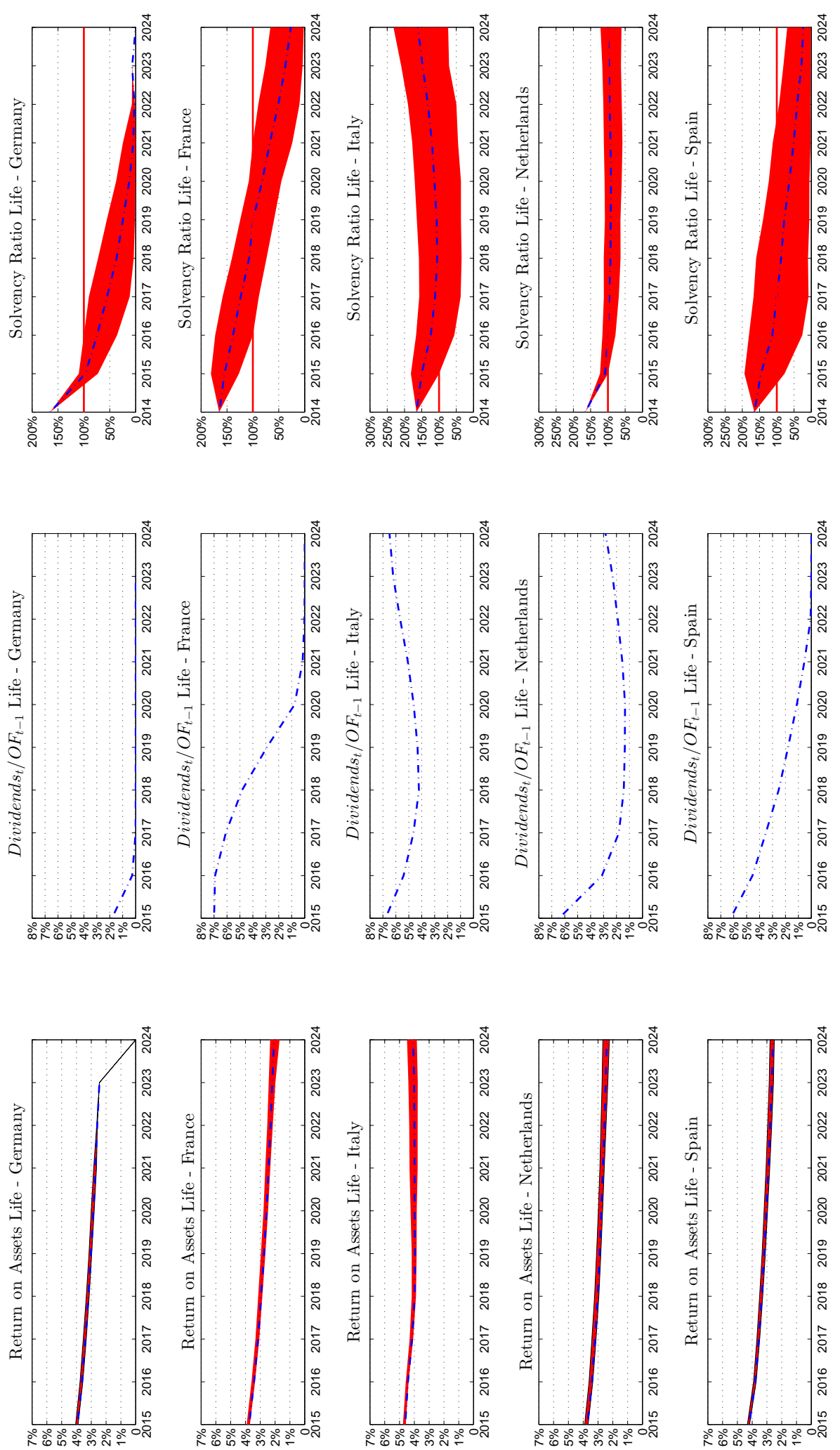
Figure 24: Results - Severely Adverse Scenario - Specification 2: Endowment and Term Life Business. The Graphs show the return on assets, the return on equity (Dividends $/ O F_{t-1}$ ) and the solvency ratio; for the return on assets and for the solvency ratio we report the $95 \%$ confidence interval (shaded area) and the median (dotted line), whereas for the return on equity we only report the mean.
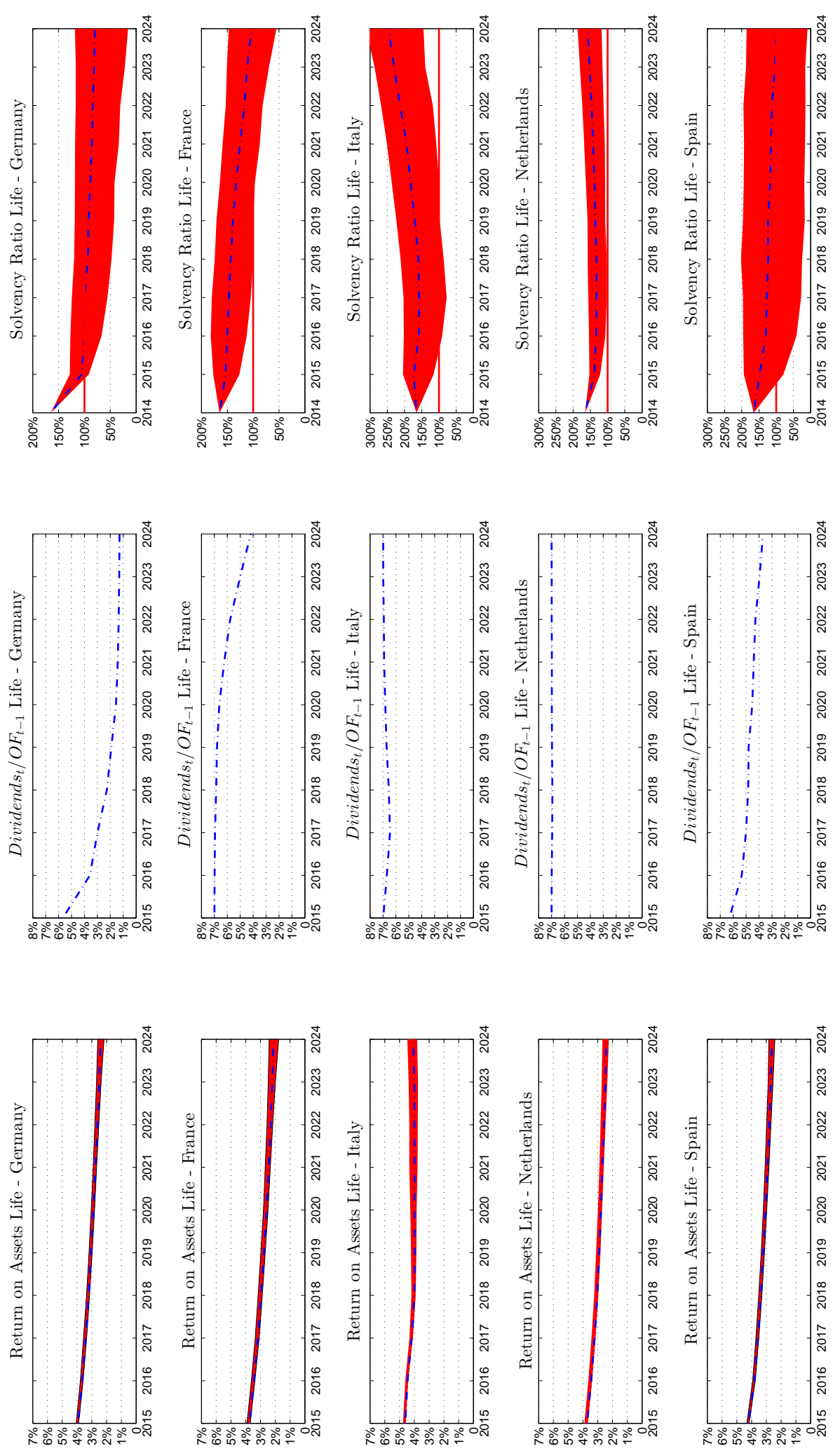
Figure 25: Results - Severely Adverse Scenario - Specification 3: Endowment, Term Life and Annuity Business. The Graphs show the return on assets, the return on equity (Dividends $/ O F_{t-1}$ ) and the solvency ratio; for the return on assets and for the solvency ratio we report the $95 \%$ confidence interval (shaded area) and the median (dotted line), whereas for the return on equity we only report the mean.
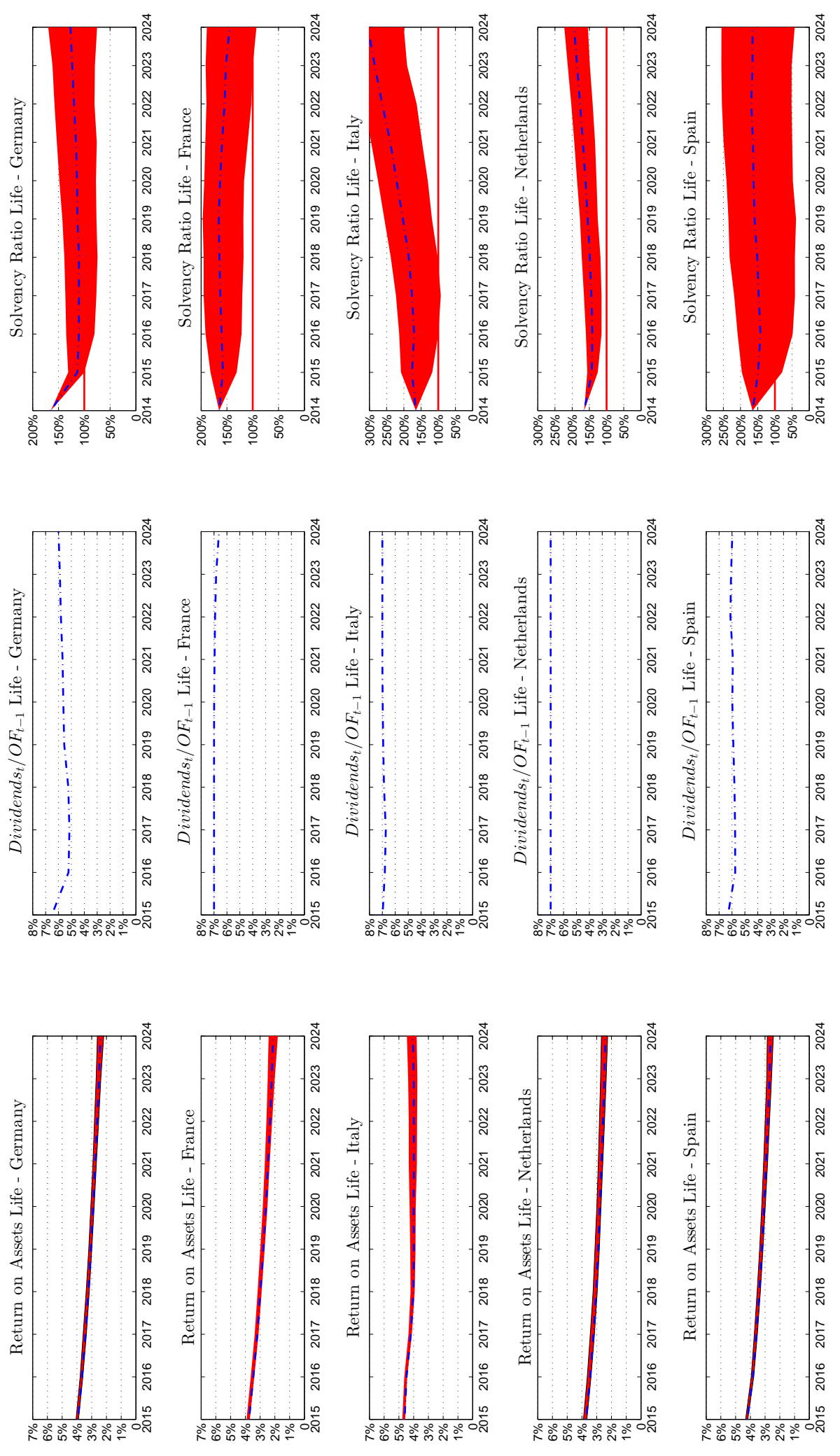
Figure 26: Results - Severely Adverse Scenario - Specification 4: Endowment, Term Life, Annuity and Non-Life Business.

The Graphs show the return on assets, the return on equity (Dividends/OFt-1) and the solvency ratio both for life an non-life; for the return on assets and for the solvency ratio we report the $95 \%$ confidence interval (shaded area) and the median (dotted line), whereas for the return on equity we only report the mean.
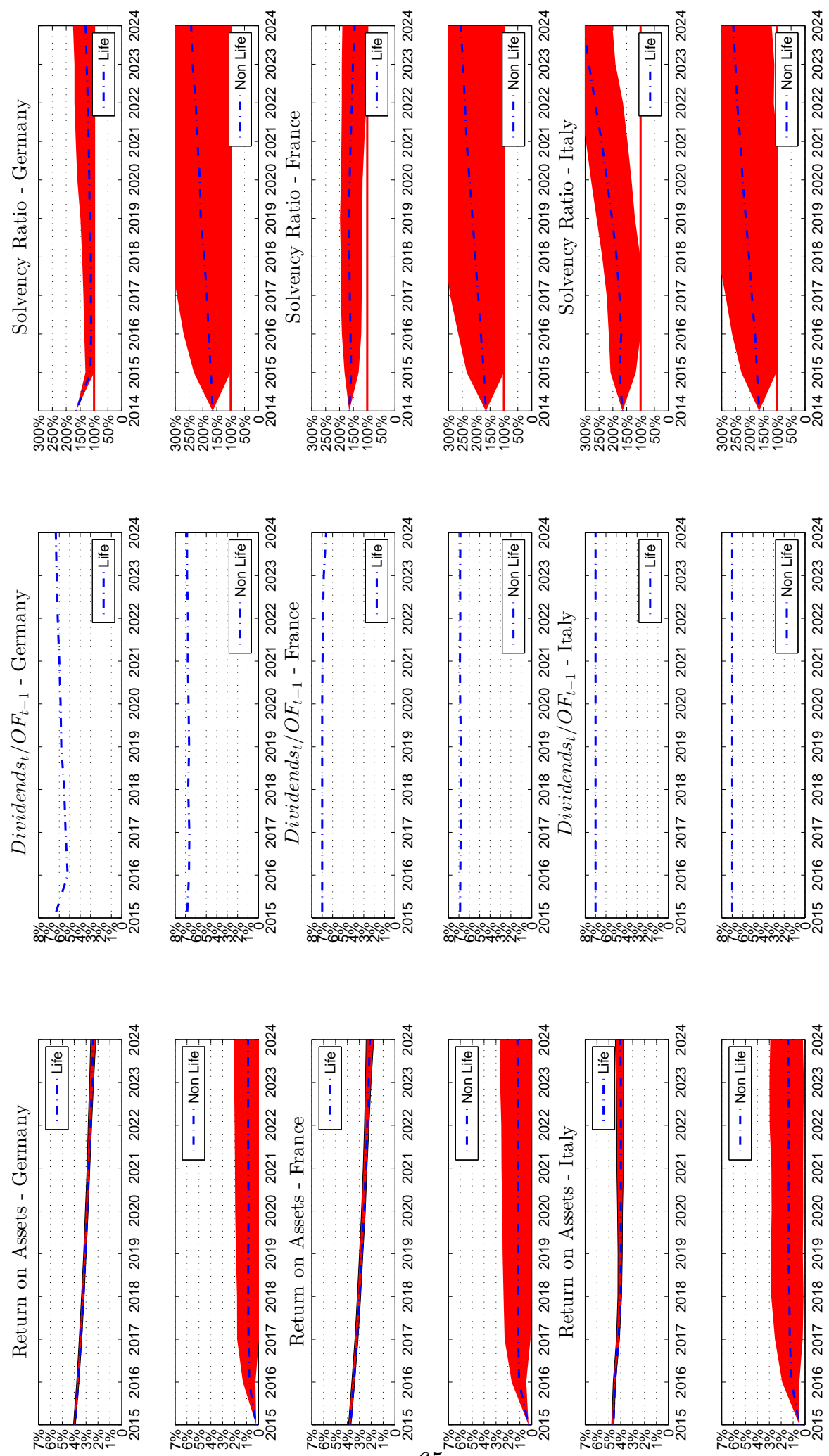
Figure 27: Results - Severely Adverse Scenario - Specification 4: Endowment, Term Life, Annuity and Non-Life Business.

The Graphs show the return on assets, the return on equity (Dividends $/ O F_{t-1}$ ) and the solvency ratio both for life an non-life; for the return on assets and for the solvency ratio we report the $95 \%$ confidence interval (shaded area) and the median (dotted line), whereas for the return on equity we only report the mean.
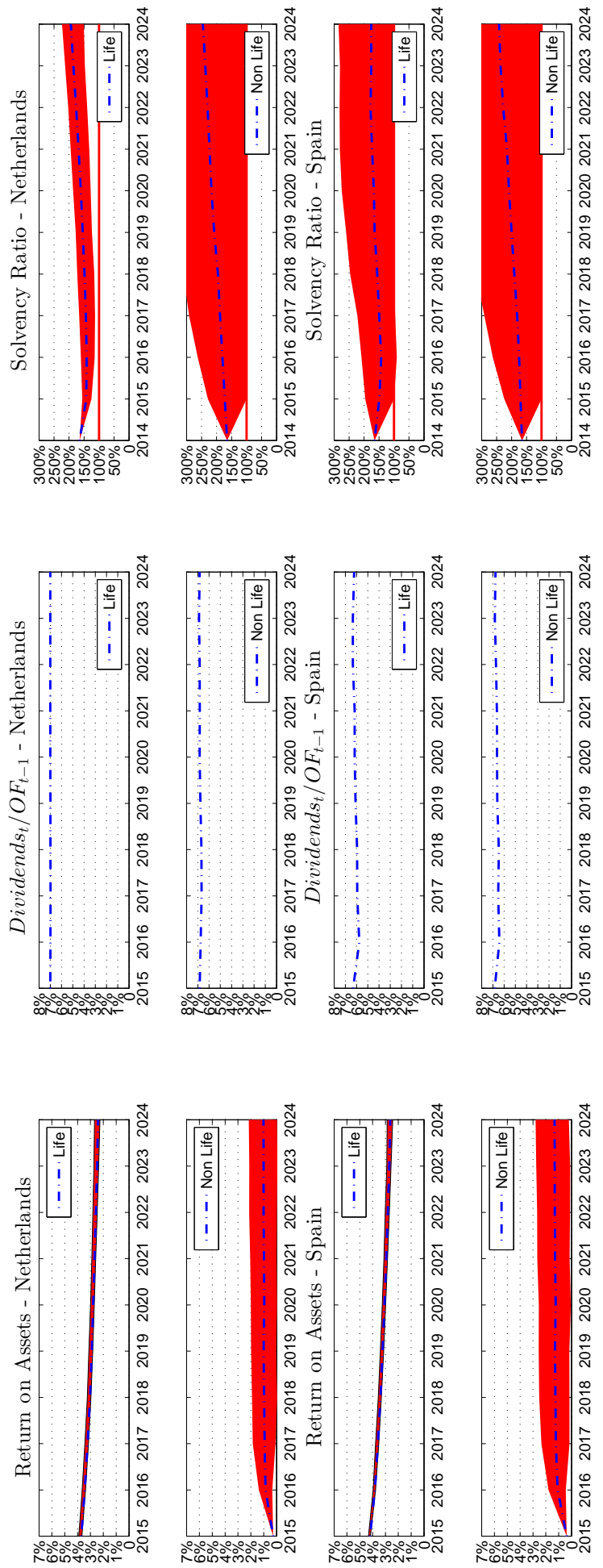
Figure 28: Median Non Life Solvency Ratio Reduction with respect to Baseline Scenario.

The Graphs show the differences between the median solvency ratio for non life under the Adverse Scenario and the Severely Adverse Scenario with respect to the Baseline median solvency ratio. Figures display the absolute percentage points change in the median solvency ratio.
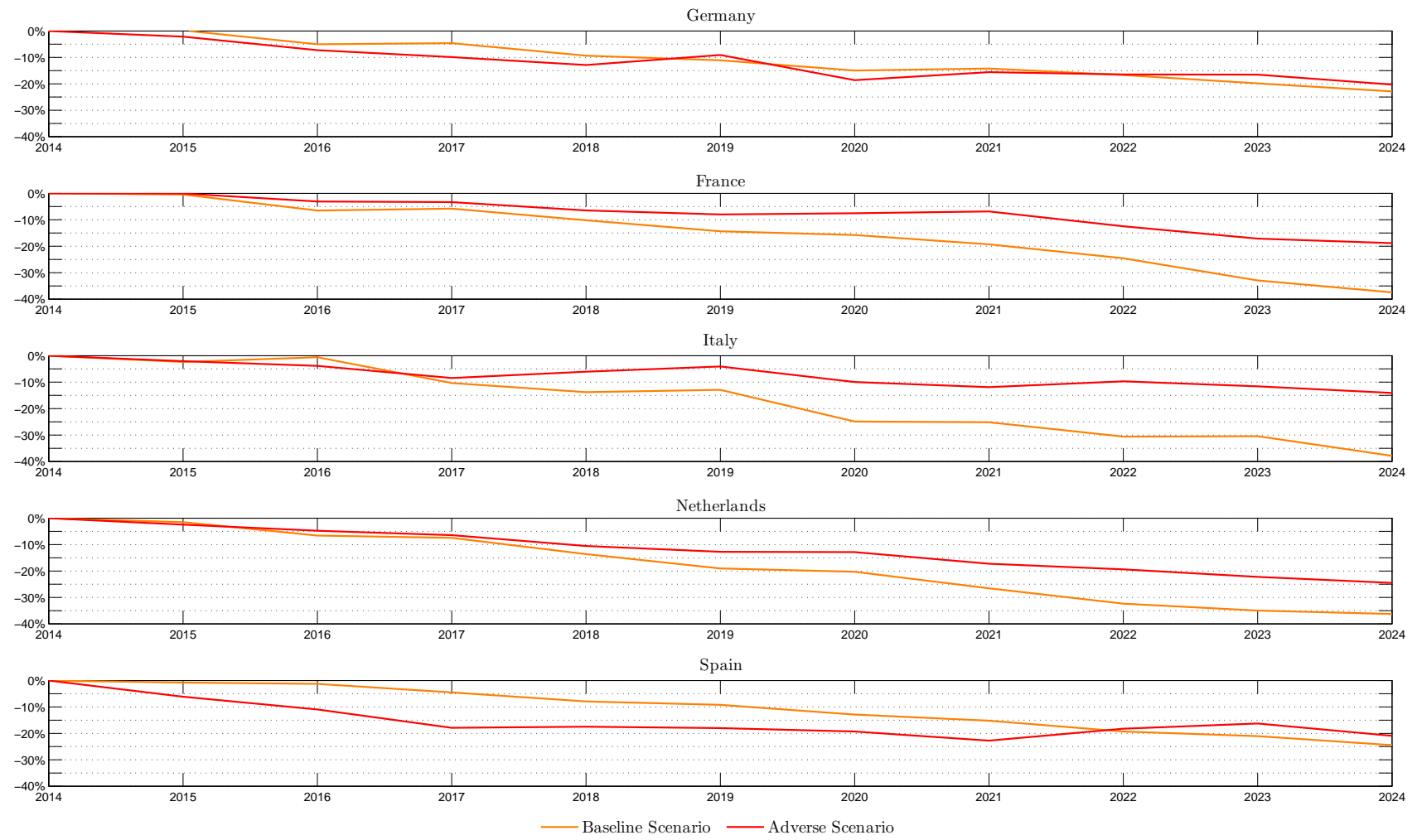


\section{Tables}

Table 1: Financial Markets Dynamics: the Vasicek Model was calibrated on the EIONIA rate between January 2008 and December 2014; All other parameters under Baseline Scenario and Adverse Scenario were calibrated during the pre-crisis period, i.e. January 1999 to December 2007, whereas Severely Adverse Scenario was calibrated over the period January 1999 to December 2014. Data for Sovereign Bonds was obtained on Datastream, whereas for Corporate Bonds data were obtained from Moody's. Stocks indexes parameters were estimated from main national indexes (DAX, CAC 40, FTSE-MIB, AEX and IBEX 35), whereas Real Estate parameters were estimated on national REIT indexes. All series are at monthly frequency. Parameters for Sovereign bonds and Corporate bonds are obtained by constructing a series generated by the mean across maturities of the spread versus the German yield curve.

\begin{tabular}{|c|c|c|c|c|c|c|}
\hline & \multicolumn{2}{|c|}{ Baseline Scenario } & \multicolumn{2}{|c|}{ Adverse Scenario } & Severely & Adverse Scenario \\
\hline \multicolumn{7}{|c|}{ Vasicek Model } \\
\hline$r_{0}$ & \multicolumn{2}{|c|}{$-0.08 \%$} & \multicolumn{2}{|c|}{$-0.08 \%$} & \multicolumn{2}{|r|}{$-0.08 \%$} \\
\hline$k$ & \multicolumn{2}{|c|}{0.5462} & \multicolumn{2}{|c|}{0.5462} & \multicolumn{2}{|r|}{0.5462} \\
\hline$\sigma_{r}$ & \multicolumn{2}{|c|}{$0.61 \%$} & \multicolumn{2}{|c|}{$0.61 \%$} & \multicolumn{2}{|r|}{$0.61 \%$} \\
\hline$\lambda$ & \multicolumn{2}{|c|}{-1} & \multicolumn{2}{|c|}{-1} & \multicolumn{2}{|r|}{-1} \\
\hline \multirow[t]{2}{*}{$\theta$} & \multicolumn{2}{|c|}{$1 \%$} & \multicolumn{2}{|c|}{$0 \%$} & \multicolumn{2}{|r|}{$0 \%$} \\
\hline & $\mu$ & $\sigma$ & $\mu$ & $\sigma$ & $\mu$ & $\sigma$ \\
\hline \multicolumn{7}{|c|}{ Sovereign Bonds } \\
\hline Germany & $0 \%$ & $0 \%$ & $0 \%$ & $0 \%$ & $0 \%$ & $0 \%$ \\
\hline France & $0.01 \%$ & $0.18 \%$ & $0.01 \%$ & $0.18 \%$ & $0.17 \%$ & $0.31 \%$ \\
\hline Italy & $0.05 \%$ & $0.19 \%$ & $0.05 \%$ & $0.19 \%$ & $0.72 \%$ & $1.12 \%$ \\
\hline Netherlands & $-0.08 \%$ & $0.18 \%$ & $-0.08 \%$ & $0.18 \%$ & $-0.02 \%$ & $0.22 \%$ \\
\hline Spain & $-0.06 \%$ & $0.20 \%$ & $-0.06 \%$ & $0.20 \%$ & $0.71 \%$ & $1.28 \%$ \\
\hline \multicolumn{7}{|c|}{ Corporate Bonds } \\
\hline AAA & $0.50 \%$ & $0.28 \%$ & $0.50 \%$ & $0.28 \%$ & $0.51 \%$ & $0.29 \%$ \\
\hline AA & $0.72 \%$ & $0.35 \%$ & $0.72 \%$ & $0.35 \%$ & $0.92 \%$ & $0.52 \%$ \\
\hline $\mathrm{A}$ & $1.02 \%$ & $0.44 \%$ & $1.02 \%$ & $0.44 \%$ & $1.31 \%$ & $0.74 \%$ \\
\hline $\mathrm{BBB}$ & $1.57 \%$ & $0.59 \%$ & $1.57 \%$ & $0.59 \%$ & $2.11 \%$ & $1.15 \%$ \\
\hline \multicolumn{7}{|l|}{ Stocks } \\
\hline Germany & $4.40 \%$ & $28.26 \%$ & $4.40 \%$ & $28.26 \%$ & $3.98 \%$ & $25.81 \%$ \\
\hline France & $4.60 \%$ & $24.09 \%$ & $4.60 \%$ & $24.09 \%$ & $0.83 \%$ & $23.68 \%$ \\
\hline Italy & $2.54 \%$ & $20.09 \%$ & $2.54 \%$ & $20.09 \%$ & $-2.91 \%$ & $24.52 \%$ \\
\hline Netherlands & $0.38 \%$ & $23.09 \%$ & $0.38 \%$ & $23.09 \%$ & $-1.34 \%$ & $25.04 \%$ \\
\hline Spain & $5.09 \%$ & $19.56 \%$ & $5.09 \%$ & $19.56 \%$ & $0.68 \%$ & $22.14 \%$ \\
\hline \multicolumn{7}{|l|}{ Real Estate } \\
\hline Germany & $7.66 \%$ & $28.93 \%$ & $7.66 \%$ & $28.93 \%$ & $0.74 \%$ & $34.51 \%$ \\
\hline France & $15.71 \%$ & $15.53 \%$ & $15.71 \%$ & $15.53 \%$ & $8.64 \%$ & $21.39 \%$ \\
\hline Italy & $15.04 \%$ & $23.73 \%$ & $15.04 \%$ & $23.73 \%$ & $0.60 \%$ & $38.38 \%$ \\
\hline Netherlands & $7.99 \%$ & $11.41 \%$ & $7.99 \%$ & $11.41 \%$ & $1.01 \%$ & $19.25 \%$ \\
\hline Spain & $14.63 \%$ & $27.80 \%$ & $14.63 \%$ & $27.80 \%$ & $-25.63 \%$ & $68.69 \%$ \\
\hline
\end{tabular}




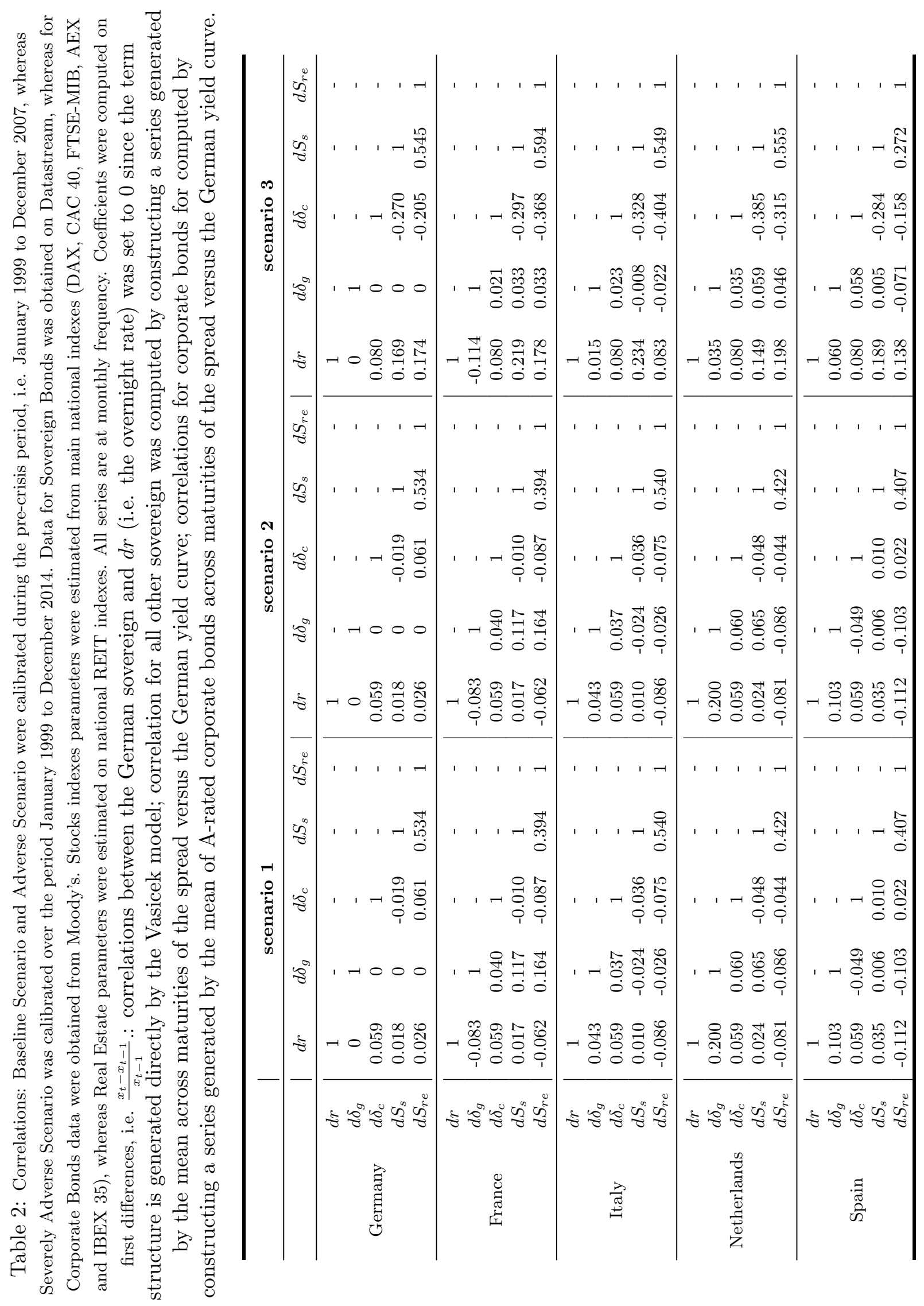


Table 3: Lee-Carter Model: all parameters were estimated on the country (yearly) mortality data, i.e. central death rates, exposure to risk and number of deaths, from 1956 to 2013, males only. Source: The Human Mortality Database.

\begin{tabular}{|c|c|c|}
\hline & $\begin{array}{c}\alpha \\
(s . e .) \\
\end{array}$ & $\begin{array}{c}\sigma_{k} \\
\text { (s.e.) }\end{array}$ \\
\hline Germany & $\begin{array}{l}-1.7623 \\
(0.3704)\end{array}$ & $\begin{array}{c}2.7352 \\
(1.4585)\end{array}$ \\
\hline France & $\begin{array}{l}-1.6367 \\
(0.3574)\end{array}$ & $\begin{array}{c}2.7614 \\
(1.2293)\end{array}$ \\
\hline Italy & $\begin{array}{l}-1.9097 \\
(0.4030)\end{array}$ & $\begin{array}{c}3.0814 \\
(1.7774)\end{array}$ \\
\hline Netherlands & $\begin{array}{l}-1.3806 \\
(0.3473)\end{array}$ & $\begin{array}{c}2.6221 \\
(1.4513)\end{array}$ \\
\hline Spain & $\begin{array}{l}-1.7275 \\
(0.4620)\end{array}$ & $\begin{array}{c}3.4860 \\
(1.7392)\end{array}$ \\
\hline \multicolumn{3}{|c|}{ Adverse Selection (Gatzert and Wesker, 2012) } \\
\hline$\phi_{1}=-0.0275$ & $\phi_{2}=1.1618 \quad \phi_{3}=-0.0004$ & $\sigma_{a s}=0.1292$ \\
\hline
\end{tabular}

Table 4: Claims Development

\begin{tabular}{lll}
\hline \multicolumn{3}{c}{ Stochastic Claims } \\
\hline Germany & $\mu_{C}=-0.005$ & $\sigma_{C}=0.1$ \\
France & $\mu_{C}=-0.005$ & $\sigma_{C}=0.1$ \\
Italy & $\mu_{C}=-0.005$ & $\sigma_{C}=0.1$ \\
Netherlands & $\mu_{C}=-0.005$ & $\sigma_{C}=0.1$ \\
Spain & $\mu_{C}=-0.005$ & $\sigma_{C}=0.1$ \\
\hline
\end{tabular}




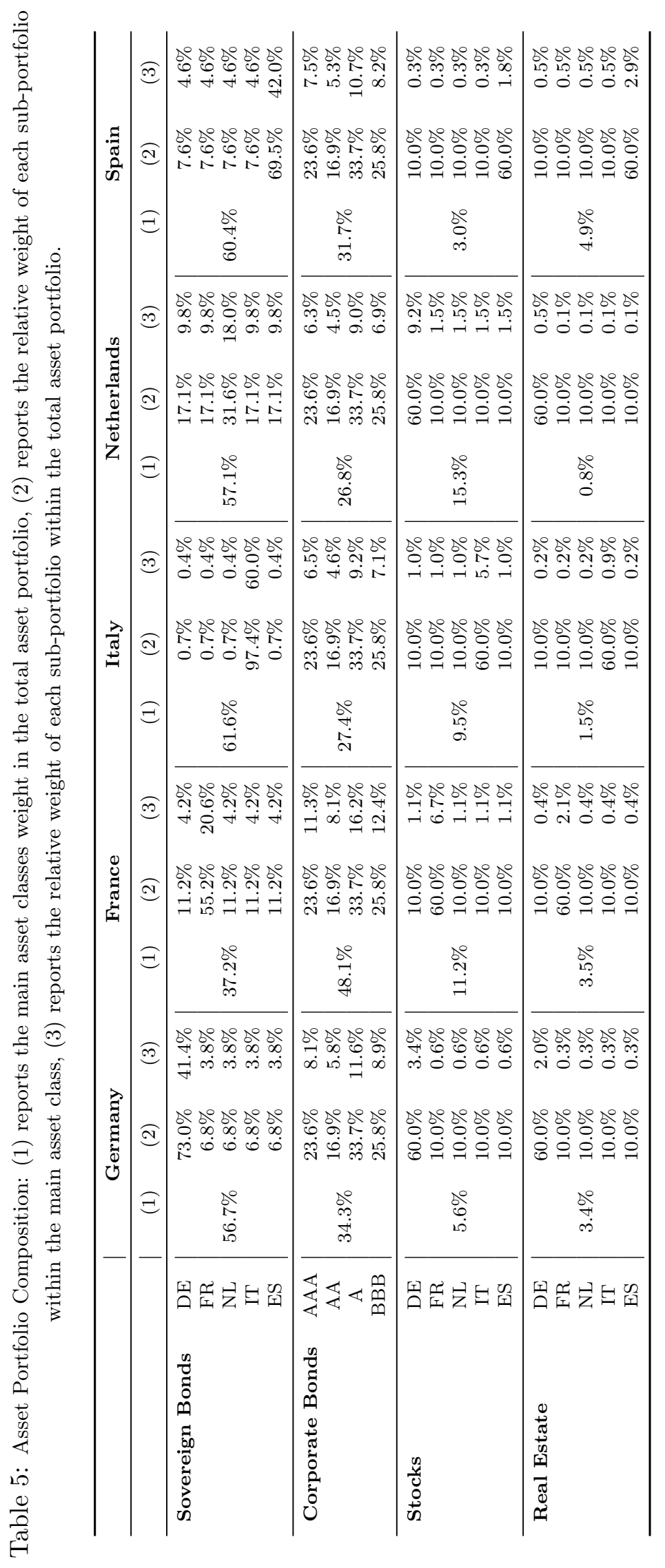


Table 6: Guarantees in (Endowment) Life Business Portfolio: data for Germany is based on Assekurata surveys, data for France is taken from Moody's Investors Service - insurance sector in depth (26/3/2015), data for Italy and Spain were implied by taking the $60 \%$ of the past 10 YTM sovereign yield in the respective countries and rounded to $25 \mathrm{bps}$, whereas for the Netherlands we relied to insurance experts of the Dutch Central Bank.

\begin{tabular}{|c|c|c|c|c|c|c|c|c|c|c|}
\hline & \multicolumn{2}{|c|}{ Germany } & \multicolumn{2}{|c|}{ France } & \multicolumn{2}{|c|}{ Italy } & \multicolumn{2}{|c|}{ Netherlands } & \multicolumn{2}{|c|}{ Spain } \\
\hline & $r^{i}$ & weight & $r^{i}$ & weight & $r^{i}$ & weight & $r^{i}$ & weight & $r^{i}$ & weight \\
\hline & $\begin{array}{l}4.00 \% \\
3.50 \% \\
3.25 \% \\
2.75 \% \\
2.25 \% \\
1.75 \%\end{array}$ & $\begin{array}{l}24 \% \\
18 \% \\
14 \% \\
12 \% \\
20 \% \\
12 \%\end{array}$ & $\begin{array}{l}3.50 \% \\
3.00 \% \\
2.50 \% \\
0.00 \%\end{array}$ & $\begin{array}{c}15 \% \\
5 \% \\
5 \% \\
75 \%\end{array}$ & $\begin{array}{l}3.50 \% \\
3.25 \% \\
3.00 \% \\
2.75 \% \\
2.50 \% \\
2.25 \% \\
2.00 \%\end{array}$ & $\begin{array}{l}6.70 \% \\
6.70 \% \\
13.3 \% \\
20.0 \% \\
33.3 \% \\
13.3 \% \\
6.70 \%\end{array}$ & $\begin{array}{l}4.00 \% \\
3.00 \% \\
0.00 \%\end{array}$ & $\begin{array}{l}40 \% \\
40 \% \\
20 \%\end{array}$ & $\begin{array}{l}5.00 \% \\
4.00 \% \\
3.50 \% \\
3.00 \% \\
2.50 \% \\
2.00 \%\end{array}$ & $\begin{array}{c}10 \% \\
5 \% \\
15 \% \\
35 \% \\
25 \% \\
10 \%\end{array}$ \\
\hline avg. & \multicolumn{2}{|c|}{$3.04 \%$} & \multicolumn{2}{|c|}{$0.80 \%$} & \multicolumn{2}{|c|}{$2.67 \%$} & \multicolumn{2}{|c|}{$2.80 \%$} & \multicolumn{2}{|c|}{$3.10 \%$} \\
\hline
\end{tabular}

Table 7: (mod.) Duration of Assets and Liabilities in (Endowment) Life Business: on the asset side, figures only include bonds, whereas on the liability side it only includes endowment/annuity business; numbers are expressed in years.

\begin{tabular}{cccccccccccccc} 
& \multicolumn{2}{c}{ Germany } & \multicolumn{2}{c}{ France } & \multicolumn{2}{c}{ Italy } & \multicolumn{2}{c}{ Netherlands } & \multicolumn{2}{c}{ Spain } \\
\hline & $D^{A}$ & $D^{L}$ & $D^{A}$ & $D^{L}$ & $D^{A}$ & $D^{L}$ & $D^{A}$ & $D^{L}$ & $D^{A}$ & $D^{L}$ \\
\hline & 7.93 & 11.43 & 7.12 & 9.68 & 6.81 & 7.44 & 7.97 & 11.46 & 8.04 & 9.47 \\
\hline$D^{L}-D^{A}$ & & $\mathbf{3 . 5 1}$ & \multicolumn{2}{c}{$\mathbf{2 . 5 6}$} & $\mathbf{0 . 6 4}$ & $\mathbf{3 . 5 0}$ & $\mathbf{1 . 4 3}$ \\
\hline
\end{tabular}

Table 8: Model's Specifications

\begin{tabular}{lcccc}
\hline & \multicolumn{4}{c}{ Specifications } \\
& $(1)$ & $(2)$ & $(3)$ & $(4)$ \\
\hline Endowment Business & Yes & Yes & Yes & Yes \\
& $\omega^{e / a}=100 \%$ & $\omega^{e / a}=95 \%$ & $\omega^{e / a}=95 \%$ & $\omega^{e / a}=95 \%$ \\
\hline Term Life Business & No & Yes & Yes & Yes \\
& $\omega^{t l}=0 \%$ & $\omega^{t l}=5 \%$ & $\omega^{t l}=5 \%$ & $\omega^{t l}=5 \%$ \\
\hline Annuity Business & No & No & Yes & Yes \\
& $\theta^{a}=0 \%$ & $\theta^{a}=0 \%$ & $\theta^{a}=5 \%$ & $\theta^{a}=5 \%$ \\
\hline Non-Life Business & No & No & No & Yes \\
& $\omega^{n l}=0 \%$ & $\omega^{n l}=0 \%$ & $\omega^{n l}=0 \%$ & $\omega^{n l}=$ country specific \\
\hline
\end{tabular}


Table 9: Other Balance Sheet Parameters

\begin{tabular}{|c|c|c|c|c|c|c|}
\hline \multicolumn{2}{|c|}{ Balance Sheet Parameters } & \multirow[t]{2}{*}{ Germany } & \multirow[t]{2}{*}{ France } & \multirow[t]{2}{*}{ Italy } & \multirow[t]{2}{*}{ Netherlands } & \multirow[t]{2}{*}{ Spain } \\
\hline Life & description & & & & & \\
\hline$\omega^{e / a *}$ & share of $L^{l}$ allocated to $e / a$ & $100 \%-95 \%$ & $100 \%-95 \%$ & $100 \%-95 \%$ & $100 \%-95 \%$ & $100 \%-95 \%$ \\
\hline$\omega^{t l} *$ & share of $L^{l}$ allocated to $t l$ & $0 \%-5 \%$ & $0 \%-5 \%$ & $0 \%-5 \%$ & $0 \%-5 \%$ & $0 \%-5 \%$ \\
\hline$\theta^{a *}$ & share of $\omega^{e / a}$ annuitized & $0 \%-5 \%$ & $0 \%-5 \%$ & $0 \%-5 \%$ & $0 \%-5 \%$ & $0 \%-5 \%$ \\
\hline$\omega^{l} *$ & share of $L$ allocated to $l$ & $100 \%-87.1 \%$ & $100 \%-90.3 \%$ & $100 \%-87.8 \%$ & $100 \%-81.4 \%$ & $100 \%-85.6 \%$ \\
\hline$N^{l, e}$ & nr. of cohorts $e / a$ & 25 & 20 & 15 & 25 & 20 \\
\hline$N^{l, t l}$ & nr. of cohorts $t l$ & 15 & 15 & 15 & 15 & 15 \\
\hline$T^{l, e / a}$ & exp. time to maturity for $e / a$ & 25 & 20 & 15 & 25 & 20 \\
\hline$T^{l, t l}$ & exp. time to maturity for $t l$ & 15 & 15 & 15 & 15 & 15 \\
\hline$m w$ & money's worth ratio & 0.98 & 0.98 & 0.98 & 0.98 & 0.98 \\
\hline$\varrho^{e / a}$ & loading for mortality for $e / a$ & $-18.7 \%$ & $-18.7 \%$ & $-18.7 \%$ & $-18.7 \%$ & $-18.7 \%$ \\
\hline$\varrho^{t l}$ & loading for mortality for $t l$ & $+34 \%$ & $+34 \%$ & $+34 \%$ & $+34 \%$ & $+34 \%$ \\
\hline$\varrho^{l}$ & loading factor for premiums & $1 \%$ & $1 \%$ & $1 \%$ & $1 \%$ & $1 \%$ \\
\hline$\pi^{e / a}$ & premium & 10 & 10 & 10 & 10 & 10 \\
\hline$\pi^{t l}$ & premium & 1 & 1 & 1 & 1 & 1 \\
\hline$\vartheta$ & recovery value & $99 \%$ & $99 \%$ & $99 \%$ & $99 \%$ & $99 \%$ \\
\hline$v^{a}$ & minimum share of $r^{a}$ & $90 \%$ & $85 \%$ & $80 \%$ & $0 \%$ & $80 \%$ \\
\hline$v^{q}$ & minimum return on $r^{q}$ & $90 \%$ & $90 \%$ & $0 \%$ & $0 \%$ & $0 \%$ \\
\hline$r m^{e / a}$ & risk margin for $e / a$ & $1.83 \%$ & $1.83 \%$ & $1.83 \%$ & $1.83 \%$ & $1.83 \%$ \\
\hline$r m^{t l}$ & risk margin for $t l$ & $8.24 \%$ & $8.24 \%$ & $8.24 \%$ & $8.24 \%$ & $8.24 \%$ \\
\hline \multicolumn{7}{|c|}{ Non-Life } \\
\hline$\omega^{n l} *$ & share of $L$ allocated to $n l$ & $0 \%-12.9 \%$ & $0 \%-9.7 \%$ & $0 \%-12.2 \%$ & $0 \%-18.6 \%$ & $0 \%-14.4 \%$ \\
\hline$\varrho^{n l}$ & loading factor & $5 \%$ & $5 \%$ & $5 \%$ & $5 \%$ & $5 \%$ \\
\hline$\pi^{n l}$ & premium & 2 & 2 & 2 & 2 & 2 \\
\hline$r m^{n l}$ & risk margin & $6.39 \%$ & $6.39 \%$ & $6.39 \%$ & $6.39 \%$ & $6.39 \%$ \\
\hline \multicolumn{7}{|l|}{ Other } \\
\hline$r_{\text {target }}^{\text {sh }}$ & dividend payout target & $7 \%$ & $7 \%$ & $7 \%$ & $7 \%$ & $7 \%$ \\
\hline$\frac{O F_{0}}{S C R_{0}}$ & solvency ratio & $165 \%$ & $165 \%$ & $165 \%$ & $165 \%$ & $165 \%$ \\
\hline \multicolumn{7}{|c|}{ Mortality Developments } \\
\hline$x$ (years) & & 40 & 40 & 40 & 40 & 40 \\
\hline$\omega($ years $)$ & & 105 & 105 & 105 & 105 & 105 \\
\hline \multicolumn{7}{|c|}{ Simulations } \\
\hline$I^{f}$ & iterations for financial markets & 1000 & 1000 & 1000 & 1000 & 1000 \\
\hline$I^{m}$ & iterations for mortality & 1000 & 1000 & 1000 & 1000 & 1000 \\
\hline
\end{tabular}

*: depending on the specification 


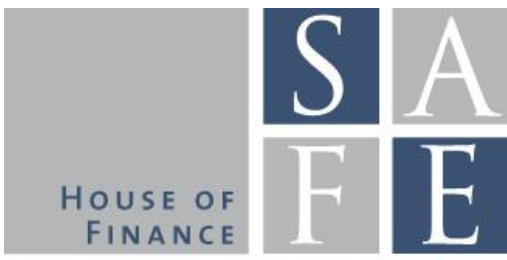

WORKING PAPER SERIES

\section{Recent Issues}

No.136 Matthias Thiemann, Mohammed Aldegwy, Edin Ibrocevic

No. 135

No. 134

No. 133

No. 132

No. 131

No. 130

No. 129

No. 128

No. 127

No. 126

No. 125

No. 124
Tobias H. Tröger, Uwe Walz

Douglas Cumming, Jochen Werth, Yelin Zhang

Markus Kröll, Devesh Rustagi

Markus Behn, Rainer Haselmann, Thomas Kick, Vikrant Vig

Rainer Haselmann, David

Schoenherr, Vikrant Vig

Nicole Branger, Patrick Grüning, Christian Schlag

Giuliano Curatola

Giuliano Curatola, Michael Donadelli, Patrick Grüning, Christoph Meinerding

Giuliano Curatola

Helmut Elsinger, Philipp SchmidtDengler, Christine Zulehner

Carsten Bienz, Karin S. Thorburn, Uwe Walz

Adrian Buss, Bernard Dumas, Raman Uppal, Grigory Vilkov
Understanding the Shift from Micro to MacroPrudential Thinking: A Discursive Network Analysis

Governance in Entrepreneurial Ecosystems: Venture Capitalists vs. Technology Parks

Got Milk? Motivation for Honesty and Cheating in Informal Markets: Evidence from India

The Political Economy of Bank Bailouts

Rent-Seeking in Elite Networks

Commodities, Financialization, and Heterogeneous Agents

Optimal Consumption and Portfolio Choice with Loss Aversion

Investment-Specific Shocks, Business Cycles, and Asset Prices

Preference Evolution and the Dynamics of Capital Markets

Competition in Treasury Auctions

Coinvestment and risk taking in private equity funds

Does Say on Pay Matter? Evidence from the German Natural Experiment

The Intended and Unintended Consequences of Financial-Market Regulations: A General Equilibrium Analysis 